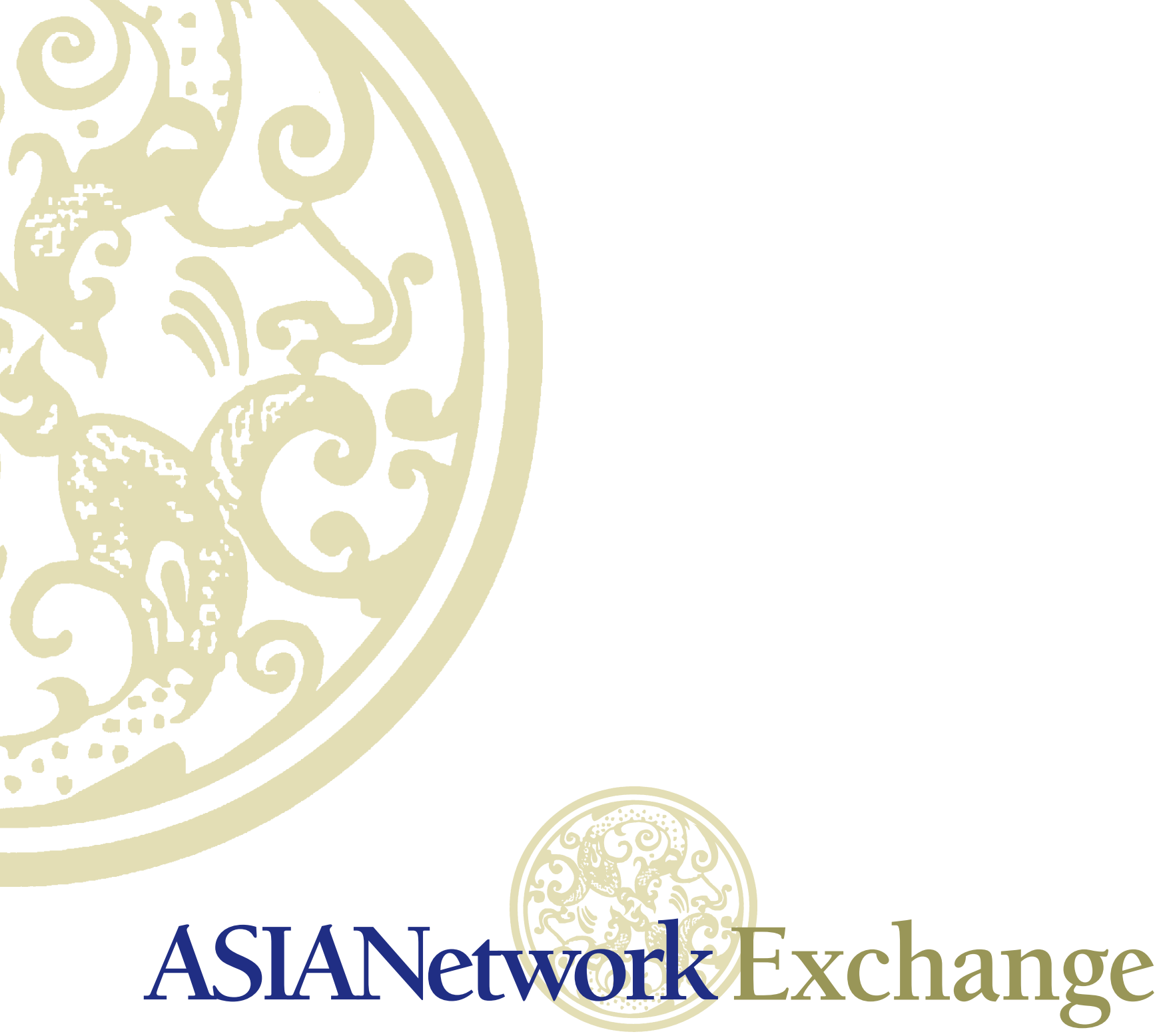

A JOURNAL FOR ASIAN STUDIES IN THE LIBERAL ARTS 


\section{Contents}

NOTES FROM THE EDITORS

IN MEMORY OF MR. HOUGHTON “BUCK” FREEMAN

Van J. Symons

SHARIA, JUSTICE, AND THE POLITICS OF INTIMACY

Rafia Zakaria

CLASSICAL CHINESE GARDENS IN TWENTY-FIRST CENTURY AMERICA: CULTIVATING THE PAST

Carol Brash

BETWEEN YESTERDAY AND TODAY: CONTEMPORARY ART IN NEPAL

Kathryn Hagy

ASSESSING POLITICAL DYNAMICS IN CONTEMPORARY MALAYSIA:

IMPLICATIONS FOR DEMOCRATIC CHANGE

Surain Subramaniam

TREE ORDINATION AS INVENTED TRADITION

Avery Morrow

A REVIEW OF THE DOCUMENTARY SHUGENDŌ NOW 


\section{Notes from the Editors}

This issue marks an exciting new departure for both ASIANetwork, as an organization, and for its journal, the ASIANetwork Exchange: A Journal for Asian Studies in the Liberal Arts. As a consortium of one hundred and sixty colleges and universities seeking to strengthen the role of Asian Studies within a liberal arts context, ASIANetwork has used its journal as a critical means of promoting the field since December 1992. In the many years since its first publication as The Asian Exchange, editors including Marianna McJimsey, Anne Prescott, Ben Nefzger, Marsha Smith, and, most recently, Thomas Lutze and Irving Epstein, have worked hard to establish the publication as a critical tool of ASIANetwork members. We are mindful of the hard work that each of the previous editors of ASIANetwork Exchange has done for the publication and hope that our own term as co-editors will leave the publication in a strong position within our field.

Before we go on to share some of the exciting new things about the ASIANetwork Exchange, we would like to express our gratitude. We would like to thank Cathy Brown at Hamilton College for helping us to use the graphic identity of the organization in such a powerful and pleasing manner for the journal. We would like to thank Craig Rice for making the journal's new design work in electronic form. We would like to acknowledge Roberto Dosil and his team at the Canadian Centre for Studies in Publishing, for the design of the website and article layout. We would also like to acknowledge both Hamilton College and St. Lawrence University for supporting us in this endeavor. Without the foresight of our respective administrations, which recognize editing a journal in the field to be a critical part of both our service to our field and our professional development, we would not have the chance to pursue this remarkable opportunity. We would like to thank the board of directors of ASIANetwork and its Executive Director, Teddy Amoloza, for their confidence and support as we have developed and implemented our vision for the journal. Most of all, we would like to thank Thomas Lutze and Irving Epstein, who preceded us as co-editors and have set a very high standard to which we aspire. Tom and Irv have inspired us to imagine that we could embark on such an undertaking and have generously shared their wisdom and experience. We want them to know that our conversations and correspondence have been critical to our own approach to editing the journal. It is to Tom and Irv, therefore, that we dedicate our first issue as co-editors.

With the publication of this issue, the ASIANetwork Exchange also introduces its new mission and vision statements:

The mission of the ASIANetwork Exchange is to highlight the central role of reflective research to teaching about Asian societies and cultures. The Exchange shares information useful to educators in liberal arts settings through the publication of original research and media reviews in order to provide materials to assist teachers in their own professional development and to deepen the understanding of Asia among campus communities.

The Exchange serves the unique needs of teaching at a liberal arts college, both to the specialist and non-specialist. The journal intends to make research and pedagogy about Asia accessible to a broader audience of faculty and students. As a scholarly journal dedicated to peer review, the Exchange provides a format and forum for the publication of current research that interrogates Ernest Boyer's four categories 
of professorial scholarship: discovery (disciplinary research), application (applying scholarship to address societal issues of concern), integration (interdisciplinary collaboration), and teaching (pedagogical innovation). In serving teachers and students of Asia in the liberal arts, the editors of the Exchange seek out ever new ways to promote and advance scholarly innovation in the field(s) of Asian Studies.

The mission and vision for the journal are the product of many productive and exciting conversations over a number of years with Tom Lutze and Irv Epstein during their tenure as co-editors, the board of directors, and at least two recent iterations of the publicity committee. These statements express both the organization's and journal's commitment to continue promoting Asian Studies in the liberal arts, and will provide the journal with guiding principles as it continues to grow. As editors, we seek to encourage quality scholarship in Asian Studies in ways that are meaningful to the ASIANetwork membership and beyond. We wish to continue the journal's commitment to publishing pedagogically relevant content and also to encourage the publication of short scholarly articles so that the journal reflects the multiplicity of ways our members engage in Asian Studies. It is our hope that the journal will develop much in the way the annual conference has, becoming a place that showcases the best work of the scholar-teachers who make up our membership.

Since its early days, ASIANetwork has pursued its goal of supporting the study of Asia in the liberal arts curriculum in a number of important ways, including through publication. Our most basic responsibility as co-editors is to make sure that this legacy is maintained and continues to grow. In seeking ways to further the reputation of the ASIANetwork Exchange, we have established both an advisory board and an editorial board. The purpose of the advisory board is to help the co-editors establish long-term goals for the journal that better position its reputation in our field and to develop concrete steps to accomplish these goals. We are fortunate to have secured the participation of a number of leading scholars of Asia on our Advisory Board, including several with longstanding ties to the organization. We are pleased to recognize the following scholars as members of our advisory board: Donald Clark (Trinity University), Lucien Ellington (University of Tennessee at Chattanooga), Carol Gluck (Columbia University), Rita Kipp (Marietta College), Barbara Metcalf (University of California, Davis), Henry Rosemont Jr.(Brown University), and Hal Roth (Brown University, Contemplative Studies Initiative).

In addition, we hope to continue to strengthen the quality of the journal by establishing a constructive and reliable blind peer review process for our members. Toward that end, we have established an editorial board with members who are representative of the organization both in terms of disciplinary training and geographical area of expertise. The editorial board assists the co-editors in the initial screening of submissions for their suitability for the journal, as well as facilitates the identification of appropriate reviewers for each submission. We are pleased to recognize the following scholars as members of our editorial board: Timothy Cheek (University of British Columbia), Ben Dorman (Nanzan University), Steve Emmanuel (Virginia Wesleyan College), Pat Giersch (Wellesley College), Jih-un Kim (Webster University), Siti Kusujiarti (Warren Wilson College), Darrin Magee (Hobart and William Smith Colleges), Mary-Ann Milford (Mills College), Brandon Palmer (Coastal Carolina University), Marjorie Rhine (University of Wisconsin--Whitewater), Laura Ring (University of Chicago), and Paul Watt (Waseda University).

One of the most exciting changes introduced with this issue is our decision to move the journal to an online, open access format This change makes the journal more accessible to those in our membership and beyond. The new digital format will make the journal 
accessible not only to our members and their students, but also to scholars and students in Asia where resources for library journal subscriptions may be more limited. It is our hope that the new format will also help us increase the readership of the journal, as well as make it that much easier to use the Exchange material in the classroom. Articles can be downloaded separately or an issue can be downloaded as a whole, making it easier for us, as scholar-teachers, to access and for our "digital native" students to find and use. The new online format also opens possibilities in the work we publish. Authors will not face the same restrictions in publishing high quality images with their articles and they also can now include hyperlinks and video clips in their articles. With our new format, ASIANetwork has joined an international movement of digital scholarship that enacts the spirit of exchange embodied in the journal's title and our organizational mission. We encourage our readers to learn more about the principles of open access and public knowledge. We are very excited about these new possibilities and look forward to serving ASIANetwork as co-editors of its journal.

\section{IN THIS ISSUE}

A key supporter in the development of ASIANetwork has been the Freeman Foundation. We open the issue with Van Symons' moving memorial of this great friend of ASIANetwork, Mr. Houghton "Buck" Freeman.

Rafia Zakaria's Plenary Address/Hot Topic at the 2011 annual conference in Chicago, "Sharia in America: Why Bans are a Bad Idea," was a moving and thought-provoking talk that challenged both our ideas about the promise of legal rights for women in the United States as well as women's rights in divorce in Muslim societies such as Pakistan and Jordan. It also asked us to consider the limitations of secular feminism and the possibilities of religious feminism, not only in Muslim societies, but also in the West. A revised version of Zakarias talk appears here along with some suggested readings that will be of use for faculty and students.

Carol Brash's "Classical Chinese Gardens in Twenty-first Century America: Cultivating the Past" presents a brief examination of three tracts of American real estate that have been transformed into Chinese-style gardens. Hybridization is unavoidable when transferring a cultural icon, especially one so layered in meaning as the garden in China. Each representation serves a specific function at its particular site and also creates and perpetuates symbolic meaning that goes beyond the individual site to connect to other sites past and present. In each case, the re-presentation demonstrates adaptations and continuations in function and meaning. The three sites used to illustrate the range of adaptations were chosen for their diversity in several areas: the defining and re-inventing of authenticity, their sizes and locations, the type of installation, their origin story and funding, the reflexivity of the institution about the changes made, and programs to produce meaning for the viewers. In their commitment to preserve, recreate, and sustain the past, these institutions have transformed the physical form of the garden. Kathryn Hagy's "Little Brother, Little Sister: Contemporary Art in Nepal" examines works from the last decade by six Nepalese artists. When visiting Kathmandu, Nagy discovers that, like the ancient sculptures, paintings, and temple architecture that exist on every corner, the art of contemporary Nepal is everywhere as well. Her article explores how today's artists align themselves between their contemporary context and their country's ancient arts. What is the conversation about globalism and its impact on artists? How do artists deal with social pressures and do these pressures directly affect the content of their work? Through her in-country research and subsequent study and interviews with artists, Nagy reveals an energetic art scene that draws much of its 
inspiration from a local context, whether it affirms or protests against that context to some degree.

Surain Subramaniam's "Assessing Political Dynamics in Contemporary Malaysia: Implications for Democratic Change" focuses on the 12th General Election of 2008 and the opportunities and challenges it presents for liberal democratic change in Malaysia. Subramaniam argues that democratization in Malaysia is already occurring, albeit at a gradual pace, as it is pushed by the new political forces of civil society actors, recently empowered opposition parties, and the Internet-based media. The political competition between statusquo and reformist forces in Malaysian society are simultaneously shaping and contesting the boundaries of this emerging democratic space. . Some institutional changes have expanded the parameters of democratic space, although the entrenched dominant institutions of the ruling regime continue to wield sufficient amounts of institutional capacity to subvert any consolidation of these democratic changes for now.

Avery Morrow's article on "Tree Ordination in Thailand" discusses how western scholarship perceives the ordination of trees as monks as proof of the power of Buddhism to spur ecological thought. However, a closer analysis of tree ordination demonstrates that it is not primarily about Buddhist teaching, but rather an invented tradition based on the sanctity of Thai Buddhist symbols, as well as those of spirit worship and the monarchy. Tree ordinations performed by non-Buddhist minorities in Thailand demonstrate a political commitment rather than a religious one.

Erin McCarthy (St. Lawrence University) and Lisa Trivedi (Hamilton College) 


\title{
In Memory of Mr. Houghton "Buck" Freeman
}

\author{
Van J. Symons
}

Van J. Symons, a Qing dynastic Chinese historian, teaches East Asian history courses at Augustana College in Rock Island, Illinois. He served on the ASIANetwork board from 1995-99 and as ASIANetwork's Executive Director from 19992005. He currently serves as the program coordinator for the ASIANetwork Freeman StudentFaculty Fellows Program.
Shortly after hearing of Houghton Freeman's death on December 1, 2010, in Stowe, Vermont, leaders of ASIANetwork created a window on our website to enable members to submit letters of condolences to the Freeman family. What followed was amazing as literally dozens and dozens of individuals wrote to express their appreciation for Buck and for the Freeman Foundation. Some of those writers were board members and ASIANetwork leaders, while others were consortium members who had participated in the Freeman Foundation-funded "College-in-Asia" and "Student-Faculty Fellows" programs. All were aware that without the early and continued support of Buck and the Freeman family, the impressive emergence of ASIANetwork could not have occurred.

It is fortuitous that the beginnings of the Freeman Foundation and ASIANetwork both occurred in 1992. Mr. Freeman was newly retired after serving for a decade as chief operating officer of American International Group (AIG), and he was eager to manage a trust-initially started by his father, Mansfield Freeman, in 1978 - committed to developing mutual understanding among Americans and East Asians. Shortly thereafter, in the summer of 1995, the chair of the ASIANetwork board of directors was able to meet with Buck in Stowe. Buck quickly realized that this small but growing national consortium of liberal arts colleges might become a suitable vehicle for his foundation to accomplish some of its goals.

Buck read about Augustana College's study-in-Asia program in our March 1996 newsletter and soon after, he informed the leaders of ASIANetwork that he was willing to support a grant initiative to encourage college faculty and administrators to develop similar term or semester-long study-in-Asia programs. Leaders of the consortium accepted his offer and, in the fall of 1996, submitted to him a dual proposal, which, once funded, established the "College-in-Asia" program to enable representatives from 25 different colleges between 1998 and 2004 to travel to East Asia to help them start term-in-Asia study programs. It also created the "Student-Faculty Fellows" program to facilitate undergraduate research in East and Southeast Asia, which since its inception has provided 158 grants to 696 "fellows" from 94 different colleges.

Early on in our conversations, Buck made it clear that if we met his expectations, his commitment to ASIANetwork would be solid and unwavering, and he kept this promise. His support for these programs helped us generate interest in ASIANetwork and grow our institutional memberships. Moreover, the small amounts of money built into grant budgets to run these initiatives were central to our remaining financially solvent, especially early on. In addition, much of the leadership of the consortium has been drawn over the years from colleagues who were first introduced to the consortium by serving as mentors to students participating in the "Student-Faculty Fellows" program.

In my first conversations with Buck, as a member of the board and then as the executive director of ASIANetwork, he suggested that one of the primary goals of the Freeman Foundation was to provide firsthand experiences in Asia to young people. He felt that such experiences would transform their lives and that they would then, through their actions, draw Asia and North America closer together. His programs, managed by the Institute for International Education to provide grants to hundreds of young people to study Asian lan- 
guages in Asia and by ASIANetwork to fund undergraduate research throughout East and Southeast Asia, converted this dream into reality.

Mr. Freeman informed me that he was pleased by ASIANetwork's growth because he realized that our national consortium of liberal arts colleges had become a means to funnel Freeman support to small colleges throughout North America. His father, he, and his son all graduated from Wesleyan University, and Buck was keenly aware of the importance of small colleges in the landscape of American higher education. Simply put, because the Freeman Foundation was and still is a small family-run endeavor, he, Doreen, Graeme and the limited staff working with them could not micromanage the reviewing of grant proposals from myriads of small colleges throughout the country. Consequently, ASIANetwork became a valued means for him to enhance the study of Asia at the more than 150 colleges in the consortium. Through his support, ASIANetwork has grown to help him achieve this outreach.

While this memorial has focused on Buck's significant contributions to ASIANetwork and our institutional members, it is important to recognize that the outreach of the Freeman Foundation has been and continues to be much greater than this. The foundation's focus has been Asia and includes a deep and abiding commitment to the National Consortium for Teaching about Asia, created by the Freemans to help infuse instruction about Asia into K-12 education; support for the Asian Studies Development Programs of the East-West Center and their outreach to community colleges; mine removal in Vietnam; rebuilding of educational institutions in Thailand and Indonesia after the 2004 tsunami; restoration of the Northeast section of the Qing Forbidden City in Beijing and of the Joseph Stillwell mansion in Chongqing; support for BBC news broadcasts on PBS; and a range of ingenious grants to sustain education and environmental concerns in his beloved Vermont.

One cannot be certain that the Freemans fully know how immense their impact has been for good through the Freeman Foundation, but I know we, at ASIANetwork, do. We will miss Houghton Freeman's vision, his energy, and his commitment to deepening the understanding of Asia in North America and to facilitating dynamic interactions between the peoples of Asia and our country. We are truly grateful for his help and encouragement in getting us started.

Sincerely,

Van J. Symons 


\title{
Sharia, Justice, and the Politics of Intimacy
}

\author{
Rafia Zakaria
}

Rafia Zakaria is an author and human rights attorney focusing on Muslim women and minority rights. She co-founded the Muslim Women's Legal Fund which provides legal representation to Muslim women facing domestic abuse in family and immigration law cases.

She is author of the forthcoming book "Silence in Karachi: an intimate history of Pakistan" (Beacon Press). She writes a weekly column for DAWN, Pakistan, and blogs at Ms.Magazine, Dissent and Guernica.

\begin{abstract}
In the war-ravaged decade following 9/11, every aspect of Muslim women's lives has become a fulcrum of political contestation. From burka bans in Belgium to proposed Sharia bans in Oklahoma and Tennessee, saving Muslim women is advertised as a purported aim for broad and varied campaigns that in actuality have little to do with them. In private conversations and in public forums on these issues, the questions on many lips are inevitably "But doesn't Islam really oppress women?" or "Doesn't Sharia law treat women as second class citizens?" Because these observers see Islam, Sharia, and Muslim women undifferentiated monoliths, the answers to their questions consequently fit the binaries that produce them: good and bad, just and unjust, oppressive and liberating. The assumptions buried inside these perceptions rest on western law, in which gender equality is safe, while in Sharia law, its specter hung with images of hacked hands and stoned women, it is not.
\end{abstract}

The consequence of looking through these prisms is that everyone, reader and writer, scholar and student, is required to pick at team and then sit as onlookers in a civilizational contest that had little room for nuance or dialogue. All writing about Islam and Muslim women must thus ascribe to this paradigm, either an unequivocal defense or a fervid denigration, a prioritization of being either Muslim or female ,and always an "either/or" and never ever a uniting "and."

The essay presented here is a small rebellion against precisely this arrangement, one that insists that we choose a side, and immediately agree or disagree, before we understand or empathize or make any attempt to feel how the world appears to others seated at different places in the arena or to those in the ring itself. Rather, liberation and justice are complicated issues that defy the construction of neat lines across cultures and contexts and individual lives.

Keywords: Sharia, Muslim Women, Family Law, Islam, Islamic Law, Divorce, Gender, Pakistan, Marriage Contract, American Court system, comparative law

I grew up in the eighties in a Pakistan that had recently escaped the shackles of military rule. It was an euphoric time when Pakistan was about to elect its first female Prime Minister, Benezir Bhutto (1953-2007). It had been a grisly decade, one in which Sharia law, or at least Pakistan's own militarized version of it, had played a defining role in creating a new kind of Pakistan. In an effort to legitimize his dictatorship, General Zia ul Haque (19241988), who had grabbed power in a military coup in 1977, had initiated an "Islamization" program. With the goal of producing a "pure" society by criminalizing all temptation, Zia and his allies produced laws whose true character was cleverly disguised in Islamic-sound- 
ing terms and references, which served to mask the draconian, authoritarian, and misogynistic rule that served his interests. What did this mean for the everyday life of a child in Pakistan? Children like me watched British sitcoms so drastically censored that they often lasted only ten minutes. Women appearing on television suddenly were required to cover their hair. Women were never shown having any physical contact with men on screen.

Aside from what was happening on television, men and women could be asked at any time to produce their marriage documents by any police officer. In other words, the introduction of 'Islamic' norms, which were quite new to the population, suddenly transformed the daily lives of Pakistanis.

I certainly was not preoccupied about Islamic law in those early years of my life, nor was I worried that legally I counted as only half a witness, while my twin brother, with whom I competed daily, counted as a whole. Yet the existence of these precepts and their ubiquity in determining relations between men and women were an invisible, though determinative, aspect of my life. They dictated, for example, the manner in which our home was arranged, such that an unrelated male, upon entering, would be led directly to a reception room in the front of a house and never encounter any of the women. In later years, it would constrain whom I was allowed to visit and when, as well as which schools I would be sent to for study. Eventually, the extension of President Zia's rule had an effect upon a myriad of details in my life, as well as the lives of the other women in my family. The "Islamization" programs that had been initiationed under Zia’s rule continued long after his death in 1988.

My Aunt Amina was married before I was born and so, though she was a frequent visitor to our home, she did not live with us. Her visits were a cause of much excitement to my brother and me, whose ordered lives of school and homework did not allow for the many novel experiences her visits invariably produced. For example, in the early years of their marriage, Aunt Amina's husband, Uncle Sohail, rode a motorcycle, providing us kids hours of entertainment and excited speculation. If adults were around, we were sometimes allowed to sit and pose on it, a delight for my brother especially. But would we be allowed to ever ride the motorcycle? On one and only one occasion, I remember our being given a ride around the block. Oh, the exhilaration, when the achingly familiar landscape of our block was suddenly and completely transformed into a whizzing blur of shapes. We may not have gone very far in distance, but in terms of our imaginations we had traveled to another place altogether! On other occasions, Aunt Amina would come alone to spend an afternoon with us. She often came bearing special treats that she had made just for us. Whether it was with her thoughtfulness or new experiences, Aunt Amina occupied a much beloved position in the hearts of her young niece and nephew.

In fact, Aunt Amina's position in our minds was even more special because ordinarily the adult worlds of our elders were separated from us not simply by the boundaries of generation, but also of language. My paternal grandparents, migrants from India, spoke a North Indian dialect that I was never formally taught. A quick turn into this language could insulate adult discussions from the curious ears of children and servants, in a world with very little privacy from either. Of course, despite having not been taught the language of the elders, by the age of six I was beginning to decipher just enough, quickly translating the words falling from my grandmother's mouth as I played with a doll or stared at a jigsaw puzzle. When conversation slipped into the mysterious dialect, I became immediately alert that some juicy bit of news was about to be divulged. It was through these shifts in language that I pieced together my Aunt Amina's increasing struggles with her in-laws and her husband.

After seven years of marriage, Aunt Amina had failed to bear her husband any children. 
Her apparent infertility was the source of unending troubles for her, which were becoming increasingly serious and painful. Subject to constant taunts in her own home, she was treated like a maid by some, rather than being afforded the respect due a wife. She was relegated to some of the crudest of domestic tasks as a reminder (or was it a punishment?) of her status as a barren woman. Weddings were particularly difficult times for Aunt Amina, as she found herself excluded from celebrations. In one particularly cruel instance, Aunt Amina's eldest sister-in-law forbid her from greeting and kissing the young, new bride, proclaiming loudly to all who were present that the touch of a barren woman was too inauspicious on such an occasion. I pieced together all of this, bit by bit as unfamiliar words fell word from word from the mouths of our elders.

It is difficult to know precisely when and where cultural perceptions are transmitted to children, but I remember feeling terribly sorry for my aunt on many occasions. My brother and I, always looking for new playmates, who in our imaginations would have piles of new toys to share with us, imagined Aunt Amina's childless house to be a singularly boring place. No playmates meant no toys, or so we thought. Aunt Amina proved us wrong every time we visited by pulling out a collection of toys that she kept just for us. Her little house, fascinating to us because it represented a miniature version of the large dwelling we inhabited ourselves, was decorated everywhere with pictures of children. Pictures of babies from all over the world, cut out from calendars and magazines, adorned the walls of the kitchen and living room, and were stuck between cabinets and even under the glass of the dining table. For Aunt Amina, they were perhaps shining talismans of hope. They formed a silent chorus of encouragement for my aunt; she clung to the dream of becoming a mother.

It was just another pleasant winter morning when I woke to find Aunt Amina sitting at our breakfast table. Her presence was ominous since she had never, in my ten years, spent a night in her father's house. She always returned to sleep in her husband's home, as tradition and culture demanded. Her hair, always neat and in a thick dark braid, was strangely unkempt; her wheat-colored skin, usually flawless, was noticeably covered with blotchy tear stains. She managed a weak smile when she saw me sit at the table, already in my school uniform. I looked at her with the mixed curiosity and apprehension of a child who did not yet know how to react to distraught adults. None of the elders gave me much information that morning. On my way to school, I finally worked up the courage to ask my mother what I imagined to be the worst possible senario: "Has Uncle Sohail died?" I can only imagine what my mother must have thought of that question. Uncle Sohail hadn't died, but perhaps it would have been better for Aunt Amina if he had.

Uncle Sohail had chosen to take a second wife, a woman who worked with him at the bank. He had known her for many years, before he had married Aunt Amina. For three days and nights she had pleaded with him to reconsider and every time he had refused, reminding her that this was his right as a Muslim man. Polygamy is not very common in urban Pakistan; indeed, I had never before heard of it and no one in our family at the time had multiple wives. But, as of late, it had become more acceptable as a religiously prescribed social panacea to the problem of too many destitute women. Aunt Amina had come to our house after she refused to accept Uncle Sohail's decision to take a second wife. She must certainly have known that polygamy was a possibility—men were increasingly throwing around the threat of another wife-but she had never really expected it to happen in her own home. She did not know any other family where there was more than one wife. She had told Uncle Sohail that it was better to kill her than to force her to watch him marry again, sharing everything that was theirs with another wife. As it turned out, Uncle Sohail's decision had not been taken in anger or at the spur of the moment. The annex that he had 
been building all year, under the pretext that they might need to accommodate visiting relatives, was in fact additional space for his new wife.

Again and again, Aunt Amina pleaded for help from my grandfather and father, her male guardians. In hushed tones, the topic of divorce, or khula, was discussed. But how would this happen? Would Uncle Sohail allow it? Aunt Amina's marriage contract had been drafted by an old imam, who had not thought to add a clause allowing her to petition for divorce. I did not understand the gravity of the discussions then. I did know that I had never heard of divorce; the women around me, every single one, were either too young to be married, awaiting marriage, or married with broods of children. I understood the idea of divorce with the same foreboding invested in it by all of the women of my family. For days, my aunt remained in my grandmother's room, leaving only to pray after the call was sounded from the neighborhood mosque. Sometimes she would join us at the dinner table, but she ate little and did not speak at all. A few times, my brother and I tried to joke with her, imagining that our childish insistence could lift her out of her misery, but we were unsuccessful. Parades of older male relatives came to the house and had conferences with my father and grandfather; the women of the family were completely excluded. The Imam, who had performed her marriage and authored the marriage contract, came to advise the family of the religious and legal options, providing little solace. The marriage contract he had drafted did not provide any options for her: it did not contain a clause forbidding polygamy, it did not provide for a significant settlement to be paid to her in the event of divorce. As a divorced woman, Aunt Amina would not only be destitute but also stigmatized. It would be even worse than her humiliation as a rejected wife. Aunt Amina found little comfort from either her religious community or her family.

And then, one morning, as suddenly as she had appeared, my Aunt Amina was gone. The belongings that she had neatly arranged on a bureau in my grandmother's room had been replaced by the porcelain knick-knacks that stood there before her arrival. I was told that she had returned to "her" house; Aunt Amina had returned to her husband's home. Because the information supplied was so meager and because the uncomfortable silence she left in her wake provided so few clues to what had happened, I spent hours imagining what she must be going through. Her husband would marry a new woman and she would be there to witness it. Uncle Sohail for his part had offered Aunt Amina the new annex to the house as a sort of consolation. I imagined her standing at the upstairs window of her house looking down into the central courtyard and the other apartment where the new bride would soon live. Weddings are such noisy affairs in Pakistan. The arrival of a bride would certainly be accompanied with fireworks, music, and great fanfare. I imagined Aunt Amina alone and watching her husband as a bridegroom greeting his new bride. There would be a grand feast with the very relatives who had previously welcomed Aunt Amina into their family years ago. These people knew her family. Had they pretended to care for her at the time of her wedding? For all these years? I imagined her as she watched them down below consuming celebratory plates of rice and mutton, as well as the sweet delicacies provided to celebrate the second wife's arrival. How unconcerned they all were at the life that lay destroyed just upstairs from these festivities.

And so the marriage took place. The new wife's name was never mentioned in our house, a wishful invisibility perhaps that became a habit. In the end, the marriage arrangement was both surreal and terribly ordinary in its pragmatism. Her husband rotated wives every week; during "her" week he would live upstairs, taking all his meals with her. The following week he would switch. In the weeks she was "off" my aunt was excused from 
all wifely duties. His affections, of course, were similarly divided.. Much of my aunt's life became defined by watching from her windows. She kept vigil to see how her husband changed as he descended the stairs from his life with her to another one life entirely. She would talk of how hurtful it was to watch from her upstairs window, stranded and alone, as her husband and new wife got dressed and went off in the car for the evening. Divided thus between off and on weeks her life oscillated between loved wife and abandoned wife, between servitude and loneliness.

In the decades since I migrated to the United States, it was convenient to relegate Aunt Amina's story to an instance that took place "back there at home" with little or no seeming relevance to my life as a Muslim woman in the United States. The term Sharia was imbued with all the emotional negativities of Aunt Amina's situation. I felt that a clean line could be drawn between the legal secular world of American law in which I was being trained as a scholar and practitioner on the one hand and the transcendent gray areas of women's rights and responsibilities in Islam on the other. Certainly Muslim women living in the West, like myself, could take advantage of the rights available to women here, get divorced, remarry, and not have to worry about the possibility that their husband would take another wife against their wishes. Although a practicing Muslim, I did not believe that the messy issue of Sharia or Islamic law had any place in an American courtroom. It was easy, it seemed to me, to simply take the rights available and leave the vexing terrain of Sharia to be wrestled with in the Muslim world.

So it was with these assumptions that I began a one-year stint working at a domestic violence shelter in Indianapolis, Indiana. I had just finished defending a dissertation that focused on the choices between religious and gender identity that Muslim women face as members of minority communities in the West. A partnership between the domestic violence shelter and a local Muslim community organization provided a unique opportunity to work with women I had written about. The project aimed to provide legal assistance to Muslim women filing for divorce, with the idea to show them that the community supported survivors and not their abusive husbands. It was meant to tackle head-on taboos that would otherwise prevent women from seeking separation. Providing a context that was sensitive to religious and cultural identity would help in the transition to independence.

Academia, with its well-known insularity, provides depth but also isolation from many of the challenges that face people in their daily lives. So while I had passed the bar and begun to practice law, I had little direct experience working with abused women and the problems that they face. I was well-schooled in the battles of Muslim women in the United States to advocate for changes within their own communities, including efforts to redefine the faith from within and to lobby for increasing representation and equality within mosques, but I continued to view the battle to define women's equality within American Islam as an issue of interest only to a small group of activists and even smaller number of scholars. In other words, the latter groups were for the most part engaged in issues that were far from the everyday realities of ordinary Muslim women and their lives. My views on all these matters were informed by feminism, but one that was situated both within my religious community and certainly not particularly urgent. I believed that the task of re-interpreting Sharia law was integral to reclaiming the arena of faith as one of equality for Muslim women, but did not understand what role I had to play in that process. As I lived in the West, I saw myself and my most direct concerns focused here. The secular U.S. legal system, in my opinion, provided sufficient protection to Muslim women in diaspora communities. I believed lay the bulwarks of equality lay in American law, rather than religious 
law, and would ensure that, at least in the West, Muslim women would not be discriminated against. The shelter at which I went to work provided me with a shocking first step into the world of the proximate and urgent problems facing Muslim women in the United States.

I picked up Zainab ${ }^{1}$ from the motel where her husband, Said, had abandoned her three days earlier. Married only a year earlier in Amman, Jordan, she could not drive and spoke little English. Zainab had left behind friends, family, and a job to be with a man who had promised her a life of comfort in the United States. She had met her future husband at a wedding two years before, when her cousin had wed one of his brothers. Their encounter was punctuated with the romance of the wedding, one of the few instances when young men and women could socialize in Amman with some degree of freedom, although under the watchful eyes of their families. Once or twice they had been able to have a few clandestine conversations, when a lenient chaperone left them alone. During one of these rare moments of privacy, he had slipped her a small gold ring and asked her to marry him. The act was unusual and certainly unexpected. Marriages were nearly always initiated by elders in Zainab's conservative community and the fact that Said had taken the step of asking her himself, even if secretly, won her heart.

A few months after Said's departure following the wedding, his family showed up at Zainab's home to arrange the marriage. Said's family was already known to Zainab's, but this was the first time they had visited her home. Zainab remembered well serving tea to his old mother, who inspected her from head to foot without any hesitation or embarrassment. A little daunted by the severity of her potential mother-in-law's black attire and sharp, scrutinizing gaze, Zainab consoled herself with the thought that she and Said would live in the United States after their marriage, not with the old lady. When her father called her to his room later that night to ask if Zainab wanted to accept Said's family's proposal, Zainab was delighted to say yes. Even though she had exchanged barely twenty words with Said at the wedding and had only a few brief moments alone with him, Zainab called their match a "love" marriage.

This kind of transnational marriage has become a common occurrence in many Muslim families with the departure of many young males to foreign countries. Embellished with the glamour of life abroad, young men return to their home countries and often have their pick of brides. Young women, like Zainab, daunted by the specter of marriages defined by meddling mothers-in-law, expectations of producing broods of children, and juggling careers in tough economic times, have their own interests in accepting proposals from men settled abroad. Many imagine that the man himself, after having lived abroad, is likely to have a far less traditional view of marriage and will necessarily be freed of the dominating views of his family. In other words, young women like Zainab assume that matches with foreign settled men provide freedom in many forms, adding to the allure of such a match. In the piles of glossy wedding pictures that Zainab and I pored over in the days that followed our first meeting, I saw an opulent ceremony attended by hundreds of guests and well wishers and a resplendent bride who barely resembled the drawn and terrified woman I saw before me.

Things had unraveled very fast after her arrival in the United States. During a hurried "honeymoon" in Chicago, Said appeared preoccupied, a marked and drastic change from the attentive groom of barely a week earlier. Several times during the night, he had stolen outside to talk on his cell phone in rapid English, which Zainab did not understand. It was after one of these conversations, when Zainab insisted on knowing with whom he had been speaking, that Said struck her across the face. It was the first but not the last time. A stunned Zainab recounted that she lay in her bed crying for the rest of the night, suddenly 
filled with trepidation about this new life in which she was all alone. After months of nights spent imagining what America would be like, and how she would decorate her new American home, Zainab longed for her childhood room and the bed she had shared with her younger sister. She longed for her family and the support that they could offer in her time of trouble.

It was not long after arriving at their suburban condominium that Zainab discovered that Said had an American girlfriend. He made no effort to hide either his phone calls with her, his visits to her, or the fact that he had no intention of leaving her now that he was married. In a photograph stuck in a kitchen drawer, Zainab saw that she was an older woman, perhaps even older than Said, who at thirty-five was ten years older than Zainab. Zainab confronted him one night when he returned home. "Why had he said nothing in their long conversations and Internet chats over the ten months of their courtship? Why had he married her and told her he loved her when he was in love with someone else?" She had many questions for him that night, but in exchange she received only blows. Later that night he raped her. This became the pattern of their marriage. Every time she confronted him about leaving her alone while he went to visit his girlfriend, she was punished. After one grisly fight during which she threatened to tell her parents and his family what was going on, he imprisoned her in a closet for two days. He disconnected the phone line in the apartment and allowed her to call home only through his cell phone with a phone card. He watched her the entire time she spoke to her family; she spoke for no more than ten minutes at a time. If she gave any indication of her unhappiness during these conversations, he promised to punish her.

Despite the pain and humiliation she faced, Zainab did not leave Said. Even as she recounted the story to me in tears in the shelter office that first day, Zainab insisted that she had wanted desperately for the marriage to work. She did not know how she would face her friends and relatives at home if she were sent back a divorced woman. As was the case for Aunt Amina and the women in my family in Pakistan, divorce for a woman was too terrifying prospect to pursue.

Zainab had not spoken to her family in over three months when Said dropped her off that day in front of the Extended Stay America Motel where I would pick her up a week later. Sitting in the brand new Nissan Altima that he had bought with the wedding money they had received in Jordan, he looked at her calmly and in Arabic pronounced the words "I divorce you" three times. Then he had gotten out of the car and unloaded her things on the sidewalk. Before driving off, he had handed her a stack of legal papers. In the long days that Zainab spent sitting alone, hungry, and frightened in the motel room, she had gone over each page as best as she could. They were divorce papers from a court in Indiana that had pronounced her divorced. Said had evidentally signed Zainab's name fraudulently several times, alleging in the papers that they mutually agreed to the divorce. Only once did she remember signing a single page at his request, which Said had pulled out after a rare meal they had shared at a restaurant. Zainab had been so delighted at his affectionate behavior that evening, reminiscent as it was of better days in Jordan, that she had not even read the page before she signed it, only glancing at it before printing her name in neat letters. Through a string of deceptions, Said had managed to legally divorce Zainab in the United States without ever entering a courtroom and without her even knowing what was happening to her.

Poring over Zainab's case in those first few days, I felt dejected. While I could get her case re-opened by demonstrating the fraudulent circumstances behind the divorce decree, there were few options to get her the much-needed monetary support she would need 
beyond the basics of survival that were available to her at the shelter. Why did she face such an uphill battle? In recent decades, most states have passed legislation that makes divorce a "no-fault" issue. This means simply that if either a husband or wife asks a court for a divorce, it is automatically granted without anyone having to prove extreme conditions, such as adultery or abandonment, as was the case in decades past. Divorce in America is no longer treated in punitive terms. Instead, courts have turned away from deciding whether the husband or the wife is responsible for the breakdown of the marriage, an issue considered legally irrelevant to their future lives or their rights at the time the marriage is dissolved. These changes make sense in a post-feminist society, where women can marry and divorce at will and are unlikely to be stigmatized by the breakdown of a marriage. With the emergence of "no-fault" divorce as the standard in family law, litigation focuses on property division rather than the moral contours of why the relationship had broken down. In a world of blended families and frequent divorces, few U.S. judges imagine a marriage as short as a year to have significantly impeded the life of either the husband or the wife. Spousal support, or the idea that the husband should have to pay the expenses of his former wife until she gets back on her feet, is largely unimaginable.

And so I faced the task of explaining an American legal reality of freedom and consent to a woman who had been married under circumstances that could not have been more different. Zainab expected spousal support and her argument for it was simple; she had given up everything to be married to Said and she feared the pain of an ineradicable stigma if sent back to Jordan as a divorced woman. Again and again, she would ask me about her rights under the Islamic marriage contract, and repeatedly, I would tell her that an Indiana court would not enforce a marriage contract based on Sharia law. Then she would exclaim aghast that if she could not get any rights or restitution under Islamic law, what indeed were her options under American law? My response that I expected that all she would receive from an American court was a legally recognized divorce, no property, no spousal support, and no amount awarded for repudiating the marriage contract was impossible for Zainab to digest. "How can this be?" she would ask. "This is America... women are supposed to have rights here... how can a judge tell me that I deserve nothing after having been abused and abandoned?"

There I was, with my first Muslim client, confronting a predicament in which the American legal tools at my disposal did not promise the best result for my client, a Jordanian Muslim woman. In my legal training, as well as my academic work, my focus had been almost entirely on the task of introducing women just like Zainab to the idea that the American legal system allowed them a level of equality and self-realization that was not yet available in Muslim countries. But figuring out what precisely would be judicious in this case was challenging. Should Zainab, who had been so visibly wronged, be treated like the average American woman petitioning for divorce after a few months of marriage? Should Said be treated like any other American husband whose marriage hadn't worked out as he had hoped and who therefore wanted to be with another woman? Should Zainab's unique situation as a Muslim woman, whose chances of remarriage were severely affected by her divorce, be considered in the case or ignored? More importantly, should Said have to pay to support a woman he had only been married to for a little over a year? All of these thorny questions were implicated in Zainab's case, which questioned the core premises of fairness and equity in marital relationships.

As a lawyer, I had been trained to find the fair and just result for my client, one that would make her whole and give her the best chance at rebuilding her life. And ironically, it was Zainab's Islamic marriage contract that seemed to me to provide her the best hope in 
this regard. Unlike the perfunctory and often poorly drafted marriage contracts frequently used in my native Pakistan, Zainab's contract had been drafted by an attorney, duly signed and witnessed, and had certified translations in English. Its clear stipulations mandated not only that Said did not have the right to contract any polygamous marriages, but also that Zainab had the right to divorce him, something otherwise difficult for many Muslim women to do. The contract also imposed additional duties upon Said in event of divorce. He would have to provide spousal support for two years, and also pay Zainab a pre-fixed amount, $\$ 10,000$ dollars in this case, if he chose to divorce her. The terms of the contract were indeed hopeful in their specificity, if they could be enforced in the United States. But in the post-9/11 climate, where the term Sharia evoked imaged of the Taliban and of gruesome amputations, I struggled to find a way to introduce the Islamic marriage contract into the case without prompting a flood of negative impressions about Islam and the Sharia that might destroy Zainab's chance for success.

Further research into the matter provided more hope than I had expected. After a discussion with some colleagues, I found that the Islamic marriage contract, because it had been so carefully worded, fulfilled all the requirements of an enforceable contract under U.S. law; there was no reason to keep me from asking that it to be honored as a prenuptial agreement. While it had indeed been prepared under the directives of Islamic law, there was nothing in it that contravened any of the principles of American law. The contract's specific requirement that Said pay Zainab the equivalent of $\$ 10,000$ if he divorced her provided me with the legal ground I needed to reach the best solution for my client, who was at the time living alone and penniless in a domestic violence shelter. In the end, I decided that I would risk admitting the Islamic marriage contract into the court's record as a valid prenuptial agreement that must be honored as part of the divorce settlement.

I represented Zainab in a U.S. court with this argument. Only few days after I submitted it to the court, I got word that the judge had signed the order and approved the proposed settlement. The judge had not questioned the premises of the agreement at all, accepting the Islamic marriage contract as a valid contract, rather than investigating the legal basis of its origins. Said and Zainab's marriage contract was accepted by the court as a prenuptial agreement since it met all the criteria for an enforceable contract under Indiana state and U.S. federal law. The final order of the court was that Said should pay support to Zainab for two years, as well as the $\$ 10,000$ to be paid in installments during the same period. Clutching the court's order that summer afternoon, Zainab was happier than I had ever seen here before; the Court's decision meant that Said could not simply use Zainab and then cast her away without any consequences. Surprisingly, neither U.S. law nor Islamic tradition alone had shielded Zainab from Said's actions. Instead, the traditions of her Muslim faith and the legal system of her American future worked together in a manner that avenged, at least partially, the abuse she had suffered. Within a month, Zainab had moved out of the shelter and into an apartment and was beginning to take the first tentative steps toward a new life in the United States.

For me, Zainab's case called up the very ghosts I thought I had left behind in Pakistan. Zainab and Aunt Amina's stories, though separated by culture, time, and the vastly different Muslim societies in which they lived, illustrate the complexity of Muslim women's position within the context of varying forms of Islamic law. In the patriarchal culture of Pakistan, Aunt Amina's remaining a rejected wife was better than being a discarded one. Decades later, Zainab struggled with the same issues, and yet could not simply turn to western culture or legal conventions alone. Instead, she had to rely upon the type of marital contract 
that had failed Aunt Amina. Because Zainab's contract was so specific and it could be enforced in the United States, Zainab's life was not constrained by polygamy under threat of divorce. Her story exposed to me the superficiality of the logic that in America and under American law, justice is a guarantee for women, in contrast with Islamic law, under which women would perennially be oppressed.

Zainab's case does not and cannot change the fact that in the vast majority of Muslim countries, Islamic law, interpreted for centuries by men, continues to be used as a tool to enslave women and enable the sort of tragedies that defined Aunt Amina's life. But it also suggests that if things are to change, the solution lies not in eliminating faith from the legal sphere entirely, but rather in redefining faith's relationship with the law in such a way that it empowers women rather than enslaves them.

Cases like Zainab's, even if they do occur far away in America, provide Muslim women with strategic avenues to take back their faith and the instruments of law that have been appropriated by male jurists and interpreters for centuries. Arguably, it is precisely in places like Canada and the United States, where the state einsures that reform is more likely to go in the direction of providing more rights to women, that this act of crucial taking back can be possible. This then, is the project of Islamic feminism, one defined in small piecemeal victories, perhaps even in countries without predominantly Muslim populations, that represents taking back of a realm instead of surrendering it. The outcome of the case empowered Zainab not merely because she had received a monetary settlement crucial to her survival, but also because she had, in a basic, fundamental way, been able to use her faith to define her empowerment, a prospect denied to too many Muslim women for far too long.

\section{NOTES}

${ }^{1}$ All names and identifying details of the case have been changed to protect client confidentiality

\section{COMPANION READINGS}

The Editors, in consultation with Laura Ring (Assistant South Asia Bibliographer, University of Chicago) suggest the following readings as companions pieces for delving deeper into some of the issues raised by Rafia Zakaria’s article.

Ali, S. S. and Naz, R. "Marriage, Dower and Divorce: Superior Courts and Case Law in Pakistan" in Shaheed, F. et al (eds.) Shaping Women's Lives Laws, Practices and Strategies in Pakistan. Lahore: Shirkatgah, 1998.

Fazalbhoy, Nasreen. "Marriage practices: South Asia," The Encyclopedia of Women \& Islamic Cultures: Family, Body, Sexuality and Health. Brill Academic Publishers, 2005.

Hassan, Riffat. "Marriage: Islamic Discourses" The Encyclopedia of Women \& Islamic Cultures: Family, Body, Sexuality and Health. Brill Academic Publishers, 2005.

Zia, Afiya Shehrbano. "The reinvention of feminism in Pakistan" Feminist Review 91

(2009): 29-47. 


\title{
Classical Chinese Gardens in Twenty-first Century America: Cultivating the Past ${ }^{1}$
}

\author{
Carol Brash
}

\begin{abstract}
This paper presents a brief examination of three tracts of American real estate that have been transformed into Chinese-style gardens. Each re-presentation serves a specific function at its particular site and also creates and perpetuates symbolic meaning that goes beyond the individual site to connect to other sites past and present. In each case, the re-presentation demonstrates adaptations and continuations in function and meaning. The three sites used to illustrate the range of adaptations were chosen for their diversity in several areas: the defining and reinventing of authenticity, their sizes and locations, the type of installation, their origin story and funding, the reflexivity of the institution about the changes made, and programs to produce meaning for the viewers. In their commitment to preserve, recreate, and sustain the past, these institutions have transformed the physical form of the garden. Hybridization is unavoidable when transferring a cultural icon, especially one so layered in meaning as the garden in China.
\end{abstract}

Keywords: Chinese gardens, Chinese art, US garden, Pursuing Harmony Garden, Lan Su Classical Chinese Garden, Liu Fang Yua

Carol Brash is an Assistant Professor at the College of Saint Benedict | Saint John's University. She is an art historian who teaches in the Art Department and in the Asian Studies Department. Her research interests include representations of Chinese gardens and the history of photography in China.
"How can I bear this feeling of past and present?" lamented the artist, Wen Zhengming (1470-1559), “ . . . As the present looks upon the past, so will the future look upon the present." ${ }^{2}$ Wen Zhengming brushed this poignant thought while contemplating a painting that he had done after one by his master, Shen Zhou (1427-1509), while Shen Zhou was still alive. Shen Zhou had in turn created his painting after viewing a scroll by Wu Zhen (1280-1354). By the time he made this notation, Wen Zhengming alone remained. Yet he does not seem wholly alone, gazing upon a painting that is embedded with the spirit of his master and his master's master. Time was not linear in that moment; both past and present simultaneously existed in his memory and in the painting. In their book, The Meaning of Things: Domestic Symbols and the Self, Mihaly Csikszentmihalyi and Eugene RochbergHalton propose that it is precisely this connection to memory/emotion that imbues an ordinary object with meaning. ${ }^{3}$

This accretion of memory and meaning through repetition is like a pearl forming; once sufficient layers have accumulated, a bit of sand is transformed into a pearl. In imperial China, gardens were often designed by and for viewers with a very specific education in the Chinese classics and in the history of Chinese art. Multiple layers of allusion were understood by these viewers. Can these strata of allusion be transmitted across time and space? Hybridization is unavoidable when transferring a cultural icon, ${ }^{4}$ especially one so layered in

17 Classical Chinese Gardens In Twenty-first Century America: Cultivating The Past 
meaning as the garden in China.

Elements of Chinese gardens have been migrating west for hundreds of years in various forms: the writings of Matteo Ricci, the designs of William Chambers, the Chinese fence at Monticello, the plethora of Willow Ware patterns, for example. More recently, a number of actual gardens have been cultivated in the United States. Most of these gardens have received little critical attention, although a few recent constructions have received attention in the press. To my knowledge, there is no organized history of this practice of building "Chinese" gardens in the United States. This essay, which is the start of a larger project focusing only on extant gardens, is intended to begin to fill that gap.

This paper presents a brief examination of three tracts of American real estate that have been transformed into Chinese-style gardens. Each re-presentation serves a specific function at its particular site and also creates and perpetuates symbolic meaning that goes beyond the individual site to connect to other sites past and present. ${ }^{5}$ In each case, the re-presentation demonstrates adaptations and continuations in function and meaning. Producing meaning is crucial since the majority of the viewers of these new gardens will not share the cultural memory ${ }^{6}$ upon which the older gardens were built.

The three sites used to illustrate the range of adaptations were chosen for their diversity in several areas: the defining and re-inventing of authenticity, their sizes and locations, the type of installation, their origin story and funding, the reflexivity of the institution about the changes made, and programs to produce meaning for the viewers. In their commitment to preserve, recreate, and sustain the past, these institutions have transformed the physical form of the garden.

The creators of today's Chinese gardens in the United States use and shape history, memory, and imagination in the construction of new "Classical Chinese" gardens. The term "Classical Chinese garden" is used in this essay because that is how the sponsoring institutions identify these gardens. It is not clear precisely what they mean by this term although it seems to indicate that the gardens are based on designs from southeastern China during the Ming-Qing periods (rather than imperial gardens from northern China or gardens from the Song dynasty or Sichuan-style gardens). Based on their designs, they are most likely referring to the gardens of the style promoted in the Yuan Ye, the first garden manual produced in China (around 1631). ${ }^{7}$

Many of the gardens also have somewhere in their promotional literature a claim like this: City X " . . is the proud home of the most authentic Chinese garden outside of China." It is quite common in this literature to equate "authentic" and "Chinese." Evidence for this "authenticity" consists of noting how many Chinese artisans came to build it, which (if not all) of the materials were purchased and/or constructed in China, whether or not a traditional Chinese design was consulted, and if there are plants are native to China. Yet as Spencer R. Crew and James E. Sims state in Exhibiting Cultures: the Poetics and Politics of Display:

Authenticity is not about factuality or reality. It is about authority. Objects have no authority; people do .... Authenticity-authority-enforces the social contract between the audience and the museum, a socially agreed-upon reality that exists only as long as confidence in the voice of the exhibition holds. ${ }^{9}$

In another essay in this volume, Susan Vogel provides an example of this authority. In the exhibition Art/artifact, which examined the museum experience, she invoked her authority as a curator of by creating a section that

18 Classical Chinese Gardens In Thenty-first Century America: Cultivating The Past 
... contained an unedited and untranslated videotape showing the installation of a Mijikenda memorial post, accompanied by a label stating that only the original audience could have the original experience-that all other settings were inauthentic and arbitrary to a greater or lesser degree. ${ }^{10}$

Vogel's then-experimental exhibition displayed objects in a variety of ways, using both art museum and anthropological museum practices in an effort to draw the attention of the viewer to how objects in museums are mediated. In contrast, the presentation of these gardens does not seem to be aware of the current debates in exhibition practice (which itself is based in part on shifts in anthropology and ethnography in the past few decades). ${ }^{11}$

Generally not discussed are those elements that are not related to this limited notion of authenticity. These unmentioned elements are what craft these gardens into authentic American creations, or perhaps more accurately, Chinese-American creations since they are often clearly collaborations between the two countries with the goal of strengthening the bonds of friendship and understanding. ${ }^{12}$ There are around 25 of these gardens today. (See a table with a growing list of current Chinese-style gardens in the United States in Figure 1 and see Figure 2 for a partial list of some that are at various stages in the process from fundraising to construction).

Figure 1. Table showing Chinese gardens currently open in the United States
Figure 2. Table of proposed Chinese gardens in the United States
CHINESE GARDENS CURRENTLY OPEN IN THE UNITED STATES

\begin{tabular}{|l|l|}
\hline c.1863 & Chinese Temple (1863) and Chinese Garden, Oroville, California \\
\hline 1953 & International Peace Garden Plum Pavilion, Salt Lake City, Utah \\
\hline 1971 & Chinese Cultural Garden, Overfelt Park, San Jose, California \\
\hline 1980 & Astor Court in the Metropolitan Museum of Art, New York, New York \\
\hline 1982 & China Pavilion, EPCOT, Orlando, Florida \\
\hline $1985 ?$ & Cathay in the West, Bel Air, California \\
\hline 1985 & Chinese Cultural Garden, Cleveland, Ohio \\
\hline 1996 & Pursuing Harmony Garden at the Minneapolis Institute of Art, Minneapolis, Minnesota \\
\hline 1996 & The Margaret Grigg Nanjing Friendship Chinese Garden, St. Louis, Missouri \\
\hline 1996 & Chinese Cup Garden, Schnormeier Gardens, Gambier, Ohio \\
\hline 1998 & The Gardens, Chinese Cultural Center, Phoenix, Arizona \\
\hline 1999 & New York Chinese Scholar's Garden, Staten Island, New York \\
\hline 2000 & Lan Su Chinese Garden in Portland, Oregon \\
\hline 2006 & Seattle Chinese Garden in Seattle, Washington \\
\hline 2006 & The Chinese Garden in the Riverside International Friendship Gardens, Lacrosse, Wisconsin \\
\hline 2008 & Liu Fang Yuan, the Garden of Flowing Fragrance at The Huntington, San Marino, California \\
\hline 2010 & Tacoma Chinese Garden and Reconciliation Park, Tacoma, Washington \\
\hline
\end{tabular}

PROPOSED CHINESE GARDENS IN THE UNITED STATES

\begin{tabular}{|l|}
\hline Georgia-Suzhou Friendship Chinese Garden in Asian Village, Atlanta, Georgia \\
\hline Riverfront Gardens, Des Moines, Iowa \\
\hline Kansas City Chinese Garden, Kansas City, Kansas \\
\hline The Garden of Northern Brightness (Bei Ming Yuan), Minneapolis, Minnesota \\
\hline Garden of Surging Waves (Cang Lang Yuan), Astoria, Oregon \\
\hline Chinese Garden, Dream Gardens, Grapevine, Texas \\
\hline $\begin{array}{l}\text { China Garden (Zhongguo Yuan) A Classical Chinese Garden at the U.S. National Arboretum, Washington, } \\
\text { DC }\end{array}$ \\
\hline Chinese Gazebo and Garden, Evanston, Wyoming \\
\hline
\end{tabular}

19 Classical Chinese Gardens In Twenty-first Century America: Cultivating The Past 
In the three examples below, history is layered differently. Each garden arose to fulfill a different need for a different type of institution, and yet each is called a "Chinese garden." There is a set of objects and ideas that are present in each site that link them to the claim of "Chinese garden:" rocks, plants, views, architecture, and connections to other arts. There are in some cases other overlapping concerns that are not related to being a Chinese garden, but rather to adaptations made due to being located in the United States in the twentyfirst century: accessibility, safety requirements, or education of a diverse public. All three institutions have incorporated some form(s) of didactics to increase the accessibility of their sites to a broad audience. All have useful pedagogical applications, depending on the level of the learner. If these tools are successful in creating memory and emotional connection in the viewers, they may give the site meaning to new communities of viewers.

\section{PURSUING HARMONY GARDEN}

The Pursuing Harmony Garden at the Minneapolis Institute of Arts, Minneapolis, Minnesota, is a reconstructed Qing dynasty garden that is attached to a study that was taken apart and then rebuilt inside the museum (see Figure 3). It is owned and operated by the Minneapolis Institute of Arts, although the project of finding, moving, and reconstructing

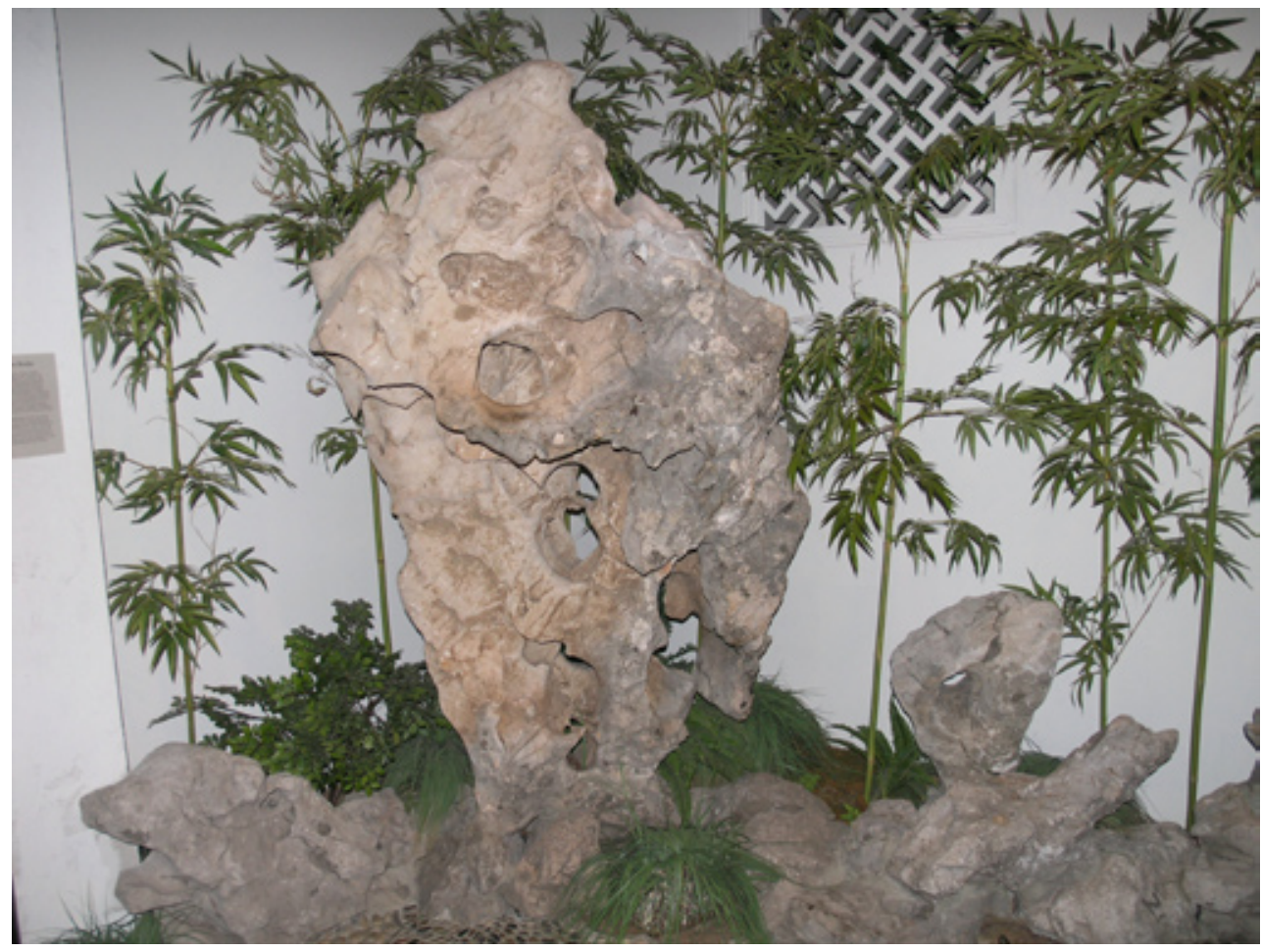

it was backed by Bruce Dayton, a frequent donor to the museum..$^{13}$ The studio/library to which the small courtyard garden is attached is called the "Studio for Gratifying Discouse" (see Figure 4). This studio/library was part of a house near Lake Tai in the town Dangli. ${ }^{14}$ When curator Robert Jacobson located it, he noted that a plaque in the garden wall dated it to 1797. Most of the original stones of the garden were missing when the studio/library was purchased in 1996, but similar rocks from other Jiangnan gardens were purchased and used. ${ }^{15}$ Jacobson was specifically looking for a library and a reception hall to showcase the furniture Dayton donated to the museum and was delighted to find a library with a courtyard garden attached. ${ }^{16}$ Chinese artisans disassembled the site and accompanied the pieces to Minneapolis to help with the reconstruction of the studio and the construction of the
Figure 3. Tai hu rock, Pursuing Harmony Garden, Minneapolis Institute of Arts, 2011. (Photo by author.) 
Figure 4. Studio of Gratifying Discourse, Minneapolis Institute of Arts, 2011. (Photo by author.)

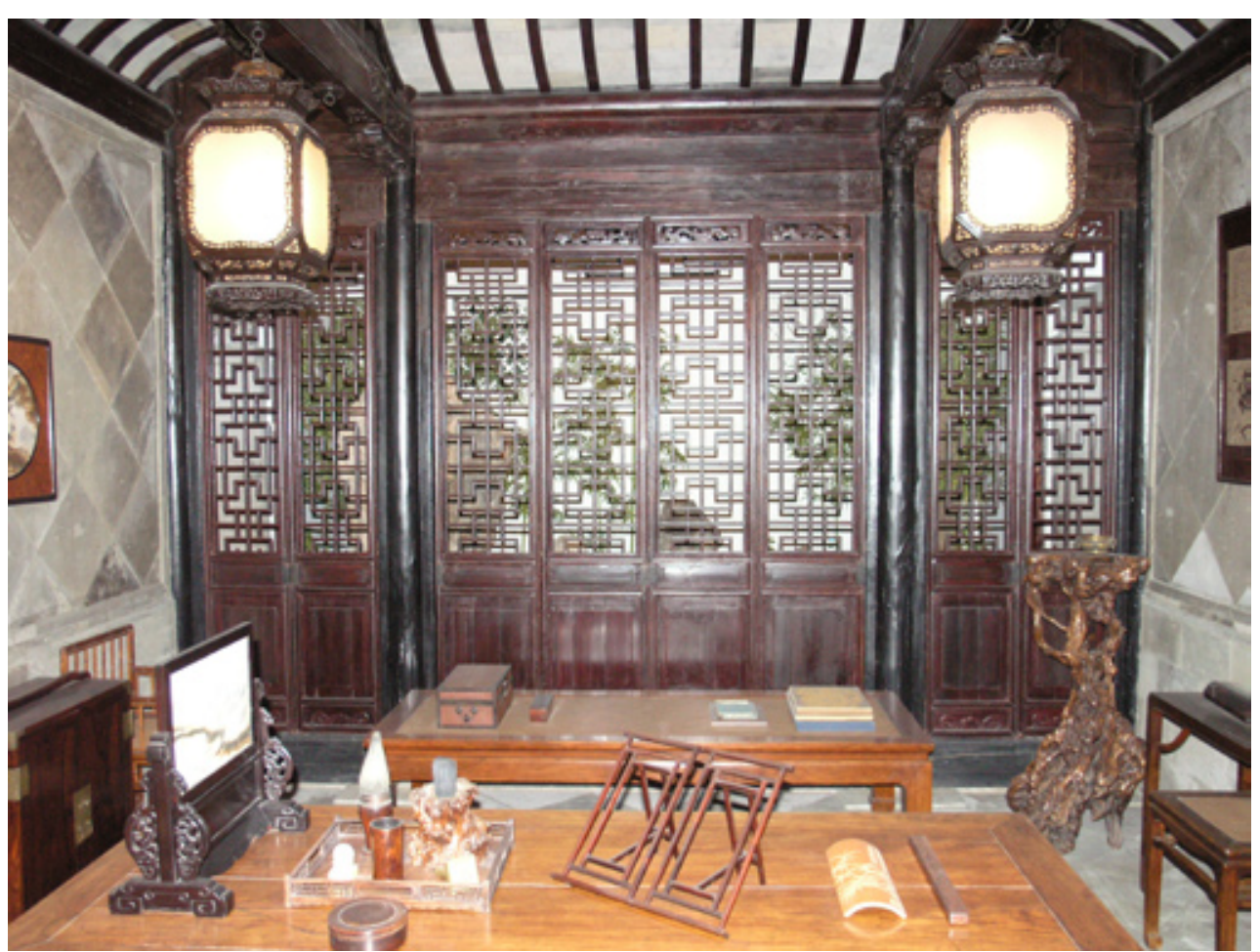

garden.

This site is the only one of the three examples located indoors, actually inside a museum. Dayton wanted the collection of Chinese furniture that he donated to have "context," ${ }^{17}$ which led to the purchase of this garden. This type of installation is what Barbara Kirschenblatt-Gimblett calls exhibiting in situ, “. . . the object is a part that stands in a contiguous relation to an absent whole that may or may not be recreated." ${ }^{18}$ Dayton's collection of objects is displayed in the studio/library and in display cases in the surrounding galleries. The garden is part of the setting and in combination with the studio/library allows the viewer to see the objects in relation to one another and to a space. The installation is part reconstruction and part new creation, but it also recalls the larger whole - the residence from which it was excised.

Visitors can walk through the courtyard garden. The doors on one side of the studio are opened and a sheet of clear glass covers the bottom, preventing visitors from entering. Although the studio cannot be entered, it is possible to see the garden through the studio, creating a view and making the garden seem bigger than it actually is (see Figure 4). A viewer could imagine herself sitting in the chair and rearranging the brushes and paraphernalia in preparation for painting. Noticing how each of the windows frames a particular view increases the sense of space while also making a connection to paintings for the knowledgeable viewer. There are bamboo paintings hung in an adjacent gallery; a perceptive viewer can make a connection between the vertical hanging scroll format and the framed view through the window.

The mosaic on the ground of the garden and the rocks are actual rocks. The plants however, are plastic, fabric, and wire (see Figure 5), making this more installation than garden. In its original context, the small courtyard would have connected to other courtyards and additional views would have been available through the other windows in the library and through the entries into the courtyard. With only a museum wall beyond the lattice windows in the garden wall, there is no borrowed view. There are no crickets or cicada, 
no sound of rain on leaves, no changing shadows on the walls, no smell of damp earth or flowers. Visitors cannot remove their shoes and walk on the stone mosaic for an acupressure massage of their feet. The form of the garden has been preserved, but not its life. By

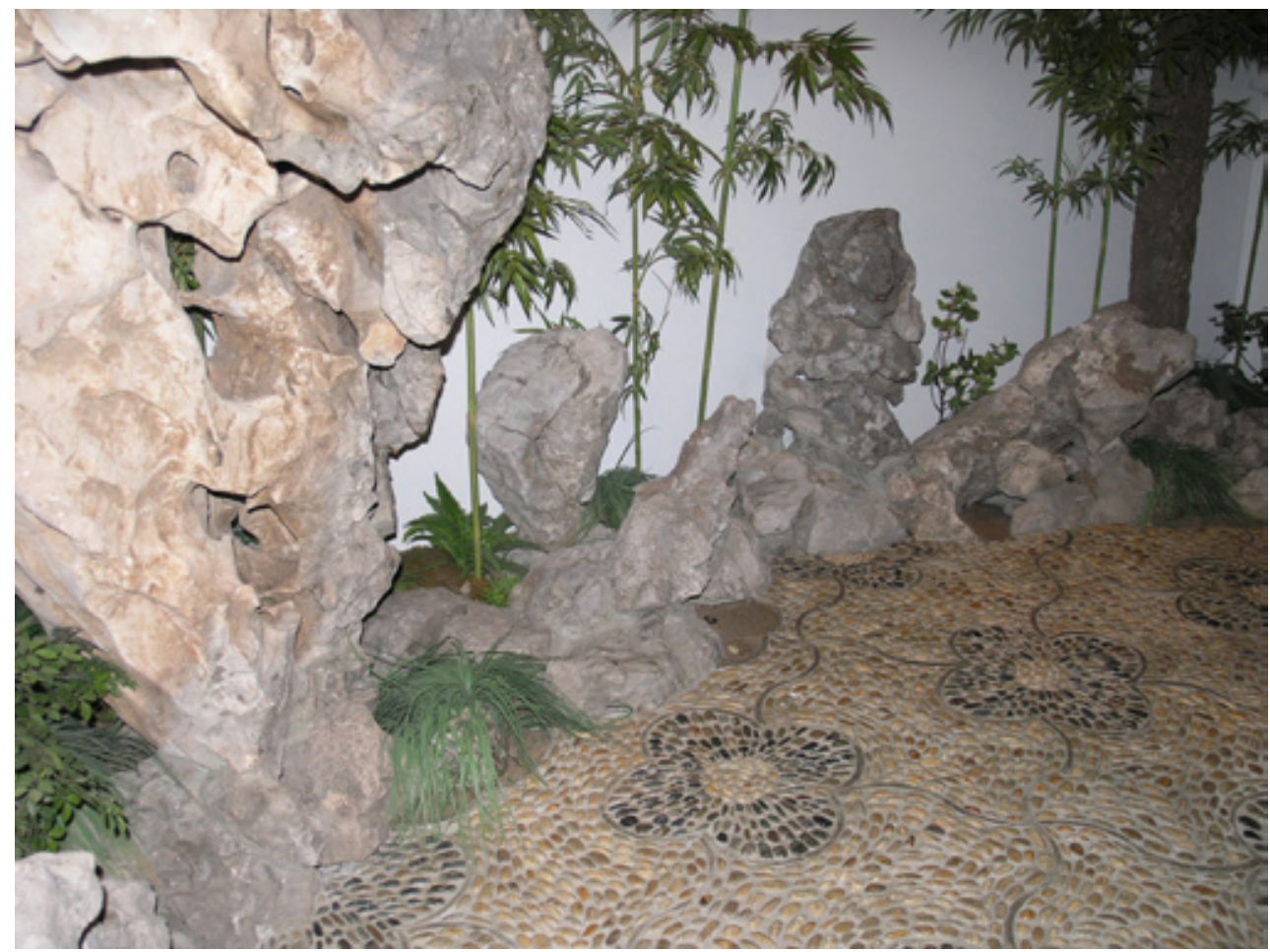

removing the garden from its outdoor context and putting it into a museum, it becomes an artifact (or as Kirshenblatt-Gimblett puts it, "a tomb with a view.") 19

Some of the galleries near the garden are filled with scholar's objects or furniture, each with wall text to lead the interested viewer further into that world. Some of the objects have audio materials via headsets. The Minneapolis Institute of Art has a website, "Arts of Asia," which features a section on the library and rock garden. ${ }^{20}$ There are docent-led tours that include the library and rock garden. In contrast to the in situ presentation of the garden, Kirshenblatt-Gimblett describes this mode of presentation as "in context:"

The notion of in context, which poses the interpretive problem of theoretical frame of reference, entails particular techniques of arrangement and explanation to convey ideas .... In-context approaches to installation establish a theoretical frame of reference for the viewer, offer explanations, provide historical background, make comparisons, pose questions ....".21

She concludes that these strategies give the viewer a reason for looking at the object. Dayton wanted the garden to function as context for the objects, but it becomes another artifact that becomes subject to interpretative strategies.

The Pursuing Harmony Garden is history that can be seen in the present. Even though parts of the site date to the eighteenth century, it is not that eighteenth-century garden. Like Wen Zhengming in the opening quote, visitors can perhaps be swept into the past by this re-presentation of a garden. It may recall past, but it is an adaptation of the present.
Figure 5. Rocks and silk plants, Pursuing Harmony, Minneapolis Institute of Arts, 2011. (Photo by author.) 
Figure 6. Knowing the Fish Pavillion, Lan Su Classical Chinese Garden, 2006. (Photo by author.)

\section{LAN SU CHINESE GARDEN (ALSO KNOWN AS THE GARDEN OF AWAKENING ORCHIDS AND PREVIOUSLY KNOWN AS THE PORTLAND-SUZHOU CHINESE GARDEN $)^{22}$}

In addition to preserving the past, Portland's representation of a Chinese garden has the added function of revitalizing another downtown neighborhood. ${ }^{23}$ It is a new construction using traditional techniques, materials, and plants (see Figure 6). It is owned by the City of

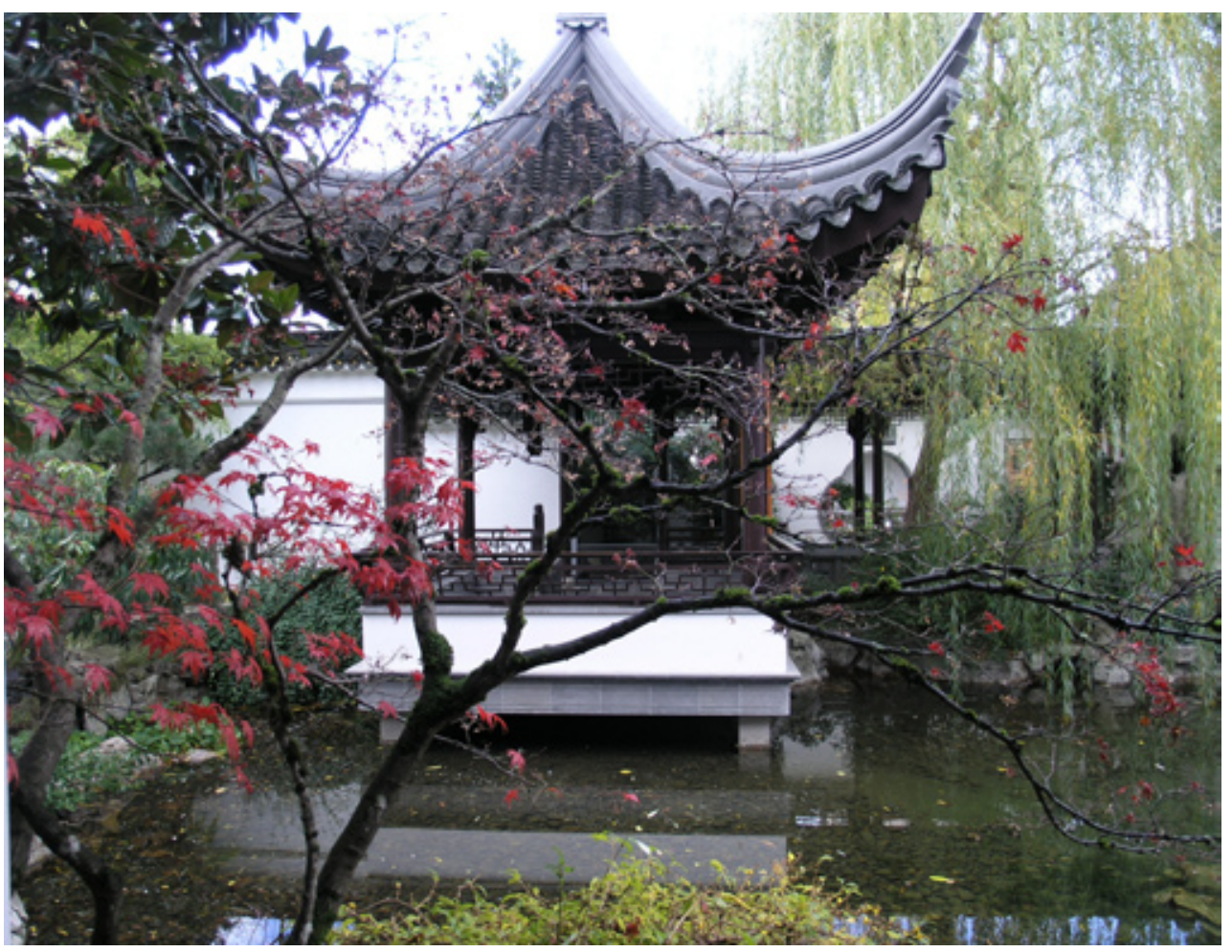

Portland and is operated by a nonprofit company. The Lan Su Chinese Garden also underscores the relationship between Portland and her sister city in China, Suzhou. In contrast to the modest Pursuing Harmony Garden, the Portland garden is essentially a city park and takes up an entire one-acre block of downtown Portland. Like Pursuing Harmony Garden, it was funded largely by donors but the land is owned by the City of Portland through the Board of Parks and Recreation.

Although "[g]arden designers and artisans from Suzhou built this Garden (sic),"24 there were also architects, engineers, and contractors from Portland involved in the construction of the garden. These are not mentioned in the promotional material, but were necessary to be sure that the garden meets state and federal accessibility and safety requirements; there is a wheelchair-accessible route through the garden. However, there are many places where more traditional Chinese aesthetics were not altered to fit American building codes-there are still steps up into some buildings and some thresholds remain intact (for instance, one must step over the threshold of the Crabapple Blossom Gate). ${ }^{25}$ A traditional Chinese garden has many liminal moments of slowing down and being more conscious of movement, stillness, and change; some of this is lost in the American descendants.

Most of the building materials and the rocks were brought from China. ${ }^{26}$ The plants are those found in Chinese gardens, but were all grown in the United States. The design is not an exact replica of an extant garden, but is an original design based on gardens in the Suzhou area of China more generally. It utilizes the shape of the site and incorporates the

23 Classical Chinese Gardens In Twenty-first Century America: Cultivating The Past 
surrounding neighborhood through leak windows and borrowed views (see the "borrowed view" of high rises in Figure 7).

In the garden's organizational profile, "garden as museum" is listed as one of the intended goals. ${ }^{27}$ It is essentially reversing the approach of the Minneapolis Institute of Arts: it is collecting artifacts to provide context to the garden rather than adding a garden to provide context to artifacts. This suggests that the garden is conceived of as a site where culture is

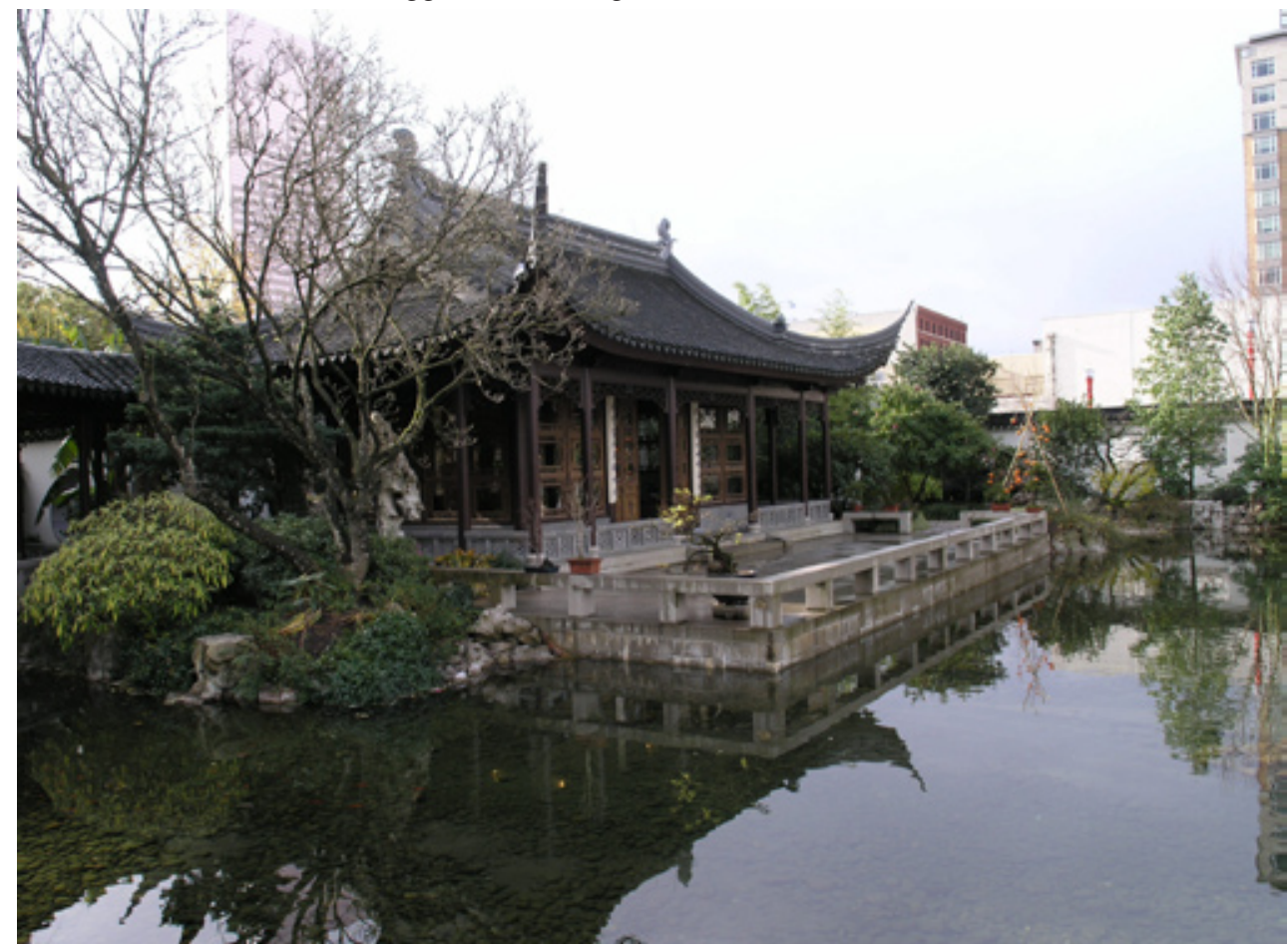

interpreted and produced. If this shift includes visible reflexivity about the installation and interpretation, it could be a powerful tool for engaging and challenging the viewers (see the discussion of Vogel's installation strategy above).

The organizational profile of the Lan Su Chinese Garden also notes that previous programming was focused too tightly on audiences that had significant knowledge of plants or Chinese art and culture. ${ }^{28}$ More recent programming reflects attempts to reach a broader audience: feng shui classes or having a favorite poem done in Chinese calligraphy, for example. Such programming not only informs a greater audience, it also gets them to enter the garden multiple times. This repetition is essential to understanding Chinese garden aesthetics (and art of any kind, really).

In addition to its comprehensive website, programming, and tours, the Lan Su Chinese Garden has a printed guide that includes a cutout to help the visitor frame views at specific "vistas" noted and described on the guide. ${ }^{29}$ This in effect teaches the viewer one mode of interaction with the garden-it teaches them where and how to look. As Robert Pogue Harrison notes in the opening to his chapter called "The Lost Art of Seeing" in Gardens: An Essay on the Human Condition:

Where appearances recede into the depths of space and time even as they come forward to stake their claim in the phenomenal realm, they make special demands on our powers of observation. That is bad news for gardens, for nothing is less cultivated these days in Western societies than the art of seeing. It is fair to say that there exists in our era a tragic discrepancy between the staggering richness of the visible world and the extreme poverty of our capacity to perceive it. ${ }^{30}$
Figure 7. Hall of Brocade Clouds, Lan Su Chinese Garden. (Photo by author.) 
The sort of intervention described is not mimicking the behavior of an imagined, long ago, far away Chinese gentleman in his garden. It is an adaptation that acknowledges that being able to see is an important skill, but one that is often underdeveloped in the here and now.

Unfortunately, the descriptions to the cultural references made in the design of the view are so general that it would be hard for a more ambitious learner to pursue more information. For example, in one of these constructed and guided views (see Figure 7), the story of a Chinese philosopher pondering the happiness of fishes is shared, but if a visitor wished to learn the whole story or who wrote it, it would be hard to research since the philosopher's name (Zhuangzi) is not mentioned. To remedy this, interested learners could also read Listening to the Garden by Reed College Professor Emeritus David Wu. Here he writes about the process of naming and providing the calligraphy for the various sites in the Lan Su Chinese Garden. He provides clear and thorough translations and explains how the translations work. He also provides a sense of the resonances created by the names chosen and names the references clearly.

Like the Pursuing Harmony Garden, the Lan Su Garden claims a Chinese genealogy, but it is also more of a hybrid. Since the initial goal (urban revitalization) and location (city block) are so different from the installation at the Minneapolis Institute of Arts, it is not surprising that the resulting adaptations are also distinctive. The challenges of interpretation and installation remain.

Figure 8. View with a distant pavilion, Liu Fang Yuan, Huntington Garden, 2009. (Photo byauthor.))

\section{LIU FANG YUAN (GARDEN OF FLOWING FRAGRANCE) - HUNTINGTON LI B R A R Y}

The third site is Liu Fang Yuan, the Garden of Flowing Fragrance at The Huntington, San Marino, California, which is an ongoing construction that is one section of a larger botanical garden in an institution that also has a world-class library and art collection (see Figure 8). It is set against the backdrop of the San Gabriel Mountains.

Since the Huntington is library and archive and botanical garden, the Liu Fang Yuan is part of a larger complex of gardens, architecture, and culture of learning. The first phase is 3.5 acres, but there are plans to eventually expand to 12 acres. This is one of the most ambitious plans for a Chinese garden in the United States. Since the mission of the Huntington is in part to "... encourage research and promote education in the arts, humanities, and botanical sciences . ." "31 the addition of a Chinese garden is logical-it provides ample opportunities for each of these goals.

In a recently published record of the garden, a short essay addresses materials in the Huntington collections that document the history of the early Chinese-American community of California. ${ }^{32}$ The essay also indicates a continued commitment to preserving the history of this growing community and closes by highlighting the programs associated with the Liu Fang Yuan, which function to "further enhance the understanding of the richness

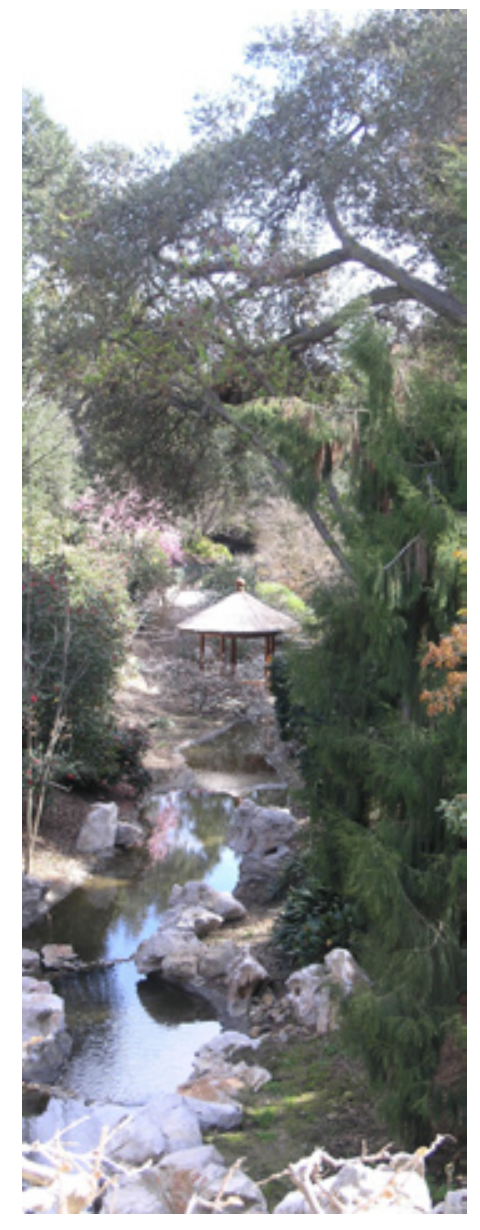


and distinctiveness of Chinese art, literature, and history."33 Although it is not located on a site particularly associated with the Chinese-American community, the Huntington recognizes a connection to and a responsibility to include this community. This function of community building appears frequently in many other sites as well.

Like Lan Su Chinese Garden, Liu Fang Yuan's construction was based on traditional designs. Both American architects and contractors and Chinese designers and artisans created the garden, using as much material from China as possible. ${ }^{34}$ In this case, the institution is very forthcoming about where compromises were made to keep the traditional form in line with contemporary building and accessibility codes. ${ }^{35}$ For example, it has included removable thresholds on some buildings (see Figure 9 for an example with the threshold in

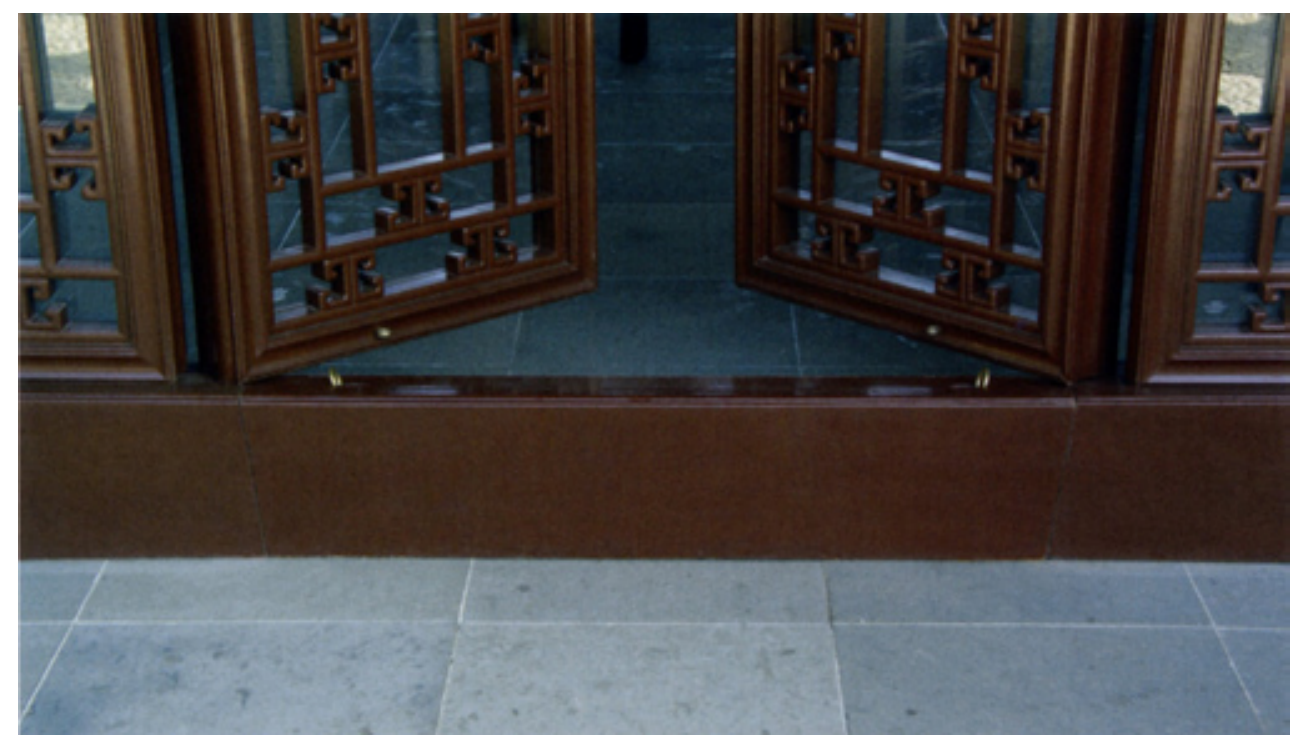

place). California has additional requirements due to the frequency of earthquakes in the area. For instance, the tai $h u$ rocks must have proper supports to prevent them toppling should any seismic activity occur in the area. These practical alterations have mostly been cleverly disguised to blend with the original design (see Figure 10 for an example of colored concrete under smaller stones used to disguise a support).

Although many of the design principles are similar in the Lan Su Chinese Garden and Liu Fang Yuan, the scale is quite different. Both utilize the shape and features of their sites to advantage. Both use leak windows and borrowed views with quite different effects. The Lan Su Chinese Garden is downtown and the borrowed views to the contemporary urban world are a stark contrast to the traditional and quiet world inside; a reminder of the separateness of the garden and how the visitor is "escaping" to nature. Liu Fang Yuan is near the mountains and the borrowed views unify the garden with the larger natural world and expand its scope; the visitor feels small in the universe. Both gardens use architecture, plants, rocks, and water features to create many series of views and layered views that can be enjoyed from stationary points along a path or while moving along a number of paths.

Just as it was in the Chinese models, a key element in the design of these views in the American gardens is naming the views and the architecture. The names reference the history of art and literature and are usually also layered in their meanings. This aspect of the Chinese garden has presented a particular challenge to today's garden builders. For much of the history of imperial China, educated men studied a series of texts in order to take the civil service examinations. There was a community of people all absorbing the same visual
Figure 9. Detail of removable threshold, Freshwater Pavilion, Liu Fang Yuan. From Laurie Sowd, "The Making of Liu Fang Yuan," in Another World Lies Beyond, ed. June T. Li (San Marino, CA: Huntington Library, 2008), 34. 
Figure 10. Detail, Taihu rock, Liu Fang Yuan (Garden of Flowing Fragrance) at the Huntington, 2011. (Photo by author.) and textual references and then using them in their own writings, paintings, and gardens. The visitors to today's gardens are much more diverse in their education and in their knowledge of traditional Chinese art and culture. Many of the references are lost on contemporary viewers (no matter their background).

The Liu Fang Yuan has also adopted both broad and focused programming to reach a variety of visitors and to encourage repeated visits. It has organized international conferences, sponsored productions of Chinese opera, held regular talks on a variety of topics related to the Chinese garden, and has ongoing programming for specialists and non-

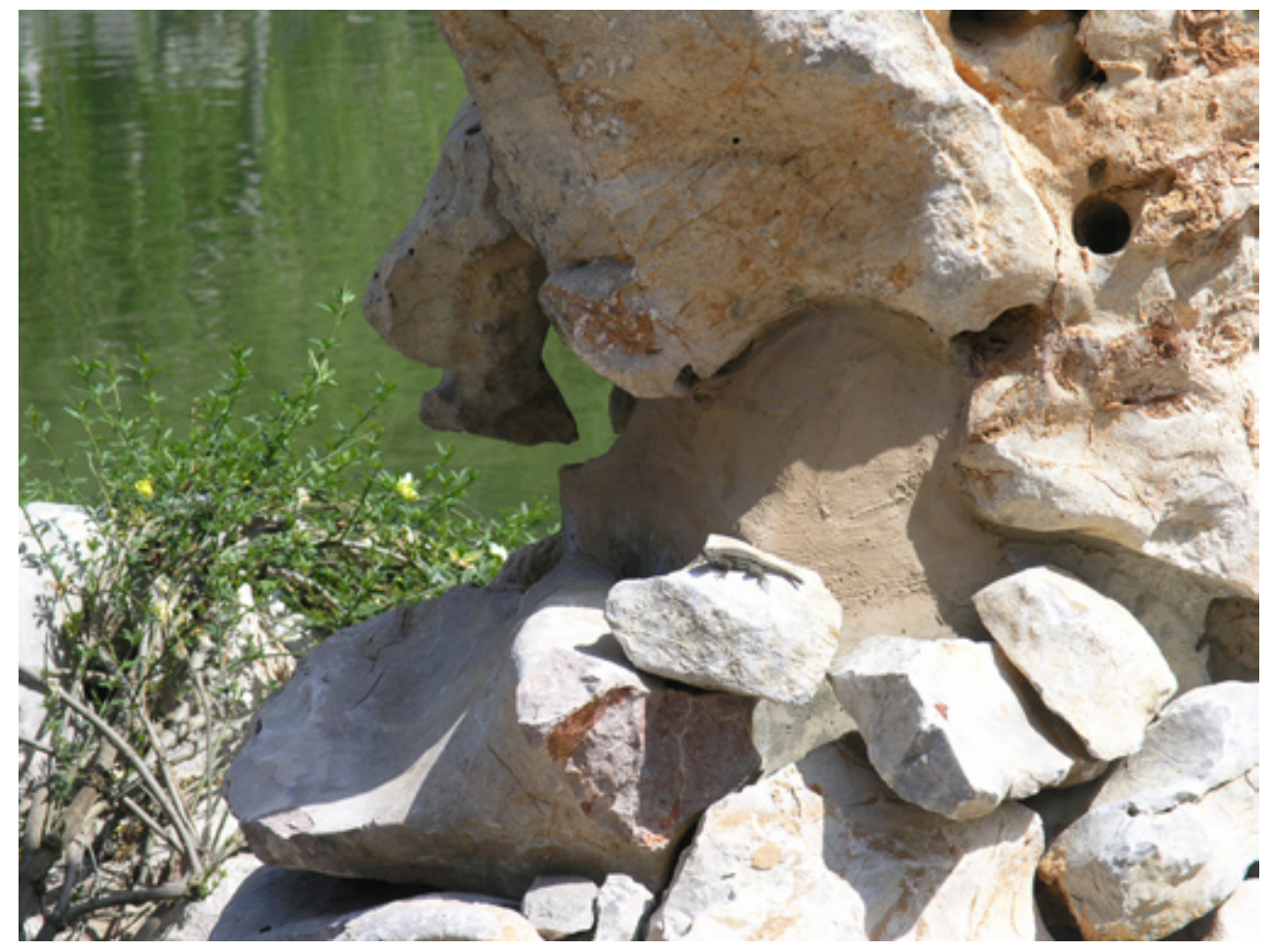

specialists.

Besides the garden itself, Liu Fang's most significant contribution to the history of Chinese gardens is the aforementioned volume edited by the curator of the garden, T. June Li, Another World Lies Beyond: Creating Liu Fang Yuan, the Huntington's Chinese Garden. Li refers to the volume as a "Liu Fang Yuan ji"-a "ji" is a "record." This is a particular form of Chinese prose; this form is one of the primary sources on traditional Chinese gardens for scholars today. This contemporary record produced by the Huntington is much more documentary than its Chinese predecessors. One frustration of contemporary researchers is that there is very little documentation of how Chinese gardens were laid out, how they were designed, how they "really" looked. The authors of premodern and early modern garden records were interested in evoking certain images and continuing to layer artistic, literary, and cultural allusions. Instead of maps and overviews and plan drawings done to scale, there is a long history of annotating the garden in China and these annotations are in some cases all that remains of a garden. These annotations come in the forms of poems, records, and paintings. From the act of naming, and from records of these names, there emerge patterns of certain images and themes, such as bamboo or rocks or the Peach Blossom Spring or Orchid Pavilion. Over time, landscapes and eventually gardens become associated with the idea of a righteous (and often reclusive) gentleman. ${ }^{36}$ In some cases, the painted repre-

27 Classical Chinese Gardens In Thenty-first Century America: Cultivating The Past 
sentations purport to be re-creations of physical gardens and others are more of a symbolic portrait of the owner's virtue. ${ }^{37}$ These images are a record of what was evocative of and meaningful in the garden.

Contemporary American notions of documentation would be quite different. The Huntington volume attempts both types, but does more of the contemporary form. It includes detailed discussions of the building process, of the naming process, of the plants, of the calligraphy, a detailed map of Phase 1; it essentially covers the mission statement of the institution. It is free of jargon and is accessible to a casual reader, but has enough depth to provide a more ambitious reader a solid basis for further study.

Like the previous two examples, the Liu Fang Yuan is one interpretation of a cultural icon. Not only has it adapted the site of the garden, but also the way in which the garden is documented.

\section{CONCLUSION}

In these three examples, the authenticating details emphasize a Chinese genealogy for the garden. Yet the alterations to the form, the diverse functions, and the necessity for community building illuminate a much more complicated identity struggling to integrate other memories and histories and resulting in distinctive adaptations. There is a growing body of sites that with some careful critical analysis could be useful as both a way of understanding the past and of understanding the evolution of the present. The writing and layering of history and memory in these gardens is even more complex. Although many layers of allusion and meaning are lost, these gardens keep the past present and also rearticulate it for the future.

Today's garden designers face the challenge of making these gardens physically, visually, and intellectually accessible to viewers who are not trained in the Chinese classics nor in the history of Chinese art. In meeting this challenge, they have continued the growth of Chinese gardens-or more accurately, Chinese-style gardens-and continue to annotate the garden archive in new ways. These new annotations aid contemporary viewers in building layers of meaning and memory that may-one day-result in a pearl.

Note: The author would like to thank the anonymous reviewers who made many helpful suggestions for revision and for additional methods for approaching these sites.

\section{NOTES}

1. This article is taken from a section of my forthcoming dissertation, Keeping the Past Present: Representations of the Garden during the Ming Dynasty.

2. This is my translation based on the transcription of the colophon on a landscape handscroll by Wen Zhengming in the British Museum (Registration number: 1955, 1210, 0.1). A slightly different translation may be found in Osvald Siren, Chinese Painting: Masters and Principles, v. 4 (New York, NY: Hacker Art Books, Inc., 1973), 176.

3. Mihaly Csikszentmihalyi and Eugene Rochberg-Halton, The Meaning of Things: Domestic Symbols and the Self, New York, NY: Cambridge University Press, 1981.

4. Thank you to the anonymous reviewer whose comments helped me to clarify this idea by suggesting the term "cultural icon."

5. I will refer to the gardens in the US as "re-presentations" since they present the form on which they are based again, but in a new way and in a new context. The paintings of gardens to which I refer in other parts of the article are "representations" in the more usual sense and so I use the hyphen to distinguish between these two uses

6. I use this term as described by Jan Assmann in "Collective Memory and Cultural Identitiy," New German Critique 65 (1995): 125-133, http://www.jstor.org/stable/488538.

7. For an English translation of this work, see Ji Cheng, Yuan Ye, translated by Alison Hardie (New Haven, CT: Yale University Press), 1988.

8. Lan Su Chinese Garden, Lan Su Chinese Garden, "History and Culture," http://www.lansugarden.org/garden/ history_culture.

9. Spencer R. Crew and James E. Sims, "Locating Authenticity: Fragments of a Dialogue," in Exhibiting Culture: 
Poetics and Politics of Museum Display, Washington, DC: Smithsonian Institute, 1991, 163.

10.Susan Vogel, "Always True to the Object, In our Fashion," in Exhibiting Culture: Poetics and Politics of Museum Display (Washington, DC: Smithsonian Institute, 1991), 196-97.

11.See, for example, Johannes Fabian, Time and the Other: How Anthropology Makes Its Object (New York, NY: Columbia University Press, 1983) and Clifford Geertz and George Marcus, Writing Culture:The Poetics and Politics of Ethnography (Berkeley, CA: University of California Press 1986).

12. These gardens are tangible evidence that a shift in the power dynamic of this relationship is evolving-China is leaving its mark on the American landscape. This is worth further exploration, but is not the focus of this piece.

13. Rita Reif, "Arts and Artifacts: Far from China, but Completely at Home," New York Times, September 20, 1998, http://www.lexisnexis.com,

14. Minneapolis Institute of Arts, "Arts of Asia: Architecture: Scholar's Library and Study," http://www.artsmia.org/ art-of-asia/architecture/chinese-scholars-study.cfm

15. Minneapolis Institute of Arts, "Arts of Asia: Architecture: Scholar's Library and Study-Garden Rocks," http:// www.artsmia.org/art-of-asia/architecture/chinese-scholars-study-garden-rocks.cfm. Note that the Minneapolis Institute of Arts (MIA) uses the Wade-Giles romanization system, but I use Pinyin, so "Jiangnan" is "Chiang-nan" in the MIA text.

16. Reif, "Arts and Artifacts," http://www.lexisnexis.com,

17.Ibid.

18. Barbara Kirshenblatt-Gimblett, "Objects of Ethnography," in Exhibiting Culture: Poetics and Politics of Museum Display (Washington, DC: Smithsonian Institute, 1991), 388.

19. Kirshenblatt-Gimblett, "Objects of Ethnography," 416.

20.MIA, "Scholar's Library and Study," http://www.artsmia.org/art-of-asia/architecture/chinese-scholars-study.cfm

21.Kirshenblatt-Gimblett, "Objects of Ethnography," 390

22.The Lan Su Chinese Garden was originally called "The Portland Classical Chinese Garden."

23. Mark Hinshaw, "Secret Garden in the City: A Classical Chinese Garden Uplifts Portland's Chinatown," Landscape Architecture 93, no. 1 (2003): 92.

24. Cynthia Johnson Haruyama, "Portland Chinese Garden Organizational Profile (PDF)," Lan Su Chinese Garden, "About the Garden," 9, http://www.lansugarden.org/garden/about_the_garden

25. A threshold is a key component of Chinese architecture: it forces the viewer to consciously raise her foot and acknowledge the movement of her body over a boundary into a new space. A threshold also provides a "foot" to a building and completes it aesthetically.

26. A more detailed account can be found in the "Organizational Profile," which is in PDF form and can be accessed through the website: http://www.lansugarden.org/garden/about_the_garden

27. Haruyama, "Portland Chinese Garden," 15.

28. Haruyama, "Portland Chinese Garden," 19.

29. This guide is available on the website in a PDF: http://www.lansugarden.org/learning/view_the_garden.

30. Robert Pogue Harrison, Gardens: An Essay on the Human Condition, Chicago, IL: University of Chicago Press, 2008, 114.

31. "Mission Statement" at The Huntington, http://www.huntington.org/mission.aspx

32.Peter J. Blodgett and Robert C. Ritchie, "The Huntington Collections and the Chinese Community," in a volume edited by T. June Li, Another World Lies Beyond: Creating Liu Fang Yuan, the Huntington's Chinese Garden (San Marino, CA: Huntington Library, 2009), 11-12.

33.Ibid., 12.

34.Even the terms used reflect the interest in both safety and authenticity— "architects" and "contractors" are job titles that have licensing and training associated with them; "designers" and "artisans" are titles that indicate a focus on aesthetics and a different type of training. For instance, "artisan" once meant "craftsperson" but is now used to indicate someone trained in traditional methods.

35.This is discussed in the most detail in Laurie Sowd "The Making of Liu Fang Yuan: A Brief History," in a volume edited by T. June Li, Another World Lies Beyond: Creating Liu Fang Yuan, the Huntington's Chinese Garden (San Marino, CA: Huntington Library 2009), 29-39.

36. For examples of some early connections between landscapes and identity, see Ellen Johnston Laings, "NeoTaoism and the 'Seven Sages of the Bamboo Grove' in Chinese Painting," Artibus Asiae 36, no. 1/2 (1974): 5-54, http://www.jstor.org/stable/3249709 and Richard Vinograd, "Family Properties: Personal Context and Cultural Pattern in Wang Meng's 'Pien Mountains' of 1366," Ars Orientalis13 (1982): 1-29, http://www.jstor. org/stable/4629310.

37. For example, see Robert Harrist, Painting and private life in eleventh-century China: Mountain villa by Li Gonglin (Princeton, N.J.: 


\title{
Between Yesterday and Today: Contemporary Art in Nepal
}

\author{
Kathryn Hagy
}

\begin{abstract}
This paper examines works from the last decade by six Nepalese artists and delves into questions such as how today's artists align themselves between their ancient arts and their contemporary context. What is the conversation about globalism and its impact on artists? How do artists deal with social pressures and is the content of their work directly affected by these pressures? Through in-country research and subsequent study and interviews with artists, what is revealed is an energetic art scene that draws much of its inspiration from a local context, whether that be affirmation of or protest against that context to some degree. When visiting Kathmandu Nepal, one is bound to discover that like the ancient sculptures, paintings and temple architecture that exist on every corner, the art of contemporary Nepal is everywhere as well.
\end{abstract}

Keywords: Kathmandu; Nepal; contemporary; art; artivism; globalism

When visiting Kathmandu, one is bound to discover that, like the ancient sculptures, paintings and temple architecture that exist on every corner, the art of contemporary Nepal is everywhere. Especially in Kathmandu, one senses the same artistic energy of cities like New York and Berlin. New artists function as educators and arts administrators and their protégés benefit from the "artivism"1 activities of their mentors. Art installations and performances spring up in Kathmandu Valley public squares utilized by both residents and tourists for practical and religious purposes. Today's performance art and installation is another aspect of pilgrimage and ritual within sacred space. Social upheavals and desperation for change shape the processes, materials, subject, and content of art in contemporary Nepal.

Globalism's effect on the booming art production and markets of India and China cannot be denied, and both countries are benefiting from the interest of local, expatriate, and western collectors. But what of the smaller countries surrounding India and China, such as Nepal? I began to think about Nepal's physical, economic, and artistic quandary while preparing for a Fulbright Fellowship in Kathmandu in 2010. There is a great deal of literature on the historical arts of the Malla and Licchavi periods and increasingly more on the arts of midcentury that depart from traditional modes. However, I found very little scholarly information on art of the immediate present-my area of interest—because much scholarship on Nepalese culture privileges the arts of the past over what is produced now. I wondered how today's artists aligned themselves between their country's ancient arts and their contemporary context. What is the conversation about globalism and its impact on artists? How do artists deal with social pressures and is the content of their work directly affected by these pressures?
Kathryn Hagy is a professional artist with a Master's degree in Painting and Printmaking from Rhode Island School of Design. In 2010, Hagy was the recipient of a Fulbright Scholarship for research in Kathmandu, Nepal where she taught art, developed her artwork related to water images, and researched contemporary Nepalese art. 
Though the Nepalese themselves acknowledge the cultural connections between their country and India and China, it is important to note that many Nepalese bristle while talking or writing about these connections, or about relationships with regions such as the West. In a survey of Nepali art from medieval to modern, scholar Abhi Subedi states that, "Extensive studies of Nepali art in various books and survey articles by different scholars have shown the uniqueness of Nepali art, especially in relation to Indian art of a similar vein in the Eastern monasteries of India. Still, many scholars and observers tend to ignore the uniqueness of early Nepali art and draw hasty conclusions about the extension of Indian influences on it."' Subedi may have read noted scholar of Nepalese studies Michael Hutt's 1994 Guide to the Art and Architecture of the Kathmandu Valley in which Hutt contends that "Contemporary [Nepali] artists are beginning to develop a school of painting that is both modern and distinctly Nepali. Nevertheless, the great masterpieces of Nepali art belong firmly to the past...." As one can imagine, these type of sentiments are met with dismay among today's Nepalese artists. The modernism to which Hutt refers came about through the return of a foreign-educated Nepalese artist named Lain Singh Bangdel (1919-2002), who studied in India during the 1940s and later emigrated to Paris where he associated with artists such as Pablo Picasso and Georges Braque.

In 1961, the King of Nepal pressed Bangdel to return and in the following year he exhibited his works within his country for the first time, marking the beginning of the modern period and becoming the father of modernism in Nepal. ${ }^{4}$ What Kathmandu viewers saw for

Figure 1: Lain Singh Bangdel, Reflection, 2000, oil on canvas, $30 \times 24$ inches. Image courtesy of Dina Bangdel

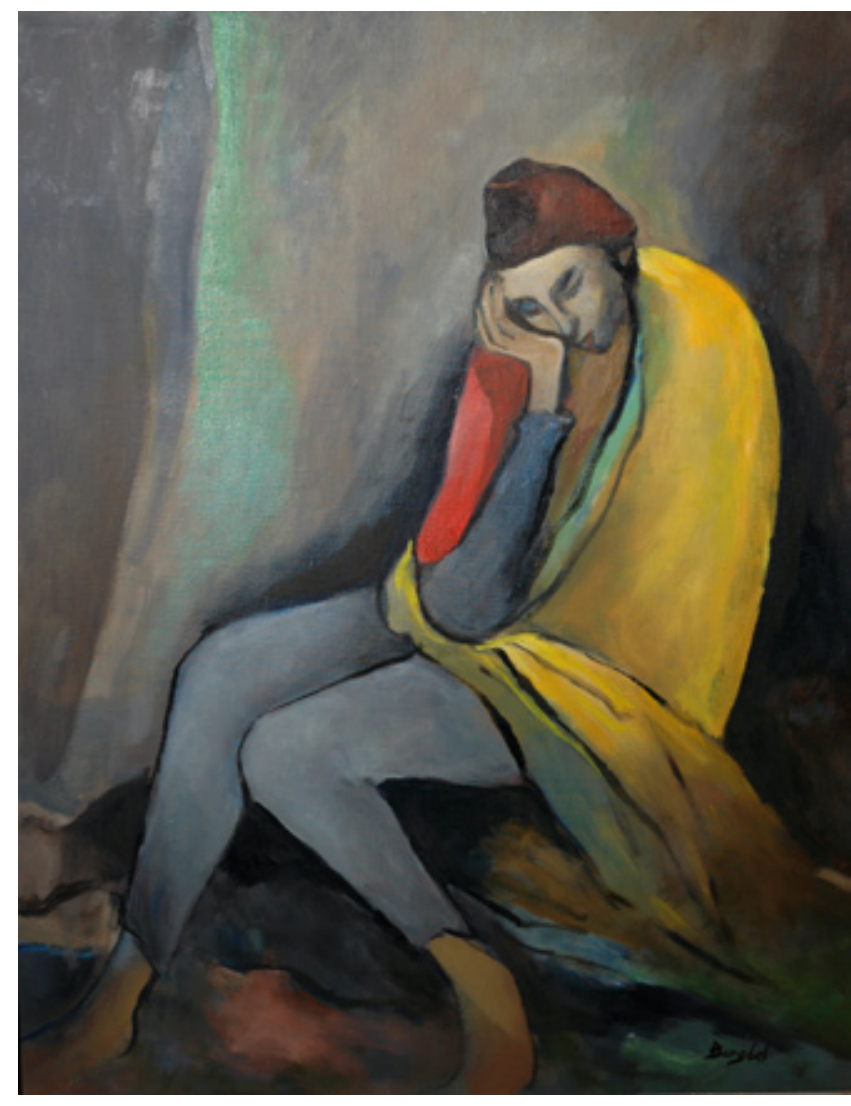
the first time was what one reporter called the "unique presentation of human drama." ${ }^{5}$ One can see the influence of both Picasso's Blue period in Bangdel's work (Figure 1) and other works employ abstract expressionist tendencies.

Nepalese artists continued studying abroad, most notably in India and Bangladesh, where western educational systems still exerted a presence in the post-colonial era. ${ }^{6}$ Bangdel's election to head the Royal Nepal Academy in the 1970s had a great impact on younger artists and art educators. What he and others like him accomplished was to bring western approaches, processes, and art media to Nepal. Western cultural tastes had already

been established in Nepal under the rule of the Ranas during the late nineteenth and early twentieth centuries, and court artists had turned "away from a mythic-religiously motivated [concept] toward works of art that served the ends of personal uplift and thus possessed a 
purely aesthetic character."' In Bangdel's work, one can see abstraction, expressionism, and the traditional western genres of portraiture over cultural motifs.

In a lecture on "Hybridity and Negotiation in Contemporary Nepali Painting," scholar Yam Prasad Sharma summarized these cultural motifs as magical, mystical, narrative, didactic, anthropomorphic, exhibiting religious harmony, meditation/concentration, union of self/cosmos, and resolving differences between the sacred and profane. ${ }^{8}$ In this Three Mother Goddesses paubha painting (Figure 2), we can see the mysticism of meditating and floating gods, including the anthropomorphic Ganesh, above an earthly narrative. In the contemporary sculpture of

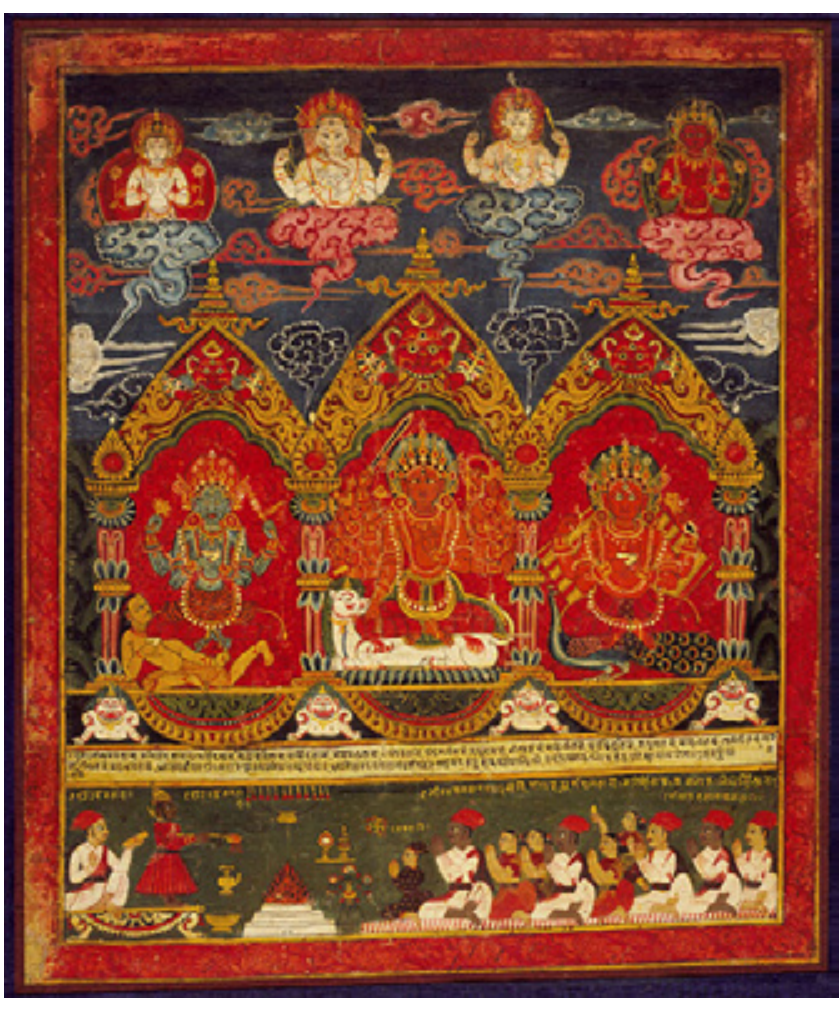
Laya Mainali, his primary subject is the Shiva linga as the resolution of sacred and profane. His bronze yoni suggests an absent linga that is further emphasized by the title Mother and Child (Figure 3).

According to Subedi, “...the most important feature of modern Nepali art is that the artist is divided between rejection and acceptance of tradition - its values and techniques. In some very well-known paintings, the tension itself is the subject matter of the painting." The work of Shashikala Tiwari is a good example of this (Figure 5). Her flower and figurative forms derive from nature, yet the swirling energy of the paintings nearly breaks the figure and flowers apart, or at least has caught these forms in inescapable eddies. The painting's tone, expressed through color and form, isn't dangerous but tense. The petal forms come to knife points

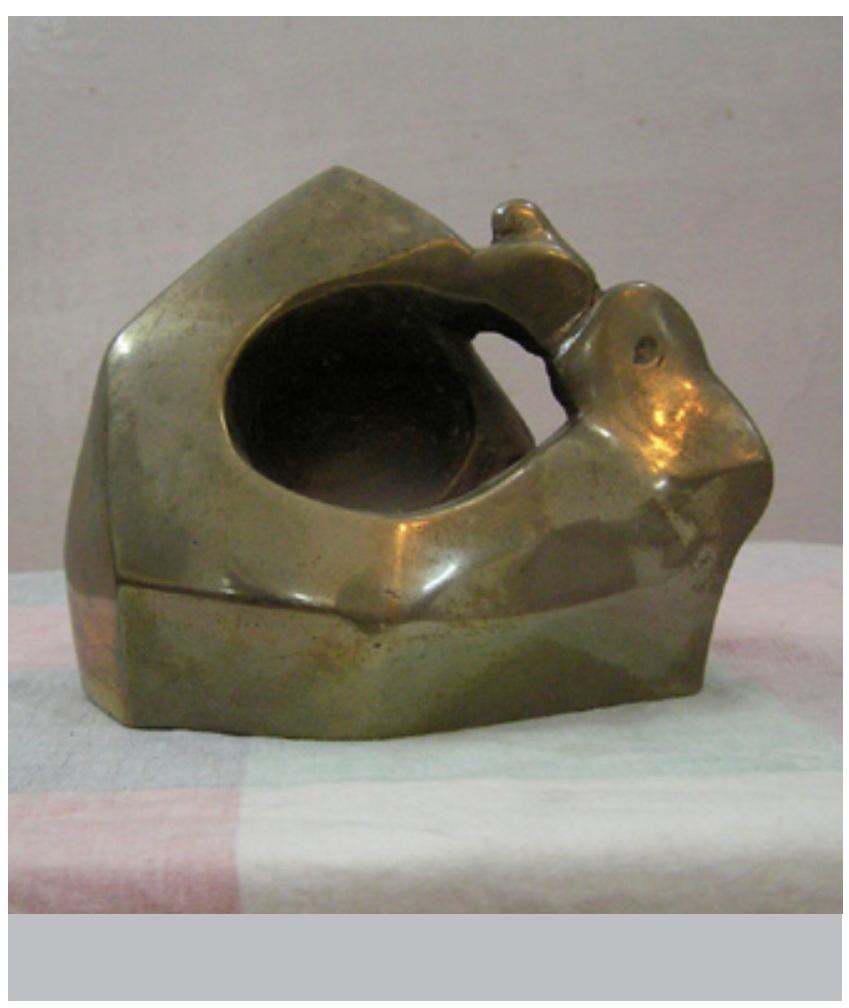

Figure 2: Three Mother Goddesses (Matrikas): Chamunda (left), Mahalakshmi (middle), Kaumari (right), 1679, Pata/Paubha painting, opaque watercolor on cloth, from Bhaktapur Nepal, 23 $1 / 2 \times 19$ 3/4"

Figure 3: Laya Mainali, Mother \& Child, 2000-03, bronze, 5 × 6 inches. Image courtesy of the artist; Bottom: Shiva Linga at Pashupati Temple, Kathmandu, Nepal 
Figure 4: Shiva lingum in one of the Pandra Shivalaya shrines at Pashupatinath Temple, Kathmandu. Image courtesy of the author.

Figure 5: Shashikala Tiwari, Mystery Morning (alternate title: Sun Behind the Spiderweb), 1998, oil on canvas, 34 x 37 inches. Image courtesy of the artist.

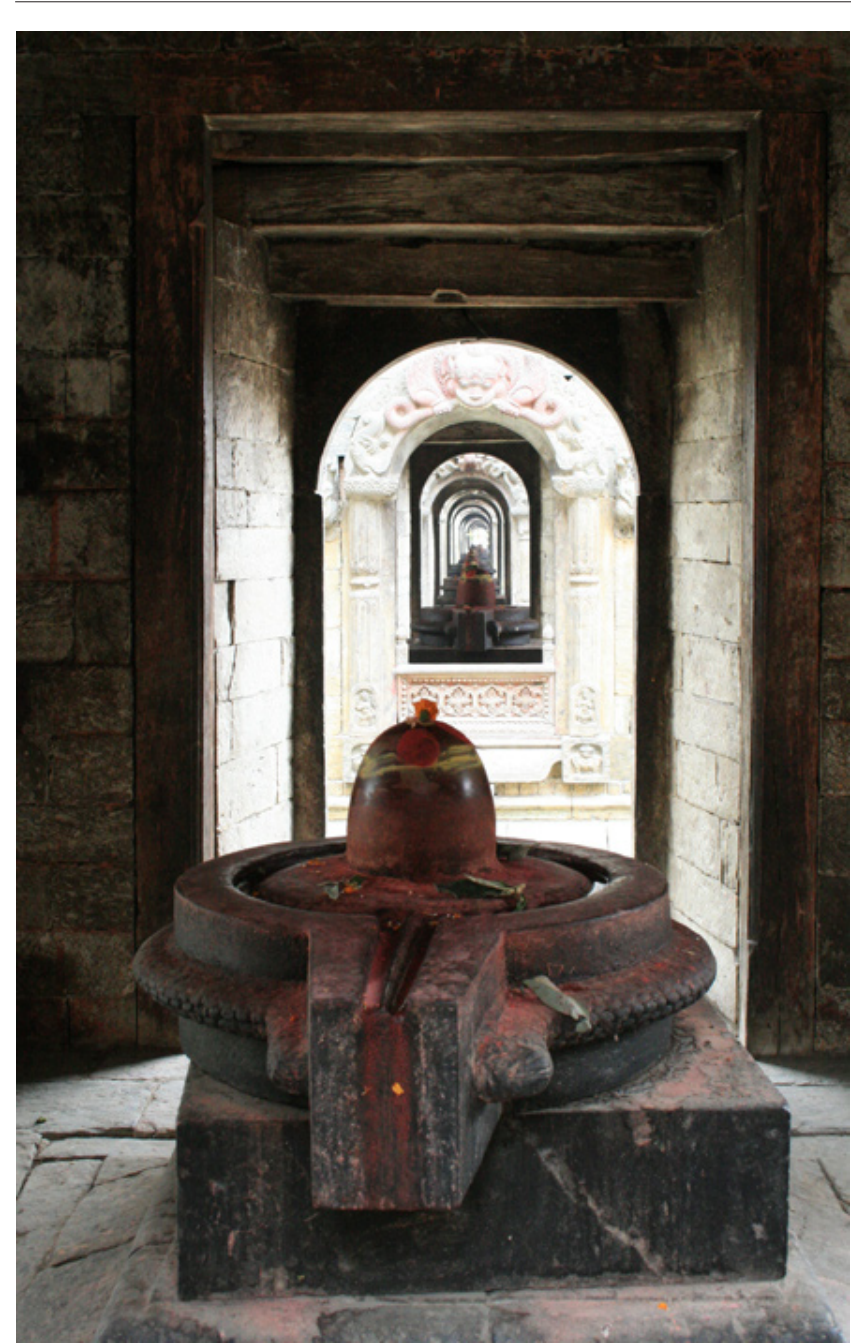

but are just soft enough to balance their jaggedness. Tiwari states that her "paintings depict the troubled, tortured, and exploited female figures in the patriarchal society through the use of mythical characters..." from Buddhist and Hindu traditions. ${ }^{10}$ Certainly Tiwari deals with the specific tensions facing women in Nepali society as a subject, but she does so by using traditional stories and figures in order to question traditional valuesboth accepting and rejecting tradition simultaneously. The artist's identity as a woman is important because of the generally second-class status of women in Nepal, and the work is edgier for it. Tiwari's paintings are a product of their local milieu and engage with western techniques of abstraction and expressionism via Lain Singh Bangdel.

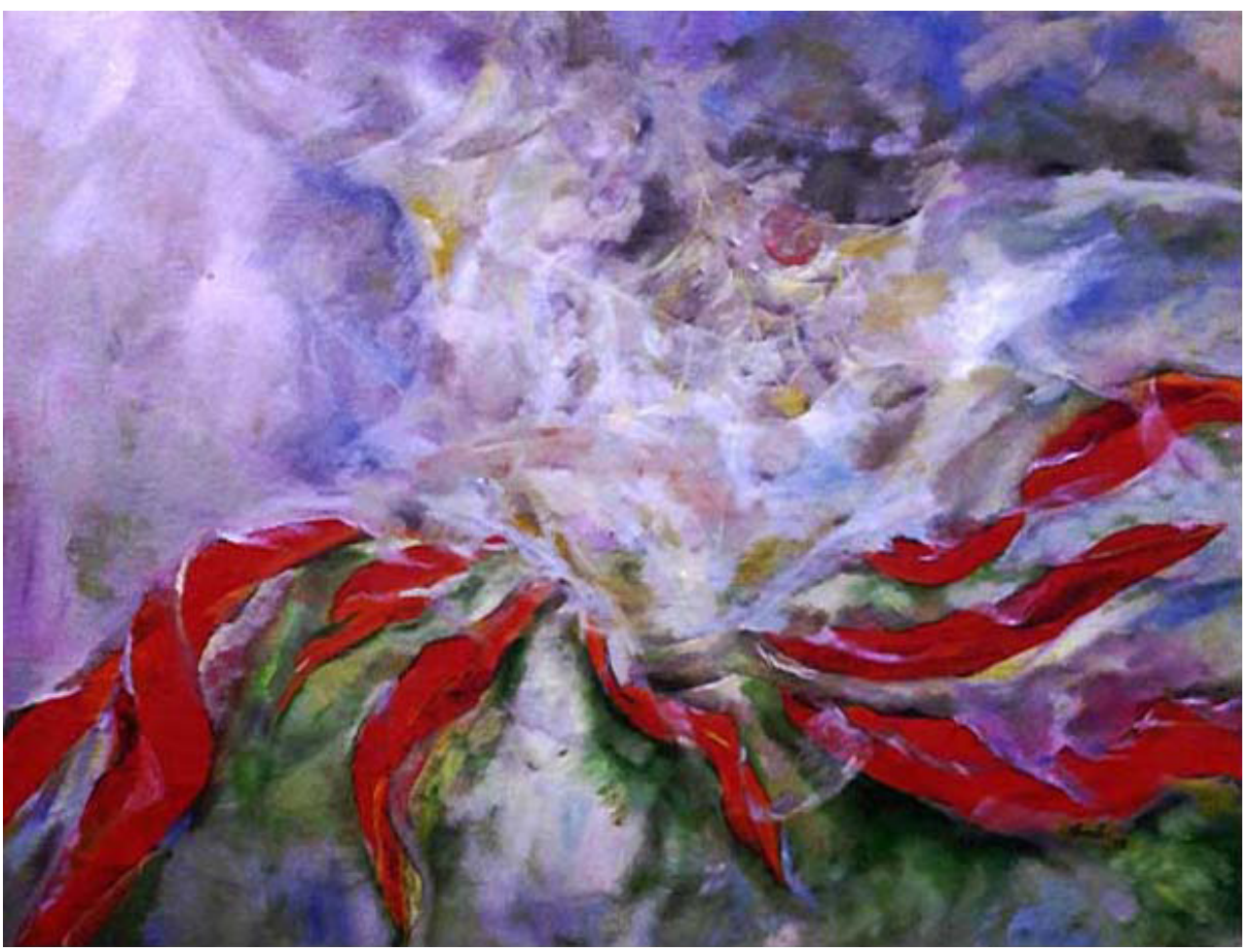

33 Between Yesterday And Today: Contemporary Art In Nepal 
Another challenge facing Nepalese artists relates to abstraction and expressionism's former avant-garde status in the modern period of western art. But -isms don't have the same effect in other contexts. As if to heed Geeta Kapur's call for those in developing countries to examine their own history and experiences in order to locate and define the modern, ${ }^{11}$ one raging topic of debate in Nepali art circles concerns how one defines the words modernism, modernity, and contemporary in Nepal, and whether these terms even apply to Nepal's art and culture. A growing but still contested definition of the contemporary in Nepal would include art with sociopolitical content and exclude artworks created today that are concerned with formal over conceptual qualities, as well as artworks in experimental media, such as performance and installation, outside of the socio-political context. The discussions are healthy but paralyzing at the same time because many feel they must contend with these issues. Tiwari's works are contemporary because an artist working today painted them within the last few years. Based on the above definition, they would also be contemporary because of the latent feminist message. However, her works reference the late modern period in the West and the new modern period in Nepal. But many Nepalese debate the beginnings of a modern period within their country due to the radical social and political transformations over the last twenty years. Countries like India seem to have dealt with these questions as part of a postcolonial dialogue. Nepal was never physically colonized by a western power but due to its strong connection to India there is a feeling of cultural colonization by both the West and its neighbors India and China.

Another debate that emerges from this anxiety is whether Nepali art should reflect an innate Nepaliness. A series of international art camps in the 1990s encouraged collaboration among artists in South and Central Asian countries like Sri Lanka, Pakistan, India, Nepal, and Bangladesh, and brought to the foreground some of these authenticity and identity issues. One participant from a 1997 camp remarked that, "We still maintain that Oriental east-west dichotomy in visual arts. Today, the West still considers the art of South Asia as fairly exotic...." ${ }^{12}$ This same sentiment is expressed by many Nepalese artists today. A further expression of the east-west dichotomy is a distrust of new media such as installation and performance, because these are perceived as western postmodernism even in a country where elaborate "installations" in the form of religious shrines have existed for centuries.

Debates about national identity are extremely important as Nepal's ethnic and caste tensions have only recently calmed after the Maoist insurgency, and the country was shocked by the 2001 massacre of the royal family.

Part of this feeling of the exoticized or culturally colonized Nepal stems from a frustration with the country's tourist image. While Nepal is proud of its artistic heritage, contemporary artist Ashmina Ranjit and other Nepalese cultural critics question what they see as the packaging and selling of heritage and the effect this has on artists in particular. According to Ranjit, whose work I will discuss in this paper, "Nepal has long been marketing itself as a Shangri-la and abode of medieval art and artifacts from the Licchavi and Malla periods-without recognition of contemporary life and cultures." ${ }^{13}$ Many in the arts are trying to foster a deeper knowledge and appreciation of Nepal's artistic past. With the founding of her arts organization Lasanaa in 2007, Ashmina Ranjit organizes workshops and events to use art as a catalyst for change within society. This activism within art has caught on and in the last few years alone, a number of new arts organizations, galleries, and performance spaces have been founded, and international collaborations have occurred.

One such collaboration, through a 2011 Arts Network Asia (ANA) grant, involves leading art students and emerging artists on heritage walks in Kathmandu Valley to foster this deeper cultural knowledge beyond the marketed "myth" of Nepal. For example, as mechani- 
Figure 6: Dhara with water spouts in Handigaon, Kathmandu. Image courtesy of the author.

cal engineer and social entrepreneur Anil Chitrakar leads these heritage walks through Kathmandu Valley, he frames Kathmandu's famed heritage with questions meant to engage participants to critically reflect on connections between past and present, tradition and change. In some cases, this search for depth is quite literal. One such walk through the old squares of Bhaktapur took an interdisciplinary approach to the architecture of water basins, known in Nepali as dharas (or hitis in the Newari language). Many of these water sources are now dry or only have flowing water for limited periods (Figure 6). The spouts of these dharas are frequently carved in the shape of mythical or symbolic creatures such as nagas or water serpents with water flowing from their open mouths. These spouts are wonderfully

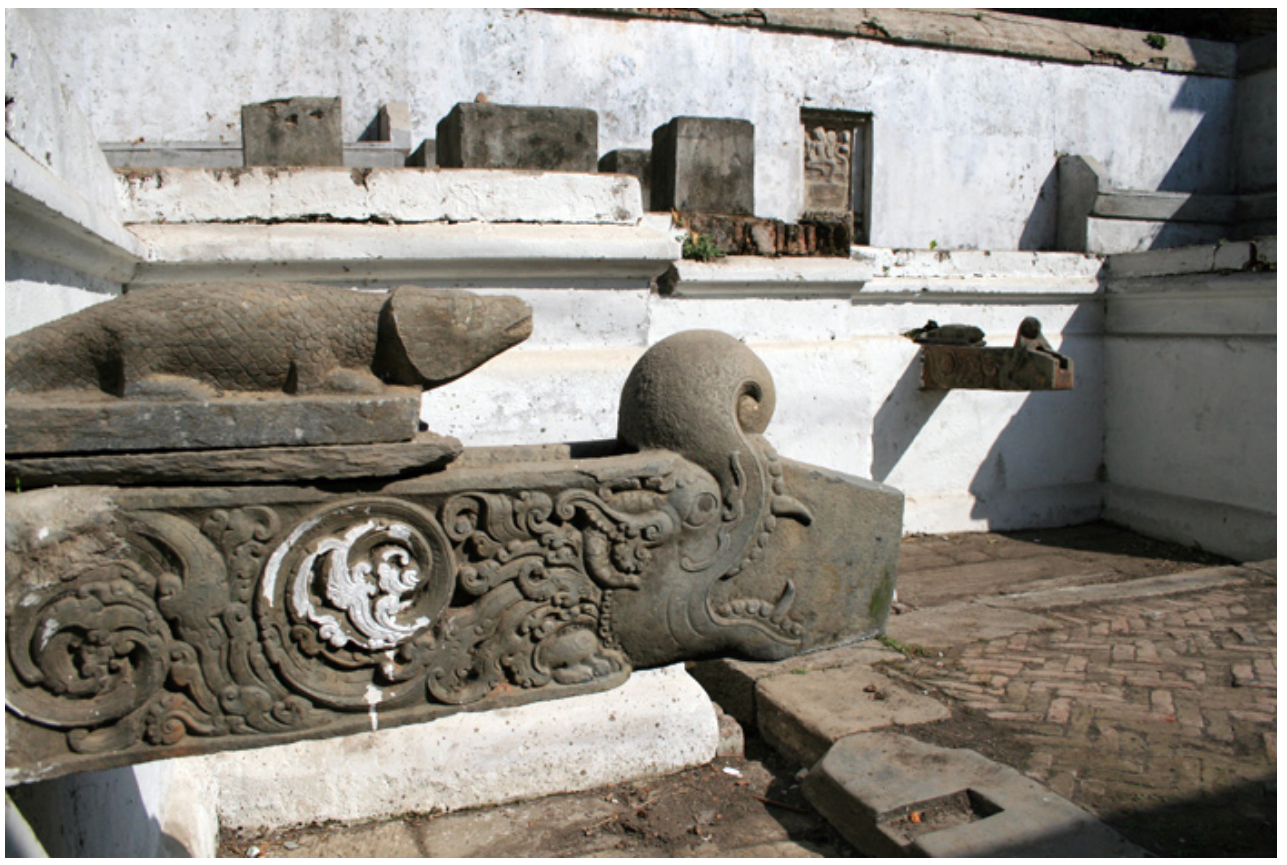

monstrous and one also sees reproductions throughout Kathmandu-in five-star hotels or at the entrance to Pashupatinath Temple for Hindu worshippers. Anil Chitrakar goes beyond the symbolic imagery to livability. In one of his tours recorded on YouTube he says, "The question is not just being able to look at the monuments and the houses and the way of life, but you have to take care of the watershed behind you." ${ }^{14}$ His talk goes on to explain the mechanics and engineering behind these historical water delivery systems and why many are nearly dry, showing the effects of modern development, political controls, and societal change.

In asking Anil Chitrakar to lead these Kathmandu Valley tours for art students and emerging artists, Ashmina Ranjit hopes they will see their history's art and architecture with fresh eyes, revealing the hand Nepalese artists and creative thinkers have long had in shaping their society. As part of the ANA grant, heritage walk participants conducted research in their own localities, interacting with citizens and field experts before creating new artworks. This is one way Nepalese artists examine their own history and experiences in order to define their presentness visually.

Today many artists openly deal with sociopolitical issues. At the same time, rather than feature what Subedi calls the "rejection and acceptance of tradition," these artists seek an acceptance of, and departure from tradition toward, works that are both local and global. Though by no means defining, a few general qualities of contemporary Nepali art include 
reinterpretation of religious stories and rituals, subversion of established icons, ambivalence toward cultural traditions and/or the West, multimedia or multigenre approaches, and integration of images and forms from nature. Each of the following artists utilizes these qualities in their work.

The artist Ashmina Ranjit received her art training in Australia and the United States but returned to Nepal during a time when Nepali artists, influenced by the international arts camp experiences, were beginning to experiment with new genres such as installation and performance. This is notable because in 1993, Nepal's Association of Fine Arts had rejected installations as unacceptable art forms. The violence of the Maoist insurgency and the royal murders dredged up raw emotions and seemed to call for art forms that could engage the public and initiate healing dialogue. In addition, artists like Ranjit wanted to challenge conventional art forms such as painting and sculpture. Her works "are designed to increase awareness of crucial ongoing

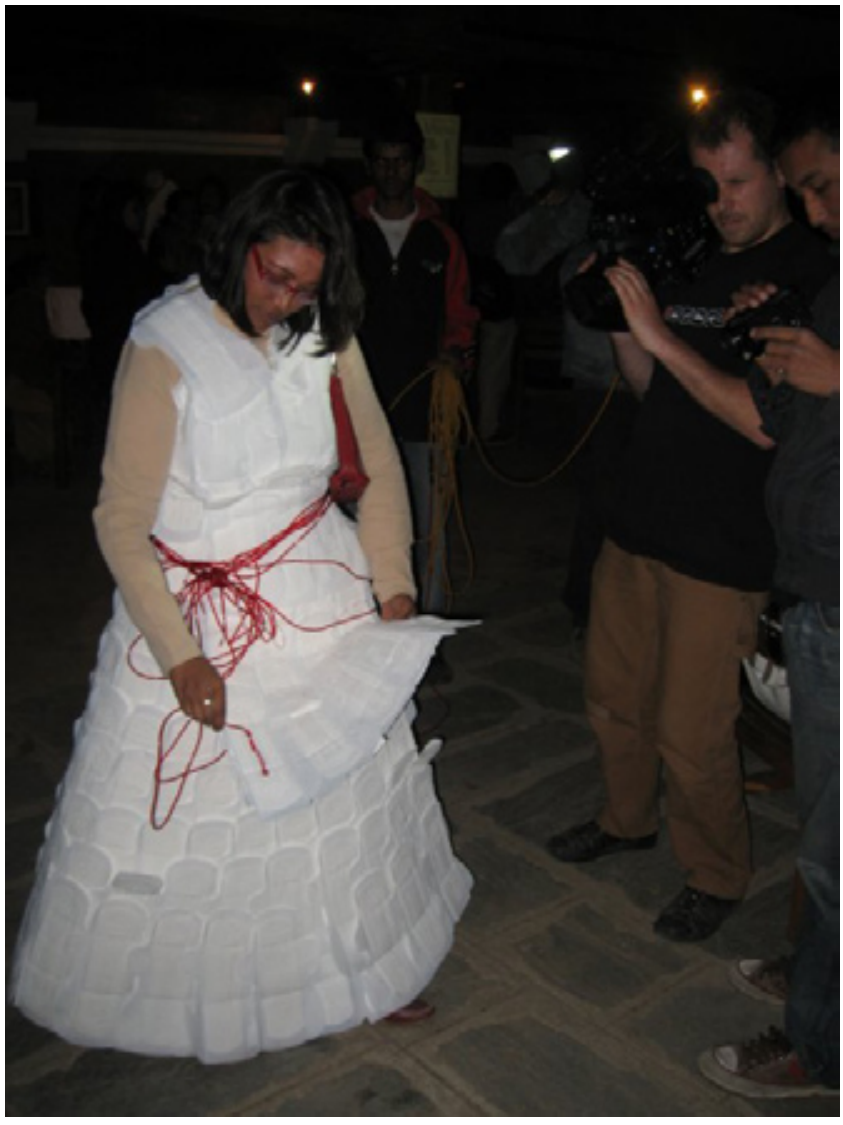
social and political issues of marginalized communities."15 In Feminine Force (Figure 7), she uses performance to express ambivalence toward the Hindu belief in the impurity of women's bodily fluids, especially menstrual blood. As she walks through the surrounding market areas of Kathmandu's Basantapur Square in her dress made from sanitary pads, she infringes upon the mental space of traditional Nepalese citizens and forces a visceral reaction. The piece draws from the western feminist artworks of the 1970s in its confrontation with women's lives, but does so within Nepal's cultural context. Ranjit is a controversial figure in Nepal but she feels that her tactics are necessary for change.

Because biotourism and cultural tourism are the greatest contributors to Nepal's economy, Kathmandu's 2010 "Planet Nepal Festival” was an artist's response to another big issue-the environment. Festival artists created films, installations, and performances of all kinds during this three-day exhibit and conference. In this second work, Ranjit transformed the courtyard of the Patan Museum where many of the conference panels took place (Figure 8). She wove mats using traditional materials and processes. Attendees were invited to sit on the mats, harmonize their relationships with nature, and imagine alternatives to "the daily rituals of synthetic modernity." ${ }^{16}$ Ranjit combines the more recent genre of installation with traditional materials and processes to reconnect audiences to their "authentic" spiritual sources, while at the same time subtlety critiquing the "synthetic" lifestyles of the West. ${ }^{17}$
Figure 7: Ashmina Ranjit, Feminine Force, 2010 performance for International Women's Day in Basantapur Square, Kathmandu. Dress made out of sanitary towels (the number of sanitary pads in the dress equals the average periods that a woman has in her lifetime -33 years $\times 13$ months $x 4$ days $=8,580$ pads). Image courtesy of the artist. 
Figure 8: Ashmina Ranjit, Indigenous Modernities, 2010, installation of woven straw from the "Planet Nepal" Festival at the Patan Museum in Kathmandu, sponsored by Alliance Francaise.
In Figure 9, Asha Dangol uses what he considers the free association techniques of the Surrealists to create paintings that reinterpret the folk arts of the Mithila ethnic groups, in which horses are prominent, or the Newar ethnic group. ${ }^{18}$ Dangol, too, is a founding member of an artist collective known as Kasthamandap Art Studio, named after the building from which the city of Kathmandu takes it names. His New Age Chariot could be a reference

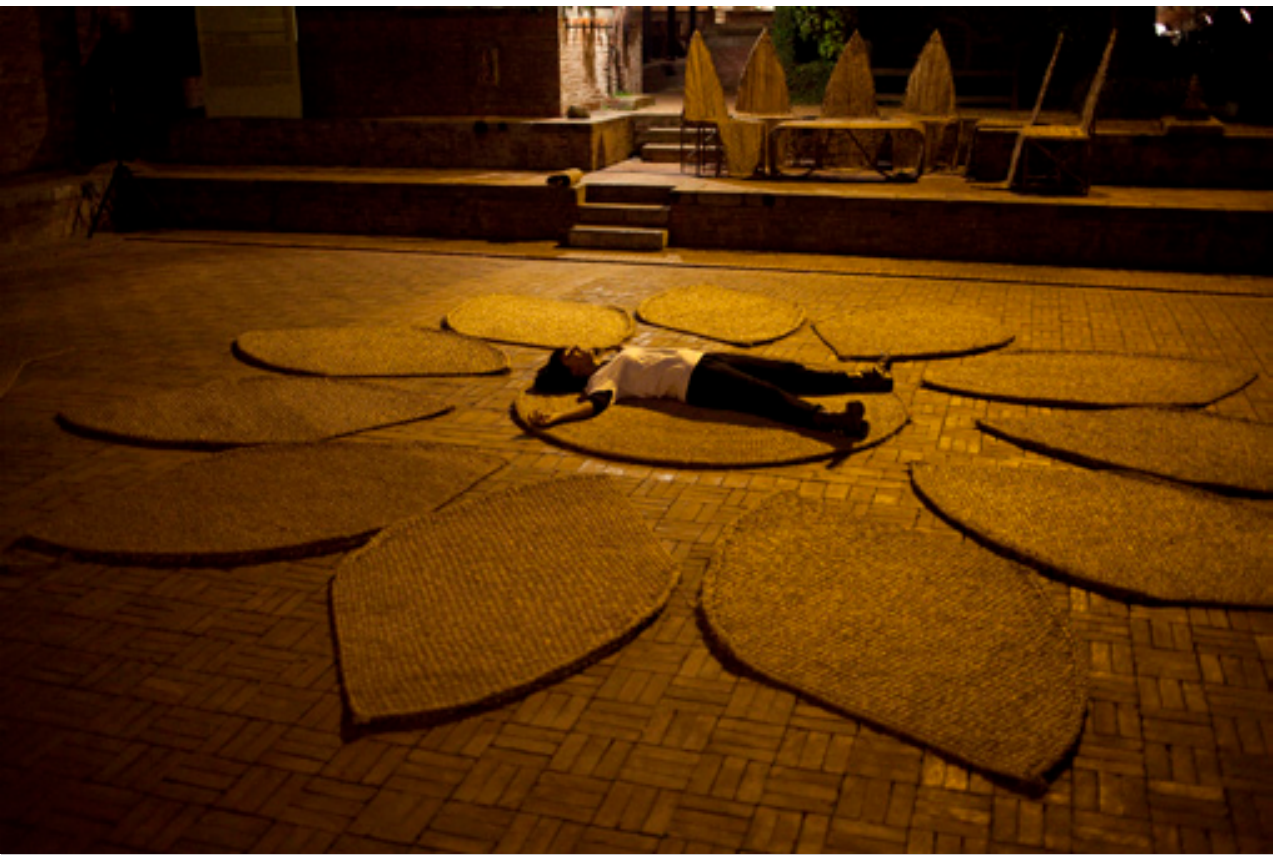

to the Newari Bisket Jatra festival, the New Year's celebration of the ancient Kathmandu Valley city of Bhaktapur. However, because the iconography diverges from Bisket Jatra, the artist is creating new meaning. This spring festival celebrates triumph over evil and re-enacts a creation story involving the God Bhairav and Goddess Bhadrakali, each of whom is pulled

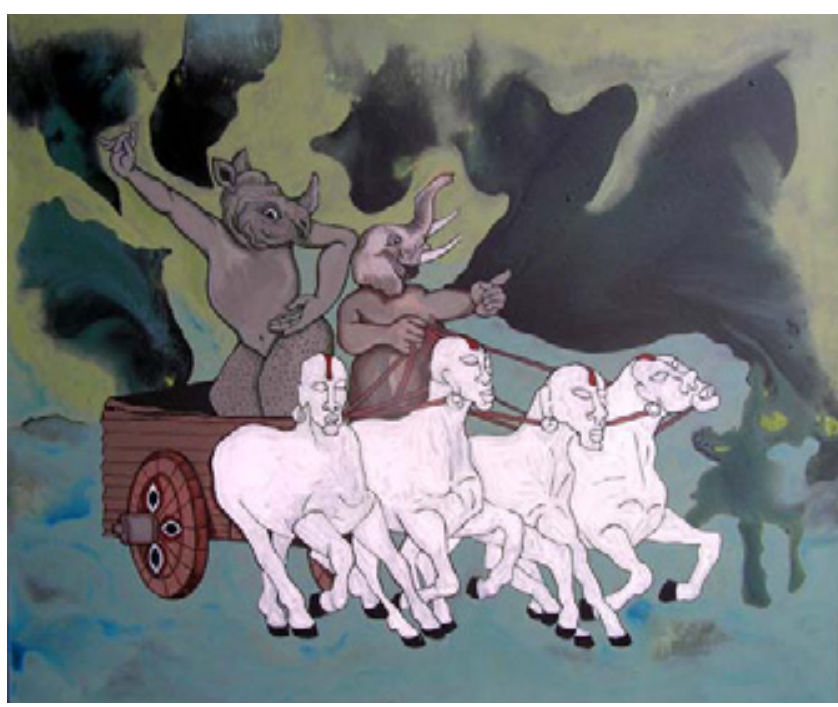
in their respective chariots. The public participates in an exciting (and sometimes dangerous) chariot pull and tug-of-war and spends the next nine days revering not only Bhairav and Bhadrakali, but a number of other Gods who ride in smaller chariots through the streets of Bhaktapur. ${ }^{19}$ The Newar pantheon also includes an elephant-headed God that may be one of the figures depicted in Dangol's chariot, and perhaps he paints those

Gods of significance to him and his family. If he is in fact using Surrealist automatism, these figures may have been randomly chosen in order to represent Bisket Jatra's essence over any particular ritual or day within the nine-day festival. The expressionless and seemingly sightless anthropomorphic horses in opposition to the eyed Gods, and the high contrasting 
stormy shapes in the background, give the dreamy Surrealism a nightmarish quality that may convey the tumultuous annual chariot pull. However, there is also joy in the dancelike posture of the rhinoceros-headed figure at left. Dangol acknowledges a departure from tradition in his artist statement, yet there is no outright rejection of tradition, as we shall see in his next work.

Only one-and-a-half years after Ashmina Ranjit's public performance condemning belief in the impurity of women's menstrual blood, Ashutosh Tiwari of the nongovernmental organization WaterAid called for artists to submit responses to Chaupadi, or the forced isolation of women during menstruation or after childbirth. The resulting exhibit, entitled "Dropping in on Development," lasted one evening in the Hotel Himalaya, a five-star hotel in Kathmandu, and was one of two events highlighting the effect that menstruation taboos have on development. Tiwari explains that, "We do not want women to drop out of schools, to drop out of jobs, to drop out of society for a few days every month, to drop out from having good health...we want them to drop in. ${ }^{20}$ Asha Dangol was one of the ten mostly male artists chosen to exhibit works. It is unclear whether the predominance of male responses to this topic was intended for greater impact, but the gender ratio was specifically noted in at least one local newspaper review following the exhibit reception. ${ }^{21}$

In Dangol's Menstruation - the Symbol of Purity (Figure 10), he uses the lotus blossom's symbol of purity to alter Hindu perceptions of women's impurity. While lotus flowers are an important symbol in Hinduism, Buddhism, and Jainism, the context clearly references the Hindu concept of pure beauty originating from the filth of muddy waters. In commenting about the installation's symbolic communication, the artist states that, "The flow of blood and breaking of the uterus lining is a process of cleansing." 22

Similar to the lotus sprouting from Vishnu's navel, in Dangol's piece a female mannequin's vaginal region sprouts long red veins blossoming into lotus flowers. The life of women is further accentuated by the
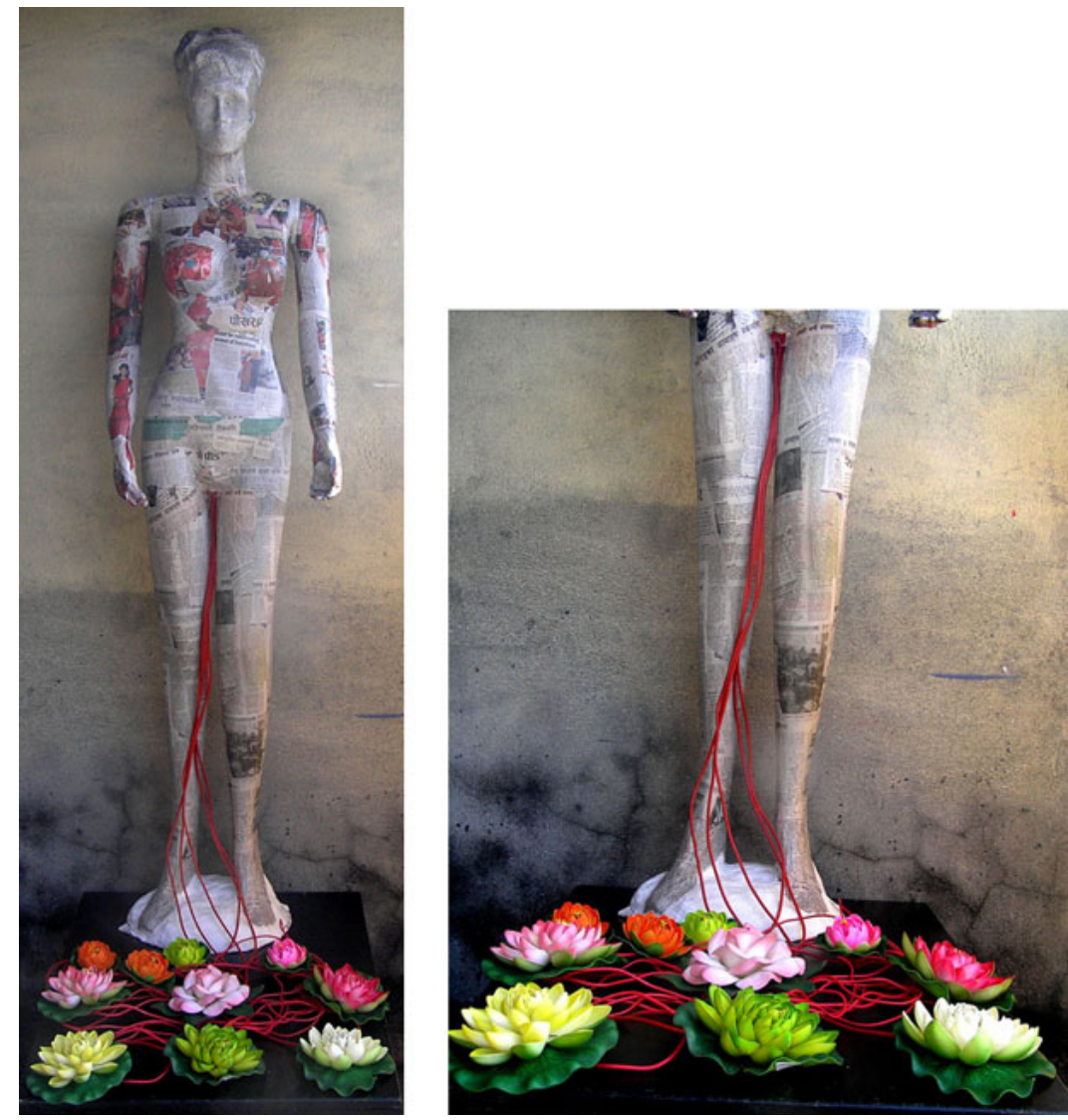
newspaper clippings coating the mannequin, featuring images and stories of women, most notably
Figure 10: Asha Dangol, Menstruation - the Symbol of Purity, 2011, mixed media installation as part of the "Dropping in on Development" exhibit sponsored by WaterAid at the Hotel Himalaya, Kathmandu. Images courtesy of the artist. 
photographs from the previous month's Teej festival. Teej represents many positive things for Nepalese women, but the aspect of purification of body and soul to exonerate sins from the previous year is closely connected with Dangol's intentions to affirm purity by recontextualizing it.

Asha Dangol's installation and the exhibit as a whole aim at a very different audience than Ashmina Ranjit's Feminine Force public performance in a city square. The "Dropping in on Development" exhibit sponsor WaterAid is not an arts organization and the event was held in a five-star hotel, so the exhibit was likely aimed at changing perceptions of ministers and other high-level attendees in a position to effect change. The resulting press would likely be the only widespread public outreach. However, this type of collaboration between artists and other members of society is one of the resurfacing trends in Kathmandu that, as mentioned in my discussion of Anil Chitrakar's heritage talks for emerging artists, may draw upon the traditional involvement of Kathmandu Valley artisans in the shaping of daily life.

Artist Sujan Chitrakar belongs to the painting caste of Chitrakars famous for documenting Nepal's daily urban life. Like Lain Singh Bangdel and Ashmina Ranjit, Chitrakar also received advanced degrees abroad (specifically in India) but returned to Nepal to advance his country's contemporary art practices by mentoring young artists through his role as the program coordinator for the Centre for Art and Design at Kathmandu University. His choice to become a conceptual artist over the painting tradition of his caste may seem like a radical departure, but the Chitrakar family painters have always dealt with the urban landscape as subject matter.

Figure 11: Sujan Chitrakar, Rickshaw Project, 2010, mixed media mobile artwork, from the "Planet Nepal" Festival at the Patan Museum in Kathmandu, sponsored by Alliance Francaise. Images courtesy of the artist.

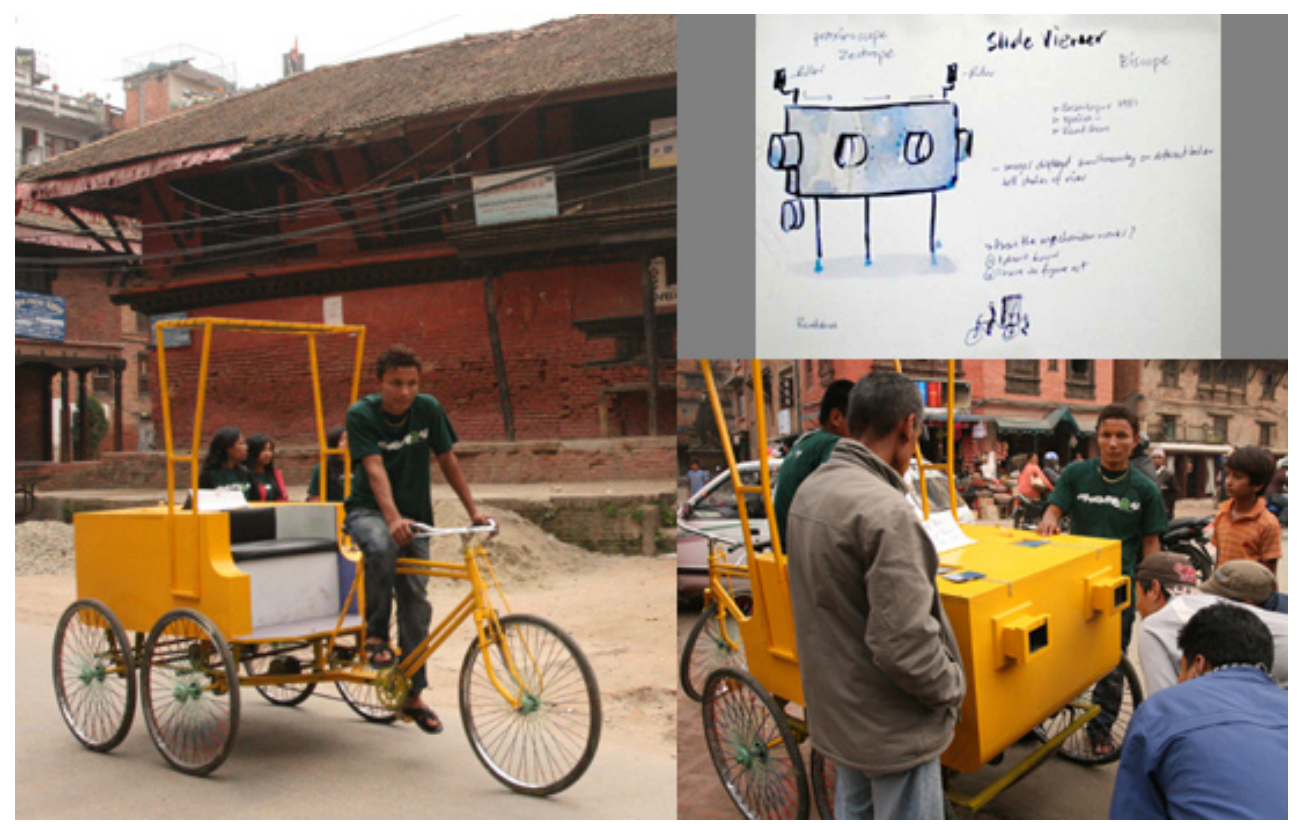

In his Rickshaw Project (Figure 11), Chitrakar embraces the protean tendencies of contemporary conceptual artists and diverges from painting into sculpture and installation, repackaging the age-old rickshaw as an environmentally friendly means of transport and a mobile art piece through the urban landscape. ${ }^{23}$ In this way, Chitrakar updates the traditions of family caste. Depicted here is just one of several rickshaw transformations that circled the city during the festival, bringing awareness to a public that may have taken these vehicles for granted in the push to modernize toward gas-guzzling vehicles. Like Ranjit, 
Chitrakar is critical of those who play it safe and he pushes his students and art public to question their traditions by engaging with art in new ways. ${ }^{24}$ Whether intended or not, Chitrakar's Rickshaw Project pokes fun at his audience because the vehicle for delivering meaning is literally a vehicle, and one powered by human effort.

For Nepal, the question of national identity comes from an unfortunately violent recent past but all facets of the society are getting a fresh start. Today's Nepal isn't afraid to reexamine its own past and contemporary life for content, forms, materials, and processes. Arguments still rage about authenticity and work that should be strictly "Nepalese" without derivation from any source. Others recognize that cultural hybridization has always occurred and they embrace globalization and are not waiting for the world to come to them. In grappling with questions of identity, the paralysis that may seem to prevent Nepalese artists from making a mark soon gives way as artists do what they have always done and solve problems through the creative process. For example, debates about whether installation and performance artforms are too foreign for Nepal don't take into consideration the religious "installations" or shrines on nearly every corner and the "performance art" that worshippers engage in during daily ritual at these shrines or spaces that are both public and private. How contemporary artists align themselves between ancient and modern, tradition and change is becoming less binary and more fluid. The lively and growing art scene in Nepal and especially Kathmandu is what makes it possible for artists such as Asha Dangol and Ashmina Ranjit to challenge traditional beliefs about menstruation in very different ways, and to hit nerves by creating works that mirror aspects of their society.

\section{NOTES}

1. Artivism is a term combining art and activism, used to describe art activities that actively engage in political and social dialogues as a way to alter the discourse and outcome.

2. Abhi Subedi, "Nepali Art: Nepali Utopia," Contributions to Nepalese Studies 22, no. 2 (July 1995): 115.

3. Michael Hutt, Nepal: A Guide to the Art and Architecture of the Kathmandu Valley (Boston: Shambhala Publications, Inc., 1994), 29.

4. Don Messerschmidt and Dina Bangdel, Against the Current: The Life of Lain Singh Bangdel_Writer, Painter and Art Historian of Nepal (Bangkok: Orchid Press, 2004), ix-x.

5. Subedi, "Nepali Art: Nepali Utopia," 124.

6. Ibid., 124 .

7. Susanne van der Heide, “Traditional Art in Upheaval: The Development of Modern Contemporary Art in Nepal," Kailash-Journal of Himalayan Studies 14, nos. 3 \& 4 (1988): 234.

8. Yam Prasad Sharma, "Contemporary Nepali Painting: Hybridity and Negotiation" (Art Discussion Series, Martin Chautari, Kathmandu, August 31, 2010).

9. Subedi, "Nepali Art: Nepali Utopia," 125.

10.E-Arts Nepal. "Shashikala Tiwari Biography”, http://www.eartsnepal.com/artist/shashikala-tiwari.htm

11.Geeta Kapur, "When Was Modernism in Indian Art?” in When Was Modernism: Essays on Contemporary Cultural Practice in India, ed. Geeta Kapur (New Delhi: Tulika Books, 2007), 298.

12.Sabine Grosser, "Contextualizing Contemporary Sri Lankan Art," in Expressions of Independence (Paris: Mona Bismarck Foundation, 2008), 67.

13. Ashmina Ranjit to Arts Network Asia, "Being in Kathmandu Valley," project statement, October-November 2010.

14.MsSGV, Anil Chitrakar's Bhaktapur Walk: Water (video), July 31, 2009. http://www.youtube.com/ watch?v=tRXeurcl_rE\&feature=related.

15. Ashmina Ranjit, "Environment Friendly Environment" in Alliance Bazaar Special Edition: Festival of Arts and Environment (Kathmandu: Alliance Francaise, September-October 2010), 10.

16. Ashmina Ranjit, "Environment Friendly Environment," 10.

17. Ashmina Ranjit, "Environment Friendly Environment," 10.

18.E-Arts Nepal. "Asha Dangol Biography," http://www.eartsnepal.com/artist/asha-dangol.htm

19. This is an extremely brief summary of Bhaktapur's nine-day Bisket Jatra festival, but necessary to give context for Asha Dangol's work. For more on this important Newar festival, see http://66.7.193.115:8080/kathmandumetro/culture/bisket-jatra-the-festival-of-dead-serpents-1

20. WaterAid Nepal Site. "News: Dropping in on development: an exhibition," http://nepal.wateraid.org/news item/63-dropping-in-on-development-an-exhibition

21. Republica. "The Art of Menstruation," review of Dropping in on Development, October 1, 2011. http://www. myrepublica.com/portal/index.php?action=news_details\&news_id=36737. 
22. Asha Dangol, "Dropping in on Development," e-mail message to author, November 22, 2011.

23. "Rickshaw Project, in Alliance Bazaar Special Edition: Festival of Arts and Environment (Kathmandu: Alliance Francaise, September-October 2010), 11.

24.Sujan Chitrakar, Let's Talk about ART Baby! (Exhibit Catalog) (Kathmandu, Nepal: Sujan Chitrakar and Siddhartha Art Gallery, 2010) 6. From an interview with the artist conducted by Pranab Man Singh. 


\title{
Assessing Political Dynamics in Contemporary Malaysia: Implications for Democratic Change
}

\author{
Surain Subramaniam
}

\begin{abstract}
This article examines political dynamics in Malaysia and assesses the prospects for change in the direction of greater political liberalization. It focuses on the 12th General Election of 2008 and its implications for opportunities and challenges for liberal democratic change in Malaysia. It discusses the role of the internet-based new media in shaping an emerging public sphere, and some factors affecting the changing role of non-Malay voters in the political process. This article argues that democratization in Malaysia is already occurring, albeit at a gradual pace; it is being pushed by the new political forces of civil society actors, newly empowered opposition parties, and the internet-based media. The boundaries of this emerging democratic space is simultaneously being shaped and contested by the political competition between status-quo and reformist forces in this society. Some institutional changes have expanded the parameters of democratic space, although the entrenched dominant institutions of the ruling regime continue to wield sufficient amounts of institutional capacity to subvert any consolidation of these democratic changes for now.
\end{abstract}

Keywords: Malaysia; Southeast Asia; Politics; Democracy; Democratization; Media; Public Sphere

\section{INTRODUCTION}

The "Arab Spring" of 2011 has renewed interest in the study of democratization in the Muslim world. ${ }^{2}$ While Muslim societies in the Arab world are attracting much attention, progress toward democracy has also been witnessed in Southeast Asia, another region with Muslim majority societies. Indonesia, the world's most populous Muslim country, experienced its transformation from authoritarianism to democracy in the wake of the Asian Financial Crisis of 1997. This article examines political dynamics in Malaysia, the second largest Muslim country in Southeast Asia, and assesses the prospects for change in the direction of greater political liberalization.

The 12th General Election (henceforth 12 GE) of March 2008 marked an interesting turn in Malaysia's political development. The outcome of this election was extraordinary in many ways. It was the best showing for the political opposition in almost forty years (since the 1969 GE). Although the incumbent Barisan Nasional (National Front, hereafter BN) coalition government won 144 of the 222 seats in the Federal Parliament, it only managed to garner 49.8 percent of the popular vote in Peninsular Malaysia, which almost tied the combined votes won by the three main opposition parties. ${ }^{3}$ The shift in electoral outcomes for the ruling coalition in the $12 \mathrm{GE}$ was particularly significant when compared to the out-
Surain Subramaniam, $\mathrm{Ph}$. D. is Associate Professor of Political Science at UNC Asheville, where he directs the Interdisciplinary Studies, International Studies, and Asian Studies programs. His research areas include democratization in Malaysia and Singapore; challenges to liberal democratic governance from rising nonWestern societies; and the effects of globalization on Asia. 
come of the 11th General Election of 2004, in which it achieved its best electoral performance since independence (see Tables 1 and 2 below).

How do we explain the best and worst electoral performances for the ruling $\mathrm{BN}$ coalition within two electoral cycles? Were there underlying structural and institutional factors that were shaping political development in new directions in Malaysia? This article will situate the $12 \mathrm{GE}$ within a broader political context and provide a preliminary assessment of the opportunities and challenges that lie ahead for liberal democratic change in Malaysia. It will discuss the role of the Internet-based new media in shaping an emerging public sphere in Malaysia and some factors affecting the changing role of non-Malay voters in the political process.

\section{HISTORICAL BACKGROUND}

Malaysia is characterized politically, socially, and culturally by its pluralism. It consists of a multiracial, multireligious, and multi-ethnic society. Demographically, Malaysia's population of 28.7 million is constituted by Malays (50.4 percent), ethnic Chinese (23.7 percent), ethnic Indians (7.1 percent), other indigenous races (11.4 percent), and other racial/ethnic groups (7.8 percent). ${ }^{4}$ The ethnic Chinese and Indians, who are predominantly non-Mus$\mathrm{lim}$, arrived as immigrants in Malaya (as it was then known) in the early nineteenth century when it was ruled as a British colony. Perhaps one of the most significant features of the Malaysian political landscape is the "special rights" of the Malays. As scholars have written, "special rights" for Malays can be traced back to the British colonial period.

The British accorded a special status to the Malays. They were regarded as the original inhabitants, although, as their name suggests, the fifty thousand or so orang asli ("aborigines") had been there longer. The British believed that they should offer "protection" to the Malays, thus supplementing the protective role of the [Malay] rulers. ${ }^{5}$

This historical legacy was institutionalized at independence in 1957 through a political compromise whereby the Chinese and Indians were given citizenship status, and the indigenous Malays retained their "special rights," so that "national and state identification was to be through 'Malay symbols', such as allegiance to Malay royalty and the declaration of Islam as the official religion." ${ }^{\prime}$ After the racial riots of May 1969, constitutional amendments in 1971 extended Malay special privileges to include, among others, preferential treatment in public service employment, admissions into local universities, and the awarding of business licenses by the government. ${ }^{7}$ The New Economic Policy (NEP) of 1970 further institutionalized these Malay privileges in the economic sphere. Based on these factors, scholars have labeled the Malaysian state as essentially "a 'Malay-based' polity, both in form and substance." In other words, "Malay political power and dominance is the overriding theme in Malaysian politics." Given this background, for decades scholars have explained away Malaysia's (liberal) "democratic recalcitrance" 10 by pointing to a combination of factors that consist of its deeply divided society along racial, ethnic, and religious lines; a compliant middle class that is politically and economically dependent on the state $;^{11}$ and the grip on power by the politically dominant United Malays National Organization (UMNO). ${ }^{12}$ All of these have to some degree acted as barriers to greater political liberalization in the direction of liberal democratic governance.

Then, slightly over a decade ago, in the wake of the Asian Financial Crisis of 1997 and the subsequent political crisis over then Prime Minister Mahathir Mohamad's sacking and jailing of his deputy, Anwar Ibrahim, civil society actors began to mobilize through the 
Reformasi movement, seeking to build the political/institutional foundations of an alternative form of governance- one that would be based on the principles of good governance and liberal democratic norms. ${ }^{13}$ However, two major developments occurred at this time: (1) the retirement of Prime Minister Mahathir Mohamad in October 2003, who was replaced both as president of UMNO and prime minister by Abdullah Badawi; and (2) the subsequent electoral victory by the ruling BN coalition in the 11th General Election of 2004, in which it won 198 of 219 seats in Parliament, (i.e., 90 percent of the total seats). (See Tables 1 and 2.) The incipient movement toward greater political liberalization appeared to have stalled, reverting back to the primacy of "developmentalism" over liberal democratic governance. ${ }^{14}$ Apart from the institutional barriers to greater political liberalization, there appeared to also be a durable political culture working against political transformation. In describing the political culture of "developmentalism," Malaysian political scientist Francis Loh Kok Wah writes,

The discourse of developmentalism came into its own amidst this economic growth [in the period between the late 1980s and the Asian Financial Crisis of 1997]. It coincided with the consolidation of Malaysia's middle classes involving all ethnic groups. Embraced by the middle classes, the new political culture places value on sustained economic growth that facilitates an improvement in material standards of living while also resulting in the spread of consumerist habits. Its corollary is an appreciation of the value of political stability, which many Malaysians believed could only be guaranteed by a strong BN-governed state even when authoritarian means were resorted to. Developmentalism, therefore, is the cultural consequence of the strong developmental state when citizens begin to enjoy improved living conditions as a result of the economic growth the state has fostered. This developmentalism increasingly displaced the ethnic political discourse and practice in the 1990s. ${ }^{15}$

\section{POST-DEVELOPMENTALISM?}

The veil of "developmentalism," however, appeared to have masked some fundamental structural and institutional inequalities underlying Malaysia’s political economy and society. The ethnic restructuring of the Malaysian economy and society through the NEP of 1970 and its successor policy, the New Development Policy (NDP) of 1990, and the affirmative action/preferential treatments given to ethnic Malays under their status as bumiputera (sons of the soil) have over time solidified a society divided between Malays and non-Malays. ${ }^{16}$ So while the discourses of "developmentalism" and political stability have been used repeatedly to explain electoral authoritarianism in Malaysia, political contestation and conflict have never been far from the surface.

Four years after BN's resounding victory at the polls in 2004, the outcome of the $12 \mathrm{GE}$ in 2008 was markedly different, with the ruling coalition losing its two-thirds majority in Parliament as well as its political control of the state legislatures in four states (bringing the total number of state governments under opposition rule to five). ${ }^{17}$ For democracy advocates, this turn in Malaysia's political trajectory, as measured by election outcomes, appeared to be the next major phase in the country's political liberalization, in effect, putting it back on the (gradual) path to liberal democratic reform. ${ }^{18}$ 
TABLE 1: FEDERAL PARLIAMENTARY SEATS WON BY MAJOR POLITICAL PARTIES, 1986 - 2008

\begin{tabular}{|l|c|c|c|c|c|c|c|c|c|c|}
\hline Party Name & $\begin{array}{c}\text { Year } \\
1990\end{array}$ & $\begin{array}{c}\% \\
\text { Change } \\
\text { in Seats } \\
\text { from } \\
1986)\end{array}$ & $\begin{array}{c}\text { Year } \\
1995\end{array}$ & $\begin{array}{c}\% \\
\text { Change } \\
\text { in Seats }\end{array}$ & $\begin{array}{c}\text { Year } \\
1999\end{array}$ & $\begin{array}{c}\% \\
\text { Change } \\
\text { in Seats }\end{array}$ & $\begin{array}{c}\text { Year } \\
2004\end{array}$ & $\begin{array}{c}\% \\
\text { Change } \\
\text { in Seats }\end{array}$ & $\begin{array}{c}\text { Year } \\
2008\end{array}$ & $\begin{array}{c}\% \\
\text { Change } \\
\text { in Seats }\end{array}$ \\
\hline $\begin{array}{l}\text { Barisan Nasional } \\
\text { Coalition }\end{array}$ & 127 & $-14.2 \%$ & 162 & $+27.6 \%$ & 148 & $-8.6 \%$ & 198 & $+33.8 \%$ & 140 & $-29.3 \%$ \\
\hline UMNO & 70 & $-15.7 \%$ & 89 & $+27.1 \%$ & 72 & $-19.1 \%$ & 109 & $+51.4 \%$ & 79 & $-27.5 \%$ \\
\hline MCA & 18 & $+5.9 \%$ & 30 & $+66.7 \%$ & 28 & $-6.7 \%$ & 31 & $+10.7 \%$ & 15 & $-51.6 \%$ \\
\hline MIC & 6 & - & 7 & $+16.7 \%$ & 7 & - & 9 & $+28.6 \%$ & 3 & $-66.7 \%$ \\
\hline Other BN Parties* & 33 & & 36 & & 41 & & 49 & & 43 & \\
\hline & 49 & $+96 \%$ & 30 & $-38.8 \%$ & 45 & $+50.0 \%$ & 20 & $-55.6 \%$ & 82 & $+310 \%$ \\
\hline Opposition & 20 & $-16.7 \%$ & 9 & $-55.0 \%$ & 10 & $+11.1 \%$ & 12 & $+20.0 \%$ & 28 & $+133 \%$ \\
\hline DAP & 7 & $+600 \%$ & 7 & - & 27 & $+285 \%$ & 7 & $-74.1 \%$ & 23 & $+229 \%$ \\
\hline PAS & - & - & - & - & 5 & - & 1 & $-80.0 \%$ & 31 & $+3000 \%$ \\
\hline PKN/PKR & 22 & & 14 & & 3 & & - & & - & \\
\hline $\begin{array}{l}\text { Other Opposition } \\
\text { Partie* }\end{array}$ & 180 & & 192 & & 193 & & 219 & & 222 & \\
\hline Total & & & & & & & & & & \\
\hline
\end{tabular}

Sources: (Ramanathan 1986; Zakaria 2000; Khoo 2005; Ufen 2009) ${ }^{19}$

*PBB (Sarawak) (1990, 1995, 1999, 2004, 2008); PBS (Sabah) (2004, 2008); Gerakan (1990, $1995,2004,2008)$

**Semangat '46 (1990, 1995); PBS (Sabah) $(1990,1995,1999)$

TABLE 2: PERCENTAGE OF THE POPULAR VOTE WON BY BARISAN NASIONAL AND OPPOSITION IN GENERAL ELECTIONS, FEDERAL PARLIAMENTARY SEATS, 1986 - 2008

\begin{tabular}{|l|c|c|c|c|c|c|c|c|c|c|}
\hline Party Name & $\begin{array}{c}\text { Year } \\
1990\end{array}$ & $\begin{array}{c}\% \\
\text { Change } \\
\text { (from } \\
1986)\end{array}$ & $\begin{array}{c}\text { Year } \\
1995\end{array}$ & $\begin{array}{c}\% \\
\text { Change }\end{array}$ & $\begin{array}{c}\text { Year } \\
1999\end{array}$ & $\begin{array}{c}\% \\
\text { Change }\end{array}$ & $\begin{array}{c}\text { Year } \\
2004\end{array}$ & $\begin{array}{c}\% \\
\text { Change }\end{array}$ & $\begin{array}{c}\text { Year } \\
2008\end{array}$ & $\begin{array}{c}\% \\
\text { Change }\end{array}$ \\
\hline $\begin{array}{l}\text { Barisan } \\
\text { Nasional } \\
\text { Coalition }\end{array}$ & 53.4 & $-2.4 \%$ & 65.2 & $+11.8 \%$ & 56.5 & $-8.7 \%$ & 63.9 & +7.4 & $51.5^{*}$ & -12.4 \\
\hline $\begin{array}{l}\text { Opposition } \\
\text { PAS, PKR, } \\
\text { DAP }\end{array}$ & 46.6 & $+5.0 \%$ & 34.8 & $-11.8 \%$ & 43.5 & $+8.7 \%$ & 36.1 & -7.4 & 47.3 & +11.2 \\
\hline
\end{tabular}

Sources: (Zakaria 2000; Gomez; Khoo 2005; Brown 2008) ${ }^{20}$

*Table 2 includes the votes from BN coalition partners in Sabah and Sarawak.

\section{LOSS OF NON-MALAY SUPPORT}

In his assessment of the $12 \mathrm{GE}$, Thomas Pepinsky identifies one of the main causes of the ruling regime's poor showing as "non-Malay voters' rejecting the incumbent coalition in favor of secular opposition parties." 21 There certainly appears to have been a shift in the level of support for the ruling BN coalition among the Chinese and Indian voters (see Table 3). ${ }^{22}$ The two ethnically based component parties in the BN coalition, the Malaysian Chinese Association (hereafter MCA) and the Malaysian Indian Congress (hereafter MIC), were the biggest casualties in the $12 \mathrm{GE}$. 
TABLE 3: ESTIMATED CHANGE IN ETHNIC VOTES FOR BARISAN NASIONAL: 2004 (11TH GENERAL ELECTION) VS. 2008 (12TH GENERAL ELECTION)

\begin{tabular}{|c|c|c|c|c|c|c|}
\hline Party Name & $\begin{array}{c}\text { Percentage of } \\
\text { Malays Votes: } \\
\text { Split Comparison } \\
2004 \text { vs. } 2008 \text { GE }\end{array}$ & & $\begin{array}{c}\text { Percentage of } \\
\text { Chinese Votes: } \\
\text { Split Comparison } \\
2004 \text { vs. } 2008 \text { GE }\end{array}$ & & $\begin{array}{c}\text { Percentage of } \\
\text { Indian Votes: } \\
\text { Split Comparison } \\
2004 \text { vs. } 2008 \mathrm{GE}\end{array}$ & \\
\hline \multirow[t]{2}{*}{$\begin{array}{l}\text { Barisan Nasional } \\
\text { Coalition }\end{array}$} & 2004 & 2008 & 2004 & 2008 & 2004 & 2008 \\
\hline & $63 \%$ & $58 \%$ & $65 \%$ & $35 \%$ & $82 \%$ & $48 \%$ \\
\hline Change & $-5 \%$ & & $-30 \%$ & & $-34 \%$ & \\
\hline
\end{tabular}

Sources: (Pepinsky 2009; Weiss 2009; Case 2010) ${ }^{23}$

This is arguably one of the most significant political developments in Malaysia coming out of the $12 \mathrm{GE}$. For over half a century (and at least since the racial riots of 1969), the non-Malay minority appeared to have settled into an implicit social/political compact with the Malay majority whereby they tacitly accepted the status of "second class citizens," subordinated institutionally to the majority Malay-Muslim population. Under the "consociational democracy" model, ${ }^{24}$ non-Malay elites had assumed the role of acting on behalf of their respective minority Chinese and Indian constituencies in political negotiations with the dominant UMNO. This, however, put the non-Malay elites in a position that allowed them to join their Malay elite counterparts in exercising control over economic resources and political institutions, often in self-aggrandizing ways. In the $12 \mathrm{GE}$, the non-Malay elites in the ruling regime appear to have lost their credibility and legitimacy in the eyes of Chinese and Indian voters, especially in their ability to advocate for their respective communities in negotiations within the ruling coalition. The emergence of the opposition alliance (PKRDAP-PAS $)^{25}$ has provided these hitherto politically marginalized voters a viable political alternative, thereby creating sufficient differentiation among the choices available for them at the polls. Non-Malay voters are now able to seriously contemplate shifting their support and allegiance away from what was until now their primary (and oftentimes only) political vehicles, their respective ethnic political parties of MCA and MIC.

\section{STREET PROTESTS ON THE EVE OF THE 12 GE}

Among the most unprecedented events to take place in the last decade of Malaysia's political history in terms of contentious politics at the mass society level were two major street protests that took place in November 2007, less than five months prior to the 12 GE. (1) On November 10, an estimated 40,000 individuals, consisting of a coalition of seventy civil society groups, joined by members of opposition political parties and concerned individuals, took to the streets of the nation's capital, Kuala Lumpur. ${ }^{26}$ Organized under the Coalition of Clean and Fair Elections (BERSIH, which is the Malay word for "clean"), this protest was to petition the king for reforms to the electoral system, which has been criticized as being biased in favor of the ruling coalition; ${ }^{27}$ and (2) on November 25, an estimated 30,000 ethnic Indians organized as the Hindu Rights Action Force (HINDRAF), an Indian nongovernmental organization, marched peacefully on the streets of Kuala Lumpur to protest the ruling BN coalition's consistent neglect of the Tamil-speaking Hindu working class, by any measure considered to be an economic underclass in Malaysia today. These large scale political protests were significant in at least two respects. First, they broke the psychological barrier among Malaysians (which has existed ever since the May 13, 1969 bloody racial riots) against voicing their political opposition publicly, and second, they emboldened latent political discontent, especially since ethnic Indians have tradition- 
ally been regarded as a passive community that loyally supports the ruling regime, despite their deteriorating economic condition for the past five decades. The sight of these protesters (often relayed through the medium of new media (e.g., YouTube video clips over the Internet, SMS messages, cell-phone images) being beaten and sprayed with acid-laced tear gas by the government's security forces marked a turning point in the politics of contention between the ruling regime and the opposition forces in Malaysia. ${ }^{28}$ Voters in Malaysia had come to realize that they now had avenues to circumvent the dominant institutions of the ruling regime, and that through these alternative avenues they could channel their voices of political dissent. In the case of the Chinese and Indian voters, these political developments have been quite unprecedented.

\section{NEW MEDIA \& THE EMERGING “PUBLIC SPHERE”}

Among the most significant new institutions that have emerged in shaping the emerging democratic space in Malaysia is new media. New media captures both the new medium of information as well as the fledgling "public sphere" that it represents through Internet-based news portals, blogs, e-mails, video clips on the web and cell phones, mobile short messaging service (SMS), and other means. Scholars have traced the introduction of new media into the Malaysian political landscape to the Reformasi movement of $1998 .{ }^{29}$ In the wake of the $12 \mathrm{GE}$, there were numerous assessments by election candidates (representing both the ruling regime and the opposition coalition, which were then confirmed by analysts) of the defining role played by new media in BN's poor electoral performance. ${ }^{30}$ In this sense, new media came into its own with the $12 \mathrm{GE}$.

Institutionally, the mainstream media in Malaysia has been firmly in the grip of the ruling regime for decades and continues to be so today, both in terms of its corporate ownership $^{31}$ and in its perceived role as a mouthpiece for the ruling BN coalition. ${ }^{32}$ In the case of the new media, it has circumvented the institutionalized mainstream media to create a parallel "institution" not only for the dissemination of information but also to facilitate the role of civil society. For example, one scholar points to the many creative ways in which different kinds of media were used during the campaign period of the $12 \mathrm{GE}$, especially in "fomenting alternative imaginaries and contesting cultural maps of meanings to Malaysian society at large, and in the process engender[ing] shifts in dominant power relations." ${ }^{33} \mathrm{He}$ goes on to state, "political parties did not have the monopoly on electoral campaigning. Numerous individuals and civil society groups also took the initiative to engage and educate the Malaysian public on what was at stake in the 12th General Election." ${ }^{34}$ Capturing the many platforms through which the new media manifests itself, he writes, "[on] polling day, the hand phone was again indispensable in facilitating timely and contrapuntal informational flow." ${ }^{35}$ In short, the $12 \mathrm{GE}$ demonstrated the various forms and broad range of new media in "the cultural production" and "contestations of social power in contemporary Malaysian society." ${ }^{\text {"3 }}$

One of the interesting insights with regard to new media during this past decade is the speed with which it has emerged as a dominant factor in the changing political dynamics in Malaysia. In a study conducted of blogging in Malaysia in 2006, based on the demographic that was actively engaged in it, the authors were not too optimistic of the potential of this form of new media to change the political landscape. They write, "the possibility of blogging to act as a vehicle for political change and democratization should be viewed with caution."37 Two years later, in their observations of the role of bloggers in the $12 \mathrm{GE}$, they reassessed their earlier conclusions, sharing the view that bloggers were now assuming the role of "thought leaders for a new generation." ${ }^{38}$ They write that, in the context of a 
controlled mainstream media, "there is no doubt that, in the recent general election, these 'thought leaders' have become crucial in 'the shaping of opinions' through 'online political discourses' of the nation...." ${ }^{\prime 3}$ The dynamic and protean nature by which the new media has developed also suggests that its next phase of transformation would be left only to the political imagination of Malaysia's netizens.

The transformation that would allow new media to form a more robust democratic culture and consequently become the next step in the trajectory of liberal democratic reform in Malaysia is through the formation of a "public sphere." Political philosopher Charles Taylor in his discussion of civil society as "public sphere" reminds us that in liberal society there is a social form of power that society wields to counteract the power of the state. ${ }^{40}$ Taylor defines a public sphere as:

A common space in which the members of society meet, through a variety of media (print, electronic) and also in face-to-face encounters, to discuss matters of common interest; and thus to be able to form a common mind about those matters. I say "a common space" because, although the media are multiple, as well as the exchanges taking place in them, they are deemed to be in principle intercommunicating (emphasis added). ${ }^{41}$

The "common space" of the public sphere then is seen as a space for discussion, not strictly a physically identifiable place, but rather, the domain in which discussions take place (i.e., through the media, books, pamphlets, and newspapers.) (2) $^{42}$ Taylor argues for a view of the public sphere as "a space of discussion which is self-consciously seen as being outside power" with its role expressed in these terms: "It is supposed to be listened to by those in power, but it is not itself an exercise of power." ${ }^{\prime 3}$ Taylor points to two justifications for this. First, that the public sphere is seen as society's check on power, that is, giving shape to the claim that "political power must be supervised and checked by something outside," so that the check can be seen to be "ideally disengaged from partisan spirit." ${ }^{44}$ Second, the rise of the public sphere effectively puts an end to the "old ideal of a social order undivided by conflict and difference." ${ }^{45}$ Quite the opposite. The public sphere is a sphere in which constant debate and argument take place; and so that these potentially divisive moments do not signal or even result in a general weakening (or breakdown) of the whole political structure (or order), it is important that the public sphere be maintained as an "extrapolitical" sphere. ${ }^{46}$ By carving out an extrapolitical status for the public sphere, it could be defended against accusations (often made by representatives of ruling regimes) that it will have potentially destructive or destabilizing effects on the whole polity. Indeed, this could not be further from the truth since the role of the public sphere is essentially to provide an arena in which potentially divisive issues could be hammered out with the ultimate hope of reaching some form of (unforced ${ }^{47}$ consensus that incorporates the common wishes of the people. Taylor elaborates that "people's views can be altered by the interchange" that transpires in the public sphere, and that "consensus sometimes emerges" through the fact that "citizens frequently understand themselves as [being] part of a community and don't vote out of individual interests alone." ${ }^{48} \mathrm{~A}$ flourishing public sphere then is essential to any democracy because it ensures that a democratic process is maintained in political decision making. ${ }^{49}$ Also, it is only if the public sphere is maintained as an extrapolitical domain that it can then be seen as a cluster that could be linked to other extrapolitical spheres, thereby forming the conceptual boundaries of a civil society in its broadest sense.

The next phase of political liberalization in Malaysia should be one where the trajectory of new media as a complementary actor or facilitator of the democratic process is institu- 
tionalized by the gradual creation of a "public sphere" as described above. It is only then that the new media could claim to be a "free" uncensored media. In other words, by circumventing the current dominant institutions that represent the mainstream media in Malaysia, new media is creating a new democratic institution.

\section{CONCLUSION}

To summarize, these are some of the institutional changes that have swept across the political landscape in Malaysia in the wake of the $12 \mathrm{GE}$ :

(1) There is now a higher level of voter choice differentiation. ${ }^{50}$ This is certainly true for non-Malay (Chinese and Indian) voters, but this is also the case for Malay voters, who now have three choices from which to choose: the status-quo option in UMNO, and two different offerings within the opposition coalition, a liberal choice in PKR, and a more conservative alternative in PAS. ${ }^{51}$

(2) For the first time in recent political history, there is an increasingly viable two-party coalition system in Malaysia, with the BN coalition parties having to face a nascent "shadow government" in the Pakatan Rakyat (People's Coalition). The PKR-DAP-PAS opposition coalition-controlled governments in the state legislatures of Selangor, Penang, Kedah, and Kelantan have provided an opportunity for these state governments to begin building the necessary levels of institutional density to create sufficient amounts of institutional capital among themselves to govern effectively. ${ }^{52}$

(3) The new media is beginning to create an Internet-based public sphere in which voices critical of the government are no longer "hidden transcripts" of the oppressed ${ }^{53}$ or the politically discontented, but rather are starting to potentially form an "imagined community" ${ }^{\prime 4}$ of democracy advocates who have become sufficiently emboldened through the act of sharing images in their minds of "the art of the possible." 55 This has resulted in citizens engaging with the political process in more direct ways than merely passively casting their ballots at every election cycle. ${ }^{56}$

When one observes political developments in the run-up to and since the $12 \mathrm{GE}$, democratization in Malaysia was already occurring, albeit at a gradual pace. Democratization was being pushed by new political forces such as civil society actors, newly empowered opposition parties, and the Internet-based media. In effect, new institutions were being formed around new political forces. The pace of change is being determined by these new political forces having to challenge structural and institutional barriers representing eliterun institutions such as the dominant political parties. Often times, sites of political contention where political change emerges are situated beyond the arenas in which elite coalitions and power-sharing arrangements are being negotiated and perpetuated. It is in these new political spaces that the contours of emerging democratic space in Malaysia are being (re) delineated, often by circumventing conventional institutional barriers to political liberalization and democratization. The democratic space that is emerging in Malaysia today is simultaneously being shaped and contested by the political competition between statusquo and reformist forces in this society. And the boundaries of this new political space are constantly being redrawn depending on the outcomes of these political contestations. Taken together, the institutional changes discussed above have expanded the parameters of democratic space in Malaysia, although the entrenched dominant institutions of the ruling regime continue to wield sufficient amounts of institutional capacity to subvert any consolidation of these democratic changes for now. We will continue to witness these new political dynamics in Malaysia in the upcoming 13th General Election, expected to be held in 2012.

49 Assessing Political Dynamics In Contemporary Malaysia: Implications For Democratic Change 


\section{NOTES}

1. An earlier version of this paper was presented at the Nineteenth Annual ASIANetwork Conference, Oak Brook, IL, April 15-17, 2011.

2. See Marc Lynch, "After Egypt: The Limits and Promise of Online Challenges to the Authoritarian Arab State," Perspectives on Politics 9, no. 2 (June 2011): 301 - 310. Also see the essays on "The New Arab Revolt," in Foreign Affairs 90 no. 3 (May/June 2011).

3. Graham K. Brown, "Federal and state elections in Malaysia, March 2008," Electoral Studies 27 (2008): 742.

4. Data from CIA, The World Factbook. https://www.cia.gov/library/publications/the-world-factbook/geos/ my.htm The 2010 Census figures by the government of Malaysia do not provide the breakdown between Malays and other "bumiputera" (or indigenous) groups. The figures are: $67.4 \%$ Bumiputera (indigenous races), $24.6 \%$ Chinese, $7.3 \%$ Indians, and $0.7 \%$ others. http://www.statistics.gov.my

5. R.S. Milne and Diane K. Mauzy, Malaysian Politics under Mahathir (New York \& London: Routledge, 1999), 10.

6. Zakaria Haji Ahmad, "Malaysia: In an Uncertain Mode," in Driven By Growth: Political Change in the AsiaPacific Region, ed. James W. Morley (Armonk, NY: M.E. Sharpe, 1999), 179.

7. These "special rights" for Malays and other indigenous races (bumiputera) are entrenched in Articles 152 and 153 of the Federal Constitution of Malaysia.

8. Zakaria, "Malaysia: In an Uncertain Mode," 179.

9. Zakaria Haji Ahmad, "Malaysia: Quasi Democracy in a Divided Society," in Democracy in Developing Countries, Volume 3: Asia, eds., Larry Diamond, Juan J. Linz, and Seymour Martin Lipset (Boulder, CO: Lynne Rienner, 1989), 375.

10.Donald K. Emmerson, "Region and Recalcitrance: Rethinking Democracy through Southeast Asia," Pacific Review 8, no. 2 (1995): 223-248.

11.David Brown and David Martin Jones, "Democratization and the Myth of the Liberalizing Middle Classes," in Towards Illiberal Democracy in Pacific Asia, eds. Daniel A. Bell, David Brown, Kanishka Jayasuriya, and David Martin Jones (London \& New York: Macmillan/St. Antony’s College and St. Martin's Press, 1995), 78-106.

12.See Diane K. Mauzy and Shane J. Barter, "Learning to lose? Not if UMNO can help it," in Political Transitions in Dominant Party Systems: Learning to Lose, eds. Edward Friedman and Joseph Wong (London \& New York: Routledge, 2008), $211-230$.

13.Surain Subramaniam, "The Dual Narrative of Good Governance: Lesson for Understanding Political and Cultural Change in Malaysia and Singapore," Contemporary Southeast Asia 23, no. 1 (April 2001): 65- 80.

14.Francis Loh Kok Wah, "Developmentalism and the Limits of Democratic Discourse," in Democracy in Malaysia: Discourses and Practices, eds. Francis Loh Kok Wah and Khoo Boo Teik (Richmond, Surrey: Curzon, 2002), 19-50.

15. Francis Loh Kok Wah, Old vs. New Politics in Malaysia: State and Society in Transition (Malaysia: Strategic Information and Research Development Centre, 2009), 32. In many ways, "developmentalism" as a political ideology resembles some of the positions associated with the "Asian values" discourse, see Surain Subramaniam, "The Asian Values Debate: Implications for the Spread of Liberal Democracy," Asian Affairs: An American Review 27, no. 1 (March 2000): 19-35.

16. William Case writes, "In its distributions of public resources, the government has heavily favored the Malays... But these same allocations and appeals have also alienated the non-Malays, belittling them with 'secondclass' citizenship." See William Case "Political Legitimacy in Malaysia: Historical Roots and Contemporary Deficits," Politics \& Polity 38, no. 3 (2010): 498.

17. In political developments subsequent to the 2008 General Elections, the ruling BN government wrested control of the state of Perak, reducing the total number of states under opposition control from five to four.

18. There have been a few studies of the $12 \mathrm{GE}$ in terms of explaining the factors that have led to the specific electoral outcomes. See Brown, "Federal and state elections in Malaysia, March 2008"; Thomas B. Pepinsky, “The 2008 Malaysian Elections: An End to Ethnic Politics?" Journal of East Asian Studies 9, no. 1(JanuaryApril 2009): 87-120.; and Andreas Ufen, "The transformation of political party opposition in Malaysia and its implications for the electoral authoritarian regime," Democratization 16, no. 3 (June 2009): 604-627.

19. Data drawn from Sankaran Ramanathan \& Mohd. Hamdan Adnan, Malaysia's 1986 General Election: The Urban-Rural Dichotomy (Singapore: Institute of Southeast Asian Studies, 1988), 50; Zakaria Haji Ahmad, in Trends in Malaysia: Election Assessment (Singapore: Institute of Southeast Asian Studies, January 2000), 8; Khoo Boo Teik, in Mavis Puthucheary and Norani Othman, eds., Elections and Democracy in Malaysia (Malaysia: UKM, 2005), 42, 44; and Andreas Ufen, "The transformation of political party opposition in Malaysia and its implications for the electoral authoritarian regime."

20.Data drawn from Zakaria, "The 1999 General Elections: A Preliminary Overview”; Edmund Terence Gomez, "Introduction: Politics, business and ethnicity in Malaysia: a state in transition?" in Edmund Terence Gomez, ed., The State of Malaysia: Ethnicity, equity and reform (New York: RoutledgeCurzon, 2004), 12; Khoo, "Limits to democracy: political economy, ideology and ruling coalition"; and Brown, "Federal and state elections in Malaysia, March 2008."

21.Pepinsky, "The 2008 Malaysian Elections: An End to Ethnic Politics?" 87, 98. Pepinsky's findings were based on cross-referencing electoral outcomes of specific political parties (UMNO, MCA, MIC, PKR, DAP, PAS) with the ethnic composition of the political constituencies. Some of his findings include (1) "in both state assembly and parliamentary elections, as the percentage of Malays in an electoral district increases, the likelihood of a BN victory increases. By contrast, as the percentage of Indians and Chinese increases, the likelihood of a BN victory decreases substantially" (105); (2) "Ethnic Chinese appear to have broken for both PKR and 
the DAP in substantial numbers; only about a third of Chinese voters are estimated to have voted for the MCA" (108); and (3) "[In] districts where the MIC fielded candidates, only three in ten Indians are estimated to have voted for them." (108). All quotes taken from Pepinsky, "The 2008 Malaysian Elections: An End to Ethnic Politics?"

22. For a critique of the Malaysian Chinese Association, the main political party within the ruling BN coalition that represents the ethnic Chinese constituency, see James Chin, "Malaysian Chinese Association Politics a Year Later: Crisis of Political Legitimacy," The Round Table 99 no. 407 (April 2010): 153-162.

23.Data drawn from Pepinsky, “The 2008 Malaysian Elections: An End to Ethnic Politics?"; Meredith Weiss, "Edging Toward a New Politics in Malaysia: Civil Society at the Gate," Asian Survey 49, no. 5 (2009): 742-758; and William Case, “Transition from Single-Party Dominance? New Data from Malaysia," Journal of East Asian Studies 10 (2010): 91-126.

24. Arendt Lijphart came up with the concept of "consociational democracy" to describe the political arrangement that could be used in ethnically divided societies such as Malaysia, whereby "the main ethnic communities are all represented in the government" in a "grand coalition consisting of leaders of each major ethnic community." "The ethnic parties of the consociational regime have to reach decisions by consensus, taking into account the disparate and conflicting ethnic interests that they represent. Moreover, the principle of proportionality should be observed in areas such as political representation, civil-service appointments, and the distribution of public funds to assure each community that its interests are truly being served," All quotes taken from Harold Crouch, Government and Society in Malaysia (Ithaca \& London: Cornell University Press, 1996), 152, 153. One of the main sources of contention among the non-Malays is that over time, and especially since the NEP, the Malays have benefitted disproportionately from public policies enacted by the ruling $\mathrm{BN}$ coalition. In the case of the elites who lead the Chinese (MCA) and Indian (MIC) ethnic parties within the ruling coalition, this has gradually eroded their legitimacy, resulting in the loss of non-Malay support for the $\mathrm{BN}$ in the $12 \mathrm{GE}$. For an assessment of the effects of the NEP on the ethnic Chinese support for the BN, see James Chin, "The Malaysian Chinese dilemma: the Never Ending Policy (NEP), Chinese Southern Diaspora Studies 3 (2009): 167-181.

25.PKR (Parti Keadilan Rakyat, People’s Justice Party); DAP (Democratic Action Party); PAS (Parti Islam SeMalaysia, Pan-Malaysian Islamic Party).

26. Julian C. H. Lee, Wong Chin Huat, Melissa Wong, Yeoh Seng Guan, "Elections, Repertoires of Contention and Habitus in Four Civil Society Engagements in Malaysia's 2008 General Elections," Social Movement Studies 9 , no. 3 (2010): 294-296.

27. On July 9, 2011, the Coalition for Clean and Fair Elections (BERSIH), with the support of the opposition coalition, Pakatan Rakyat (People's Alliance), held a follow-up demonstration in Kuala Lumpur, BERSIH 2.0., with an estimated 10,000 - 50,000 protesters. The government ordered security forces to clamp down on the protesters, arresting over 1,600 protesters, and firing tear gas and water cannons into the crowds. The government's actions were met with harsh criticism of the ruling regime, both in Malaysia, and abroad, much of the former expressed in the Internet-based new media. See "Bersih turns to social media amid police clampdown," Malaysiakini, June 29, 2011; and “170,000 'like' Facebook page urging PM to go." Malaysiakini, July 13, 2011. http://www.malaysiakini.com One of the many YouTube videos capturing scenes from the protest titled, "Truth that Cannot Be Covered - Bersih 2.0" has been viewed 946,683 times. http://www.youtube. com/watch? $\mathrm{v}=\mathrm{vCetbFLceFI}$

28. To illustrate this point, one of the many YouTube videos capturing scenes from the $2007 \mathrm{HIN}$ DRAF protest titled, "Hindraf Rally Report" has been viewed 335,614 times. http://www.youtube. com/watch?v=rlWmafBG1Md Also see "HINDRAF 1 - Samy Vellu 0" http://www.youtube.com/ watch?v=KXJTqZdlOQ4\&feature

29.Subramaniam, "The Dual Narrative of Good Governance: Lesson for Understanding Political and Cultural Change in Malaysia and Singapore."

30.Jun-E-Tan and Zawawi Ibrahim, Blogging and Democratization in Malaysia: A New Civil Society in the Making (Malaysia: Strategic Information and Research Development Center, 2008), 83-99.

31. Mustafa K. Anuar, "Media Commercialisation in Malaysia," in Free Markets Free Media? Reflections on the political economy of the press in Asia, ed. Cherian George (Singapore: Asian Media Information and Communication Center, 2008), 124-136.

32.In a study of the mainstream media in Malaysia, two scholars write, "Content analyses of election coverage show that the mainstream media in Malaysia pursue a subservient model of political news reporting. Without question, the close relationship between the mass media and the government in Malaysia is responsible for the biased coverage of national elections and the political favoritism afforded to the various parties of the ruling BN coalition," See Ezhar Tamam and Manimaran Govindasamy, "Political Communication Practices and Research in Malaysia: An Overview" in Political Communication in Asia, eds. Lars Willnat and Annette Aw (New York \& London: Routledge, 2009), 148.

33. Yeoh Seng Guan, "Introduction: Representation, cultural mediation and power in Malaysia," in Media, Culture and Society in Malaysia, ed.Yeoh Seng Guan (New York: Routledge, 2010), 12.

34. Ibid., 14

35. Ibid., 14.

36.Ibid., 15.

37.Jun-E-Tan and Ibrahim, Blogging and Democratization in Malaysia: A New Civil Society in the Making, 79.

38. Jun-E-Tan and Zawawi Ibrahim, "Postscript: Rethinking Blogging and the 12th Malaysian General Election," in 
Jun-E-Tan and Ibrahim, Blogging and Democratization in Malaysia: A New Civil Society in the Making, 92. 39.Ibid., 92-93.

40. Charles Taylor, "Liberal Politics and the Public Sphere," in Charles Taylor, Philosophical Arguments (Cambridge, MA: Harvard University Press, 1995), 257-287.

41.Ibid., 259.

42.Ibid., 261.

43.Ibid., 264-265.

44.Ibid., 265.

45.Ibid., 265 .

46.Ibid., 265.

47. Charles Taylor, "Conditions of an Unforced Consensus on Human Rights," in The East Asian Challenge for Human Rights, eds. Joanne R. Bauer and Daniel A. Bell (Cambridge, U.K. \& New York: Cambridge University Press, 1999), $124-144$.

48.Taylor, "Liberal Politics and the Public Sphere," in Charles Taylor, Philosophical Arguments, 276.

49.Ibid., 277, 278.

50.I use the term "voter choice differentiation" to capture the increased menu of choices available now to voters in Malaysia beyond the prior choices that were defined almost exclusively along communal lines. Some of the new categories that could now be used to differentiate the choices open to voters would include ideological differences and various issues-oriented distinctions that transcend the ascriptive identities of both candidates and voters.

51. Operationally, this raises some immediate challenges to the opposition coalition in terms of fielding the most suitable candidate in a given political constituency during elections both at the national and state levels. This does not however diminish my argument that these increased choices at the macro-level have changed the political landscape for voters in terms of the level of differentiation among the options available to them.

52.I use the term "institutional density" to capture the same kinds of institutional capital that has been built up among different groups of elites within the ruling coalition, as discussed in institutionalist models of durable authoritarianism. For the latter, see Dan Slater, Ordering Power: Contentious Politics and Authoritarian Leviathans in Southeast Asia (Cambridge, U.K. \& New York: Cambridge University Press, 2010).

53.James C. Scott, Domination and the Arts of Resistance: Hidden Transcripts (New Haven: Yale, 1990).

54.Benedict R. O'G. Anderson, Imagined communities: reflections on the origins and spread of nationalism (London: Verso, 1991)

55.Jun-E-Tan and Ibrahim, Blogging and Democratization in Malaysia: A New Civil Society in the Making, 95.

56.Some of these "transcripts" are powerfully captured in the writings that appeared immediately prior to and since the $12 \mathrm{GE}$, many of which had their first iteration in web-form over the new media, see Nathaniel Tan and John Lee, eds., Political Tsunami: An End to Hegemony in Malaysia? (Malaysia: Kinibooks, 2008); Liew Chin Tong, Speaking for the Reformasi Generation: A collection of articles \& essays, 2003 - 2009 (Malaysia: REFSA, 2009); Raja Petra Raja Kamaruddin, Silent Roar: A Decade of Change (Argyll, Scotland: Argyll, 2009); and Kee Thuan Chye (and fellow Malaysians), March 8: Time for Real Change (London: Marshall Cavendish, 2010). 


\title{
Tree Ordination as Invented Tradition
}

\author{
Avery Morrow
}

\begin{abstract}
The symbolic ordination of trees as monks in Thailand is widely perceived in Western scholarship to be proof of the power of Buddhism to spur ecological thought. However, a closer analysis of tree ordination demonstrates that it is not primarily about Buddhist teaching, but rather is an invented tradition based on the sanctity of Thai Buddhist symbols as well as those of spirit worship and the monarchy. Tree ordinations performed by non-Buddhist minorities in Thailand do not demonstrate a religious commitment but rather a political one.
\end{abstract}

Keywords: invented traditions, environmentalism, sacred ecology, Thai Buddhism, Eco-Buddhism

Avery Morrow graduated from Carleton College in 2010 with a degree in religion. His thesis, which reinterpreted early 20 th century Japanology and Occupation policy in the framework of Timothy Fitzgerald's Ideology of Religious Studies, was published in the Wittenberg University East Asian Studies Journal. He is currently working as a schoolteacher in Japan.
The practice of tree ordination, invented to save local forests from logging, has spread from its original home in Northern Thailand to Cambodia, Laos, and possibly Burma. On the surface, tree ordination is presented to the world environmentalist movement as a highly clever and original idea, using the widely respected symbol of monastic robes to make loggers hesitate to cut down trees. It also appears to have been created from scratch by a group of Thai forest monks called "ecology monks" (phra nak anuraksa).

However, this is only part of the story. If tree ordination were actually completely original, it would not be acknowledged. Military authorities could dismiss innovative rituals as the work of a fringe interest with no connection to mainstream Thai opinion. In fact, securing the legitimacy of the ecology monks' antideforestation program required a connection to pre-existing symbols in the cultural landscape of Thailand. Because it relies on a vocabulary specific to Thailand, it is much more culturally bound than "universally" Buddhist in nature. In short, tree ordination is not meant to be an original eco-Buddhist invention, but an invented tradition that asserts itself as continuous with Thainess (khwampenthai).

Eric Hobsbawm distinguishes invented traditions from what he considers the "custom" prevalent in pre-industrial societies. Custom, Hobsbawm says, is an informal habit that individuals will adapt to social needs without any real attachment to prior practice; the power of tradition, on the other hand, comes precisely from that attachment to the past and desire for an "unchanging and invariant" practice handed down from a forgotten age. When a tradition is invented, its inventors do not popularize the new practice by appeal to a principle, but by appealing to comfort of familiar forms (e.g., forms of dress, song, folklore, architecture, cosmology, or even power relationships). ${ }^{1}$ I argue that tree ordination fits this mold precisely.

\section{THE SPIRIT TREE}

Buddhism in Thailand has traditionally been intertwined with supernatural beliefs that 
are generally called "spirit worship" or "animism." Monks engage frequently with magic and supernatural beings, and are seen as preserving a metaphysical as well as material order in a Thai village. Although a positivist worldview represents Buddhism and animism as distinct philosophies, in fact it is hard to say in Theravada societies where the "pure philosophy" ends and "superstition" begins - tales of the Buddha's previous lives, stories of his travels in Thailand, the sanctification of Buddha images and the Thai landscape, the homage paid by monks to thewada (kind spirits), and the relationship of humans to devas (gods) and other beings, are all bound together in a seamless whole.

In studying Thai religion, comparative religionists have too often neglected the ritual and practical realms of premodern Thai life, presenting Buddhist philosophy as its most beneficial product. Midcentury western anthropologists who lived in Thai villages, such as B.J. Terwiel and Stanley Tambiah, tended to focus on the structure of festivals and monastic life, and the overwhelming complexity of even these cultural products makes that focus understandable. But the basis for tree ordination is not found in any of these things, and was only recently documented in English, out of the same environmental concern that prompted tree ordination itself. This is the belief in spirit trees (phi ton mai), which are found on the grounds of Buddhist temples, in other inhabited areas, and in sacred groves.

Trees inhabited by spirits are not the object of any special ceremony or festival in Thailand, and recognizing these trees cannot be said to be a cultural practice as much as the trees themselves figure as living characters in the Thai landscape, as the homes of family and village guardian spirits. A spirit house can be erected in front of the tree, or old spirit houses can be left there instead of being thrown away, so that the spirits might find new residence within the tree. They are ubiquitous throughout the country, and are found even in Bangkok. Sponsel and Natadecha-Sponsel, in their short environmentalist article "Why a Tree is More than a Tree," introduce the subject as follows:

Throughout Thailand from Bangkok to the remotest rural villages, one effortlessly sees colorful cloth wrapped around the lower trunk of a tree. A small spirit house with offerings such as candles, incense, and fruit may be located at the base of the tree. Local people believe that the tree is the residence of a spirit, usually from a deceased person. Generally such sacred trees are respected to the extent that they are protected. Anyone who harms such a tree might experience misfortune, sickness, or even death as the spirit takes revenge. ${ }^{2}$

Most spirit trees are notable for being large, old, or unique in the area. The Sponsels relate the stories of trees that appear to bleed, glow, and avoid lightning strikes. Bodhi, banyan, yang, and takian trees are also marked off. The first two of these are not native species to Thailand. Obviously, bodhi trees are revered because the Buddha reached enlightenment sitting under a member of their species; besides being wrapped in cloth, bamboo poles will be placed against them to support their weight. They are traditionally found in the courtyards of temples. ${ }^{3}$ Even when traditionally taboo trees are cut down for firewood due to bad economic times, bodhi trees will remain unharmed. ${ }^{4}$

The banyan tree is an interesting case: it is a relative of the bodhi tree, and is mentioned in some Buddhist texts, but is more widely held as sacred in India. The yang and takian, too, have no Buddhist connection but are rather associated with wood nymphs (nang mai) and a male equivalent, although they are found on the grounds of temples that are rumored to be haunted. ${ }^{5}$ This has led to the opinion of some Buddhists, such as Bhante Sathi of Minnesota's Triple Gem Sangha, that the "spirit tree" is simply a remnant of Hindu culture, and the Sponsels allude to this. However, the practice of marking off the tree with a colored cloth 
seems to be centered on Thailand, only occasionally stretching across national borders to Laos, Cambodia, Bali, and possibly Burma.

There are no divisions among Thais regarding the belief in spirit trees. Christians, Muslims, and Buddhists alike will honor the same trees and groves, by employing the same use of colored cloth. Sometimes entire forests are preserved in this way for hundreds of years. The interest in keeping these religions "pure" of traditional influence seems to have been secondary in Thai culture to continuing the everyday habits of village life, and indeed, in the case of Buddhism at least animism was openly endorsed as part of the cosmology.

Sponsel and Natadecha-Sponsel note that spirit trees can function as "part of a hierarchy of progressively larger ecological systems," ${ }^{\text {"6 }}$ and belief in the spirit tree as a powerful nonhuman force is certainly superior to the stereotypical "western" view that the wilderness should be subjugated to humanity. Yet the Thai worldview that recognizes spirit trees as part of the natural order is not explicitly environmentalist. Spirit trees set up a duality in which certain trees are forbidden from being tampered with, while the vast majority remain "ordinary" trees that can be used freely. The use of spirit trees to bring out a latent environmentalism was a conscious action on the part of Thai monks of the forest tradition, who combined a western ecological education with their own culture and their firsthand witness to deforestation to invent the practice of tree ordination.

\section{INVENTING A TRADITION}

Thai forest monks represent a unique combination of western education and local knowledge. Forest monks often witness deforestation in progress, including illegal logging, and can testify to its effects on ordinary villagers. Forest monasteries serve as a wildlife refuge and are often walled off with barbed wire to prevent loggers from entering. Monks are suspicious of urban society, spend most of their time walking through the forest, and are familiar with survival techniques such as whistling to ward off bears. At the same time, many are well-educated, and they come to the forest from throughout Thailand's provinces. ${ }^{7}$ It is not surprising, then, that forest monks have led the majority of environmental efforts in rural communities, both engaging in reforestation and connecting the traditionally hostile hill and valley communities (ethnically Hmong and Thai, respectively) through environmental consciousness. ${ }^{8}$

It is generally acknowledged that the first tree ordination, wherein a tree not already considered sacred was wrapped in saffron-colored cloth and given monastic vows, was performed in Thailand in 1988 by the monk Phrakhru Manas Natheepitak of Wat Bodharma in Phayao Province, Northern Thailand. Phrakhru Manas arrived at the idea after hearing the story of two highway workers who had been forced to cut down a bodhi tree, and thereafter were beset with misfortune. ${ }^{9}$ Making the connection between forest preservation and spirit trees would not have been a great leap for him, because the two had been connected in Thai culture in the past:

In the old days when certain big trees were required for the making of the traditional royal barge or posts for the tall roof of a royal pire, an offering was made and a royal proclamation was read to the spirit before it could be cut down. This was a wise practice to preserve big trees of the forest from wanton felling by the simple folk. ${ }^{10}$

Phrakhru Manas simply had to turn this old story on its head. Instead of elites protecting the forest from commoners, now it was the commoners who had to protect the forest from the encroaching elites; instead of picking trees to be felled, the villagers were 
now picking trees to be saved (ideally, hundreds of them at once). Also, although both an offering and a reference to the Thai king's ownership of the trees were included in the tree ordination ceremony, these two elements alone were not enough to combat the threat of deforestation. Villagers needed to become aware of why the forest needed to be protected, and loggers had to be sufficiently humbled before sacred symbols of Thainess.

While Phrakhru Manas was concerned with his own forests in Phyao province, the other monks who followed his example, Phrakhru Pitak Nanthakun and Phrakhru Prajak Kuttajitto, were more interested in describing tree ordination as a pan-Thai procedure and gaining media attention. The practice of tree ordination was therefore systematized in a form that involves both spirit beliefs and scientific ecology, involving both illiterate villagers and the educated workers of nongovernmental organizations (NGOs) - a powerful force in Thailand-in the several days of events. The "folk" ceremony itself is combined with "modern" agricultural projects and environmental education, and NGO workers and villagers alike are invited to participate in both events. In the case of Phrakhru Pitak, the educational portion involves a slide show of cartoons and data accompanied by his own speech filled with humor, Buddhist culture, and information about the importance of the forest. However, the tone of the entire event is one of "radical conservatism," acknowledging the existing habits of rural life rather than creating new ones. ${ }^{11}$

Rather than performing a non-Buddhist ceremony to imbue trees with spirits, the ecology monks created a ritual that employed Buddha images, chanting of scripture, and monastic robes. Although the format was of an ordination ceremony, nobody believed the tree was actually a monk. Phrakhru Manas said that he chose the word "ordination" to give the ceremony "more weight." ${ }^{2}$ According to Phrakhru Pitak, the function of this was not to use the image of the spirit tree in a "proper" ritual, but to double the spiritual power of the ceremony: "It's not true Buddhism to conduct such rituals. But in the villagers' beliefs they respect the Buddha and fear some of his power....In general, villagers also believe in spirits. Therefore, we set up a shrine for the guardian spirit together with the Buddha image. This led to the saying that 'the good Buddha and the fierce spirits work together to take care of the forest."'13 The purpose of these Buddhist symbols is not to ground the ceremony in Buddhist philosophy (although Phrakhru Pitak does seem to employ that philosophy in his speeches), but to endow the forest with the power of symbols with which local villagers, as members of Thai society, are already familiar.

As Isager and Ivarsson describe it, the actual ceremony of tree ordination is overwhelmingly Thai, and only Buddhist in the sense that the Pali scriptures and monks are sacred to the nation and providers of truth. At the ceremony they observed, before the monks arrived the local villagers made an offering of food to the "Lords of the Four Directions," inviting them to the celebration. When the monks arrived they performed a rite of renewal (syyb chataa), in which they held a white thread (saaj siin) and chanted from the sutras, transmitting truth and therefore power throughout the forest. After the chanting, local spirits were invoked, as follows:

As part of the oath a call is made to the "gods" who regulate the weather (aakaad theewadaa), Mae Thorani (Goddess of the Earth), Mae Phosop (Goddess of Rice), and the spirits in the forest and mountains (caw paa caw khaw) to assist people in preserving the forest and punishing wrongdoers. Finally, it is noted that all the merit accomplished through efforts to preserve the forest is dedicated to the royal family in Thailand. ${ }^{14}$

At the ceremony he observed, Henry Delcore saw the same use of white thread, the rite 
of renewal, and the Lords of the Four Directions. He also saw a sand stupa had been erected to invite friendly spirits (thewada) to the ceremony. This object, which he describes as "Brahman-Buddhist", was also apparently erected for the sake of sanctifying the area in the eyes of the local people. Both the monks and the NGO leaders whom Delcore interviewed claimed, similar to Phrakhru Pitak's disclaimer, that the use of spirits, Buddhist symbols, and monastic robes around trees to create an image of sanctity was a "device," "mechanism," or "trick" employed for the purpose of "psychology" and not out of any Buddhist principles. The real purpose of the event, in their eyes, was to familiarize villagers with the basics of ecology. ${ }^{15}$

Delcore also noted a general, nonspiritual affirmation of the ceremony's relevance to Thai values and the goals of the modern Thai state. The organizers introduced by name all the government officials present at the event, as well as the foreign students from a nearby university who had come to observe, demonstrating the relevance of the ceremony to Thailand's global image. Phrakhru Pitak's speech after the ordination itself emphasized how Thailand's natural resources, preserved by ordinary villagers, could become a more important gift to the king than millions of dollars donated by wealthy urbanites. After the speech, the king's anthem was played. ${ }^{16}$

\section{POPULAR RECEPTION AND MINORITY ACCEPTANCE}

Phrakhru Pitak adopted tree ordination, in his own words, because it was more effective than his own preaching and conservation efforts. ${ }^{17}$ However, the practice had to pass several other tests as well if it were to counter deforestation at a national level. For monks to continue to use it, their sangha had to approve of the new ceremony. The news media had to interpret the ceremony correctly, or else it would be ridiculed. Finally, the intent of the ordinations had to be identified with the goals of the state, as embodied in the person of the king, because any movement running counter to the king's wishes cannot last long in Thailand.

Both Phrakhru Pitak and Phrakhru Prajak involved their local sangha officials in the planning of tree ordinations. ${ }^{18}$ Jim Taylor mentions a report made for the district monastic head (cao khana tambon) of Buriiram province, which not only approves of tree ordination but suggests that Prajak's group should remain in Dongyai "and protect the forest from being destroyed. The area where the monks reside is primal forest and the area outside [is] now degraded....and generally in about ten years' time the usefulness of monks living in forests will be seen clearly." Taylor does not mention tree ordination being linked to any Buddhist philosophical principle. Instead, the monastic head seems to interpret tree ordination as supportive of the goals of the state and sangha development programs, further proof that the forest lineage can provide an important ecological education to Thai villagers. ${ }^{19}$

All of the ecology monks were initially criticized by the military and logging corporations, earning pejorative labels like "Russian monk" and "communist monk." However, support for both monks in general and tree ordination in particular overwhelmed this smear campaign. Jim Taylor claims that "in accordance with Thai custom, as with an individual in robes, he is still outwardly treated with some veneration. Such veneration at least lessens the likelihood of a direct assassination. Had Prajak been a lay person, he surely would have disappeared by now."20 While this may have saved tree ordination in its early stages, it does not guarantee acceptance of the ecology monk movement; the military could silence the movement without violence by portraying the new ceremony as a threat to Thainess. More revealing is the way the ceremony is portrayed in a political cartoon reproduced by Taylor. The cartoon shows a monk in the act of worshiping a tree, with a lit bundle of incense at his 
side. The combination of the robes, incense, and the visual form of a spirit tree make a scene that is undoubtedly Thai. Meanwhile, in the background, a group of military thugs drive through cleared forest on a foreign-made truck; the scene is surrounded with barbed wire. The cartoonist offers readers a choice between the monk "conserving the trees in the forest" and the military "conserving the forest area." We see here that although not all Thais may believe in Buddhism or spirit trees, the power of their familiar and pious images still holds when put in contrast to an inhumane and thoughtless modernity.

Although it was created by a few lone forest monks, tree ordination therefore found widespread acceptance throughout Thailand. In 1997, the king officially endorsed the practice, and asked Thai citizens to ordain 50 million trees in honor of the fiftieth anniversary of his accession. With the assistance of Phrakhru Pitak and national NGOs, this proclamation became an active campaign, the "Program for the Community Forest Ordination of 50 Million Trees in Honor of the King's Golden Jubilee," which involved outreach to hundreds of villages. Not only did this legitimize tree ordination as a mainstream practice, but it also allowed groups whose Thainess had fallen into question to perform tree ordinations in order to reassert their citizenship as Thais.

For ethnic and religious minorities in Thailand, tree ordination was not seen as an exclusively Buddhist ritual. Instead, it was recognized as a nonsectarian way to assert the Thainess of the community and commit oneself to sustainable development. For these communities, royal support was key in transforming tree ordination from an outside event held by monks to a nonsectarian event that incorporated the village into Thailand as a nation. For example, Karen and Shan communities in northwest Thailand performed the ceremony without any monks involved, as an overtly political gesture. Instead of designating the Buddha and Thai phi as the protectors of the forest, the Karen used their own symbol, the Lord of the Land, when conducting the ceremony. In a Mien village, a local shaman was invited to provide the spiritual part of the ceremony. The more important connection was to the royal family and the national tree ordination campaign; even if villagers already felt they had a sufficient sustainability program, they joined the campaign out of support for the king. ${ }^{21}$

The village of Mae Malo, which is almost completely Christian, also performed a tree ordination in 1996, and used the same syyb chataa ceremony, chanting from Buddhist scriptures, only praying to God instead of invoking local spirits. In Mae Malo, this ceremony was seen as nonreligious. The reason that the villagers dressed in saffron and wrapped the trees in saffron robes is that they wished to present the trees to the king of Thailand as a gift. ${ }^{22}$ Saffron is the color of the king as well as the color of Buddhist robes.

Hmong hill tribes in northeastern Thailand, who are not Buddhist and do not recognize spirit trees, have traditionally been discriminated against with labels like "not Thai" and "alien." In the 1990s, the Hmong were blamed for deforestation, accused of both destroying ordained trees and not doing any work to plant new trees. In order to emphasize their Thainess and devotion to the environment, the Hmong therefore adopted tree ordination as their own, joining the campaign to ordain 50 million trees by conducting five ceremonies in their own region. This supplemented their sanctification of trees through the traditional ntoo xeeb ceremony, which they described as a show of ancient environmentalism. ${ }^{23}$

\section{CONCLUSION}

I find, after Henry Delcore, that tree ordination is an invented tradition, that is, an original invention that gains legitimacy by taking on the forms of traditional practice. While forest monks may base their desire for the preservation of trees generally on Buddhist principles, the practice of tree ordination uses Buddhist symbols not for their philosophical 
value but for the traditional power they have held, and furthermore combines them with animist symbols. Delcore quotes other authors to claim that this use of "indigenous wisdom" reduces tradition into a "bite-sized" symbol "slotted into western paradigms," ${ }^{24}$ but I do not think that tree ordination represents a step away from Thainess, because its legitimacy is determined by national media that inspect it for its allegiance to Thai values. Just as sacred trees were used in the past to prevent villagers from logging trees needed by the elite, their present adaption to the environmentalist movement is not an arbitrary decision, but relies on acceptance by the general populace.

Belief in spirit trees meets several important conditions for being adapted as an invented tradition. First and foremost, most of the country recognizes spirit trees as sacred. If only the rural part of the country believed in spirit trees, they could be denounced as superstitious in the media. Secondly, belief in them is alive in Thailand, and is held out of fear and respect for great trees, which have supernatural abilities attributed to them, and not out of a feeling of quaintness or tradition, which could prevent Thais from taking tree ordination seriously. Finally, tree ordination did not remove the belief in spirit trees from its generally accepted context. It is difficult to say what Thais would or would not consider a legitimate use of the symbol of the spirit tree, due to a lack of theoretical description of animist beliefs in Thailand, but the success of tree ordination indicates that this environmentalist use was not confusing or disrespectful.

Because its legitimacy is determined by local tradition and not Buddhist principle alone, tree ordination will likely remain centered in Thailand. In neighboring Theravada Buddhist countries, even where spirit trees are common, tree ordination has not spread as rapidly, because of the ceremony's political focus on the Thai monarchy and its use of the local symbol of cloth wrapped around a tree. In Burma, for example, spirit trees are usually indicated by erecting an altar. There is an unconfirmed report that one monk was wrapping robes around a tree, but more often monks will take simpler actions such as inviting ecologists to lecture in the village, volunteering for the Forest Department, or making an entreaty to the public not to cut down trees. ${ }^{25}$

In the twentieth century, Thailand faced a cultural modernization that devalued traditional forms of Buddhist education as well as local animist worship. Thai intellectuals have typically evaluated these cultural systems in terms of their perceived benefit to the general populace. One Thai intellectual, in his plan for economic development, had written that while Buddhism can be used to find a true purpose for industrialization, spirit worship "is quite clearly counter to a scientific way of life" and should "gradually assume an ever less important role" in Thai society. ${ }^{26}$ Buddhism in this representation is essentially a philosophical system which must be reformed to erase its locally built-up superstitions, whereas animism, which is apparently nothing but superstition, has no value whatsoever for modern Thai society. In simplifying Thai culture to this duality, this author, who supports environmentalism in general, overlooks the possibility of adapting the powerful symbols of spirit worship for invented traditions like tree ordination.

Interestingly, this pits tree ordination against some of the proposed methods of western eco-Buddhism. Rather than giving up one's attachment to unsustainable and hedonistic customs, the effectiveness of tree ordination lies in an attachment to tradition. Instead of being grounded in a general principle of sustainable living, trees are preserved through belief in the power of spirits and the Buddha. This has led to some concerns that villagers do not understand the purpose of conserving trees. Just as a story of loggers being punished through karma for felling a bodhi tree was the impetus for the invention of tree ordination, many villagers seem to fear that ordained trees have been imbued with cosmic power that 
will sicken or kill those who try to cut them down, and that they cannot be harmed under any circumstances. ${ }^{27}$

\section{NOTES}

1. Eric Hobsbawm, "Introduction," in The Invention of Tradition, ed. Eric Hobsbawm (Cambridge: University Press, 1983), 2.

2. Sponsel and Poranee Natadecha-Sponsel, "Why a Tree Is More Than a Tree: Reflections on the Spiritual Ecology of Sacred Trees in Thailand," in Santi Pracha Dhamma: Essays in Honour of the Late Puey Ungphakorn, ed. Puey Ungphakorn (Bangkok: Santi Pracha Dhamma Institute, 2001), 364.

3. Anuman Rajadhon, Essays on Thai Folklore (Bangkok: Social Science Association Press, 1968), 305.

4. Jonathan Rigg and Philip Stott, "Forest Tales: Politics, Policy Making, and Environment in Thailand," in Ecological Policy and Politics in Developing Countries, ed. Uday Desai (Albany, NY: SUNY Press, 1998), 114.

5. Rajadhon, Essays on Thai Folklore, 306.

6. Sponsel and Natadecha-Sponsel, "Why a Tree Is More Than a Tree," 366-67.

7. J. L. Taylor, Forest Monks and the Nation-State (Singapore: Institute of Southeast Asian Studies, 1993), 224, 24243.

8. Rigg and Stott, "Forest Tales," 105. See also the opinion of Phrakhru Pitak given by Henry D. Delcore, "Symbolic Politics or Generification? The Ambivalent Implications of Tree Ordinations in the Thai Environmental Movement," Journal of Political Ecology, 11 no. 1 (2004): 15.

9. Lotte Isager and Søren Ivarsson, "Contesting Landscapes in Thailand: Tree Ordination as Counter-Territorialization,” Critical Asian Studies 34, no. 3 (2002): 404.

10. Rajadhon, Essays on Thai Folklore, 306.

11.Susan M. Darlington, "Practical Spirituality and Community Forests," in Nature in the Global South, ed. Paul Greenough (Durham, NC: Duke University Press, 2003), 348-51.

12.Pipob Udomittipong, “Thailand's Ecology Monks," in Dharma Rain, ed. Stephanie Kaza (Boston: Shambhala, 2000), 193.

13. Darlington, "Practical Spirituality and Community Forests," 348-51.

14. Isager and Ivarsson, "Contesting Landscapes in Thailand," 406.

15.Delcore, "Symbolic Politics or Generification?" 12-13, 16-17.

16.Ibid., 14-16.

17.Darlington, "Practical Spirituality and Community Forests," 349.

18.Susan M. Darlington, “The Ordination of a Tree: The Buddhist Ecology Movement in Thailand," Ethnology 37 no. 1 (1998): 8.

19.J. L. Taylor, "Social Activism and Resistance on the Thai Frontier: The Case of Phra Prajak Khuttajitto", Bulletin of Concerned Asia Scholars 25, no. 2 (1993): 11, 16.

20.Ibid., 13 .

21.Delcore, "Symbolic Politics or Generification?" 8-10, 13, 19. Nicola Tannenbaum, "Protest, Tree Ordination, and the Changing Context of Political Ritual," Ethnology 39, no. 2 (2000): 119, 122.

22. Isager and Ivarsson, "Contesting Landscapes in Thailand: Tree Ordination as Counter-Territorialization," 41213.

23.Paiboon Hengsuwan, "Contradictions on the Struggles over Resources and Contesting Terrain of Ethnic Groups on the Hill in Protected Area, Chom Thong, Chiang Mai" (paper presented at Politics of the Commons: Articulating Development and Strengthening Local Practices", Chiang Mai, Thailand, July 11-14, 2003), http:/ hdl.handle.net/10535/418

24. Delcore, "Symbolic Politics or Generification?" 7.

25.Dominic Nardi, "The Green Buddha: An Analysis of the Role of Buddhist Civil Society in Environmental Conservation in Burma," Southeast Review of Asian Studies 28 (2006), http://vcas.wlu.edu/VRAS/2006/VRAS\%20 Nardi.pdf

26. Sippanondha Ketudat, The Middle Path for the Future of Thailand (Chiang Mai: Institute of Culture and Communication, 1990), 74.

27.Darlington, "Practical Spirituality and Community Forests," 363. 


\title{
A Review of the Documentary Shugendō Now
}

\author{
Shugendō Now. Directed by Jean-Marc Abela. Produced by Mark P. McGuire. \\ Montréal: Empower Productions, 2009, 88 minutes. Japanese with narration. \\ English, French, and Spanish subtitles and narration. Individual use C\$20; Public/ \\ Educational use C $\$ 150$. Free copies for review, upon request.
}

Shugendō Now is a well-made documentary that sheds light upon a religious tradition that has received some attention from the scholarly community, but not as much as various other forms of Japanese religious expression such as Zen Buddhism, Japanese Confucianism, some types of Shinto, and various forms of New Religions. As such, it serves as a much-needed corrective that is highly suitable for high school and college classroom use, with a few caveats.

Shugendō is frequently characterized as a religious system that focuses upon ascetic activities performed among or on sacred mountains in Japan. It draws for its worldview and practice from a variety of sources, including esoteric Buddhism, Shinto, Daoism, and indigenous shamanistic practices. The goals of Shugendō practice include seeking personal enlightenment and the gathering and distribution of sacred power to benefit the larger community through various ascetic exercises and rituals.

The film's DVD is divided into three sections. The first is titled "The Lotus Ascent," and focuses upon a group of yamabushi embarking upon a pilgrimage through the historical heartland, with its sacred mountains, of Shugendō practice and development. Yamabushi (literally, "those who rest in the mountains" or "mountain warriors") are ascetic practitioners of Shugendō. The second section is titled "The Forest of Mountain Learning," which focuses on a famous Shugendō temple and its current head, Tateishi Kosho, as he goes through the daily routines of providing services of all kinds for those who come to the temple. The third section is titled "Frequently Asked Questions," in which ten questions are asked and generally answered regarding various aspects of Shugendō belief and practice. Running throughout all three sections are the larger questions of "How does Shugendō practice fit into the contemporary world? Why would anyone now practice this old blend of Shinto, esoteric Buddhism, Daoism, and shamanism?" Any or all of the three sections could be profitably employed in the classroom to address these and other questions as detailed next.

"The Lotus Ascent" is intriguing in its construction. The filmmaker basically allows the camera and the yamabushi to show what the mountain ascent is about, with minimal narration or voiceover. The viewer follows the yamabushi, frequently in long stretches of silence, as they prepare themselves and then climb. At one particularly interesting point, the camera focuses in upon a sign that indicates that women are not allowed to proceed further. The narrator offers no vocal comment about this, but it provides a perfect opportunity for classroom discussion. This reviewer thinks that students require some background preparation in Shugendō worldview before viewing "The Lotus Ascent"; otherwise, too much of it could be puzzling due to its minimalist narration. ${ }^{1}$

"The Forest of Mountain Learning" provides more narration and more explanation from 
the filmed practitioners of Shugendō. The setting in the temple allows the viewers to see a different side of Shugendō, in which the yamabushi, in this case Tateishi Kosho, dedicates himself to serving the needs of his community, both natural and human. We see him performing rituals for the blessing and benefit of people, and we see him performing rituals for the protection and preservation of the natural world. In one case we see him taking care of bees, and in another preparing dinner. However, he is famous locally for his opposition to a corporation's dumping of used tatami mats in the nearby mountains, and the documentary shows several people expressing their appreciation for his efforts, which were successful. Tateishi Kosho presents a fascinating character; his high levels of energy and his ability to move between the sacred and mundane worlds is riveting. His wife, Rika, also is presented as she discusses her personal journey to embrace Shugendō (and marry Tateishi Kosho). These two people demonstrate in their words and their actions why Shugendo creates and sustains a happy, meaningful life for them, and why it possibly can for others, even in the modern world. As with "The Lotus Ascent," however, this would best be shown after students have already been exposed a bit to Shugendō study.

The third section, "Frequently Asked Questions," as the name implies, is not a unified presentation, but rather a series of short clips that may or may not be thematically related to each other. These questions address some of the basic information not explicitly narrated in the other parts of the documentary, such as explaining what a kami is, how priests make a living, the significance of the clothing and some of the rituals, and in probably the most personal (if seemingly the least relevant) clip, how to make Tateishi Kosho's tofu noodle recipe. This last, though, humanizes even more the man who is the center of this community and is well worth taking the time to watch. Some of these clips may be helpful in preparing the students to view the other two parts of the documentary, but it could also be argued that it might be better to save them for last, allowing the students to try to work some things out for themselves.

Shugendō Now presents a well-crafted, engaging portrait of some aspects of Shugendō thought and practice. The overall lack of narration is an advantage, in this reviewer's opinion, as it allows viewers to really observe what is happening without an authoritative narrative voice shaping their perceptions. This in turn means that students might have more questions about or insights into the film, since they are not herded into one or another interpretation while viewing. The film itself is visually appealing, with plenty of shots from a variety of angles of natural phenomena and the people who interact with them. Of course, experts in Shugendo will find things that are omitted or represented in a way that may not be fully satisfactory, but choices must be made with limited time and resources, and all in all this serves as an excellent, thought-provoking, and beautiful introduction to Shugendō thought and practice.

\section{Robert Steed, Hawkeye Community College}

\section{NOTES}

1. For short, informative articles that explain various facets of Shugendō, see Royall Tyler \& Paul L. Swanson, "Shugendō \& Mountain Religion in Japan"; Miyake Hitoshi; "Religious Rituals in Shugendō: A Summary" ; Gorai Shigeru, "Shugendō Lore"; Royall Tyler, "Kofuku-ji and Shugendō"; Wakamori Taro, "The HashiraMatsu and Shugendō "; Sawa Ryuken, "Shugendō Art"; H. Byron Earhart; "Mount Fuji and Shugendō "; and Susan Tyler, "Honji Suijaku Faith," all in Japanese Journal of Religious Studies, 16, nos. 2-3 (June-September 1989). 
